\title{
UCRL-TR-220279
}

LAW RENCE LIVERMORE N A TIO NAL LABORATORY

Development of a Manufacturing Process for High-Precision $\mathrm{Cu}$ EOS Targets

M. J. Bono, C. Castro, R. L. Hibbard

March 31, 2006 
This document was prepared as an account of work sponsored by an agency of the United States Government. Neither the United States Government nor the University of California nor any of their employees, makes any warranty, express or implied, or assumes any legal liability or responsibility for the accuracy, completeness, or usefulness of any information, apparatus, product, or process disclosed, or represents that its use would not infringe privately owned rights. Reference herein to any specific commercial product, process, or service by trade name, trademark, manufacturer, or otherwise, does not necessarily constitute or imply its endorsement, recommendation, or favoring by the United States Government or the University of California. The views and opinions of authors expressed herein do not necessarily state or reflect those of the United States Government or the University of California, and shall not be used for advertising or product endorsement purposes.

This work was performed under the auspices of the U.S. Department of Energy by University of California, Lawrence Livermore National Laboratory under Contract W-7405-Eng-48. 


\section{Development of a Manufacturing Process for High-Precision Cu EOS Targets}

July 15,2005

Matthew Bono, Carlos Castro, and Robin Hibbard

\section{OVERVIEW}

This document describes the development of a manufacturing process and the production of $\mathrm{Cu}$ EOS targets. The development of a manufacturing process for these targets required a great deal of research, because the specifications for the targets required a level of precision an order of magnitude beyond Target Fabrication's capabilities at the time. Strict limitations on the dimensions of the components and the interfaces between them required research efforts to develop bonding and deposition processes consistent with a manufacturing plan with a dimensional precision on the order of $0.1 \mu \mathrm{m}$. Several months into this effort, the specifications for the targets were relaxed slightly as a result of discussions between the Target Fabrication Group and the physicists. The level of precision required for these targets remained an order of magnitude beyond previous capabilities, but the changes made it possible to manufacture targets to the specifications. The development efforts and manufacturing processes described in this document successfully produced a complete $\mathrm{Cu}$ EOS target that satisfied all of the fabrication and metrology specifications.

\section{TARGET SPECIFICATIONS}

An exploded view of a $\mathrm{Cu}$ EOS target appears in Figure 1. Several different target designs were originally planned for shot series, including $16 \mathrm{~kJ}$ shots on the Omega laser, 23 MBar shots on NIF, and 60 MBar shots on NIF. Each of these shot series was originally planned to include targets with $\mathrm{Cu}$ samples and $\mathrm{Al}$ samples. Each of these targets was similar to the 23 MBar Cu NIF target illustrated in the figure. The required dimensions of each of the EOS targets changed several times over the course of this effort, but the final design for the $23 \mathrm{MBar} \mathrm{Cu}$ NIF target included a baseplate of $1100 \mathrm{Al}$ of thickness $62 \mu \mathrm{m}$. A Cu sample of thickness $43 \mu \mathrm{m}$ is attached to one face of the baseplate, and a $102 \mu \mathrm{m}$ pre-heat shield composed of $6.25 \mathrm{at} \% \mathrm{ICH}$ is attached to the other face. A $32.5 \mu \mathrm{m} \mathrm{CH}$ ablator is bonded to the drive side of the pre-heat shield. Each of these components has a diameter of approximately $4 \mathrm{~mm}$. Quartz windows of thickness $100 \mu \mathrm{m}$ are bonded to the VISAR side of the baseplate and sample.

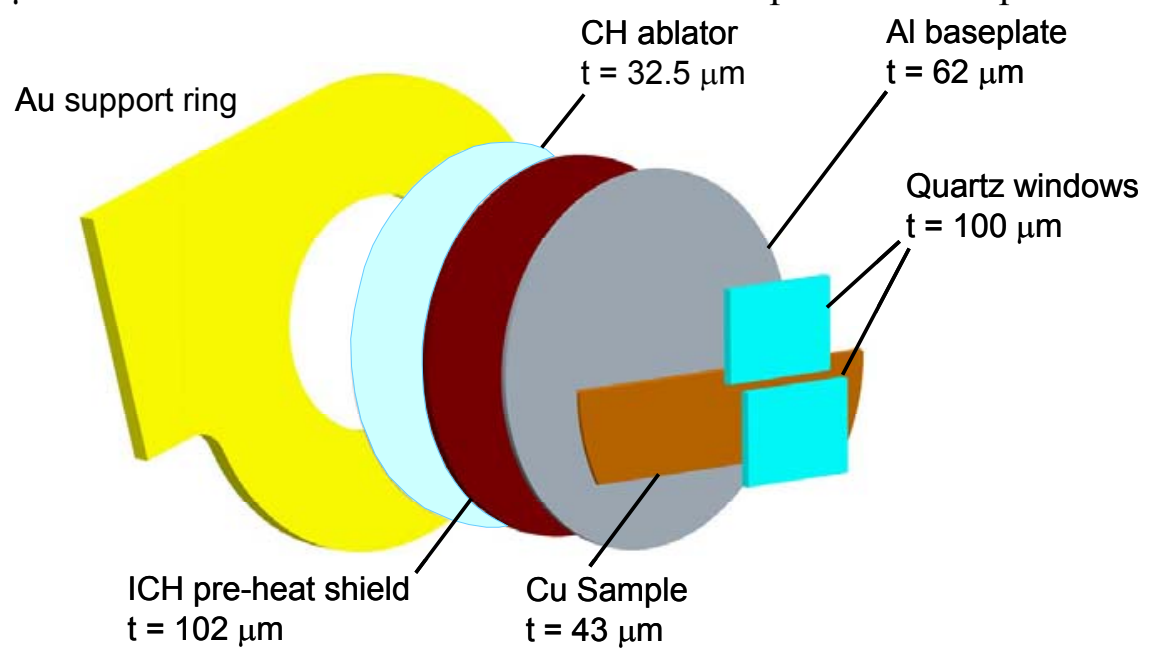

Figure 1. Exploded view of the 23 MBar Cu NIF EOS target 
The original specifications for the targets represented a level of precision far beyond the capabilities of the Target Fabrication Group. One of the most important requirements for the targets was the interface between the $\mathrm{Al}$ baseplate and the $\mathrm{Cu}$ sample. The original specification for the targets required that this interface have a thickness no larger than $0.5 \mu \mathrm{m}$. In addition, the original specification required that the surface of the baseplate have no short-wavelength features with a peak-to-valley height larger than $0.1 \mu \mathrm{m}$. The required thickness uniformities of several of the components were originally $0.1 \mu \mathrm{m}$ over the central $500 \mu \mathrm{m}$ diameter region, and the absolute thickness and thickness uniformity of several of the components were required to be metrologized with an accuracy on the order of $0.1 \mu \mathrm{m}$.

The original specifications for the targets governed the majority of the development effort. The specifications for the targets were later relaxed slightly as a result of discussions between the Target Fabrication Group and the physicists. One of the most significant changes was that the new specifications allowed a step of up to $1 \mu \mathrm{m}$ in the Al baseplate at the edge of the $\mathrm{Cu}$ sample, provided this step was measured with an accuracy of $0.2 \mu \mathrm{m}$. In the final specifications, the required thickness uniformities of the various layers of the target ranged from $\pm 0.1 \mu \mathrm{m}$ to $\pm 0.3 \mu \mathrm{m}$, and they had to be measured with this same level of accuracy. A summary of the thickness uniformity specifications appears in Figure 2. The bond layers for the $\mathrm{CH}$ and ICH components had to be less than $3 \mu \mathrm{m}$ in thickness. Quartz windows of thickness $100 \mu \mathrm{m}$ were bonded to the VISAR side of the baseplate and sample, and the bonds for the windows had to be less than $5 \mu \mathrm{m}$ in thickness. Extensive collaboration between the physicists and the Target Fabrication Group was required to obtain specifications that could be realized in the manufacturing process and satisfied the physics requirements for the targets.

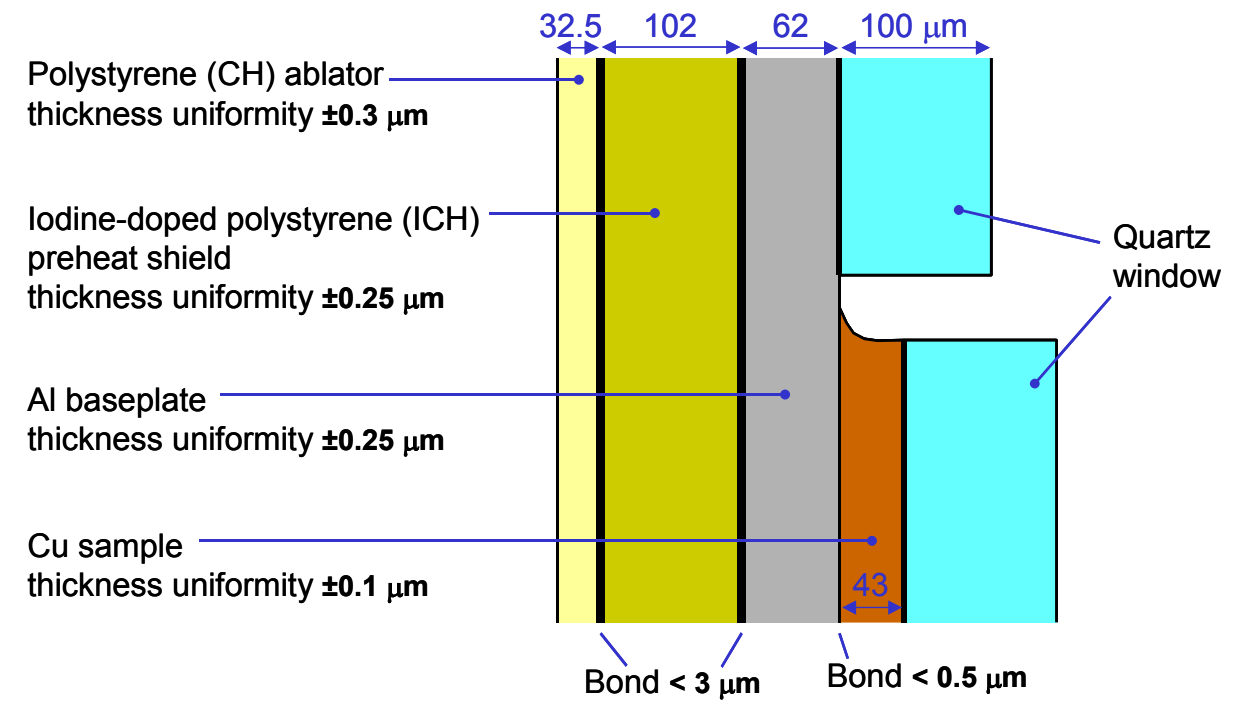

Figure 2. Summary of the specifications for the target that drove the development of the manufacturing process

A complete list of all of the specifications and acceptance criteria for the final target appears in Appendix A.

\section{PRELIMINARY INVESTIGATIONS OF MANUFACTURING PROCESSES}

Designing a manufacturing process to meet the physics requirements proved to be a challenging task. The two issues that were far beyond current capabilities at the commencement 
of this effort were the fixturing of components on the machine tool to obtain the required dimensional accuracy and metrology, and the ability to meet the interface requirements between the $\mathrm{Cu}$ sample and the $\mathrm{Al}$ baseplate.

\section{Workpiece Fixturing}

The standard practice used by the Target Fabrication Group to manufacture a component with a diameter of a few $\mathrm{mm}$ is to attach the component to a standard holder, like that shown in Figure 3. These holders are semi-kinematic mounts that can be placed onto and removed from the diamond turning machines with a repeatability of approximately $0.25 \mu \mathrm{m}$. These holders are used to produce target components with sub- $\mu \mathrm{m}$ accuracy, which is usually more than adequate.

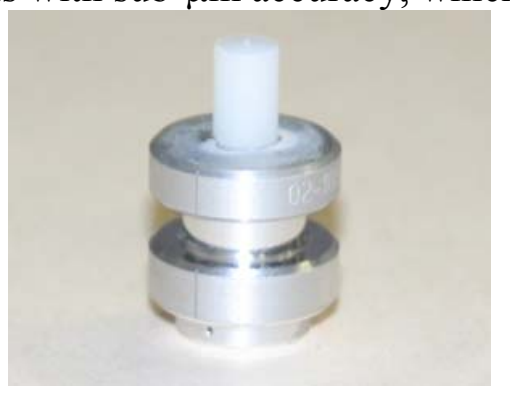

Figure 3. Standard Al holder used to mount workpieces on the DTM

Unfortunately, these standard holders do not have adequate precision to achieve thickness uniformity and metrology on the order of $0.1 \mu \mathrm{m}$. Some simple tests were performed to estimate the repeatability of these holders. The tests indicated that when inserting and removing these holders from the diamond turning machine, angular errors of up to $0.014 \mathrm{deg}$ can occur. In order to meet the requirements for the targets, a different type of workpiece fixturing with greater precision was required.

Several different methods for fixturing the workpieces were considered. The method selected uses a "narrow land" vacuum chuck to hold a workpiece of diameter $100 \mathrm{~mm}$, as shown in Figure 4. A vacuum chuck with lands smaller than $50-75 \mu \mathrm{m}$ is known to be able to hold flat workpieces with a repeatability of $25 \mathrm{~nm}(1 \mu \mathrm{in})$ when used properly. The workpiece diameter of $100 \mathrm{~mm}$ makes the parts easy to handle, so they can be properly inserted and removed from the vacuum chuck with the required accuracy. The large diameter of the workpiece also has the advantage that any axial runout of the workpiece due to a seating error on the vacuum chuck will correspond to a small angular error, which leads to machined parts with improved thickness uniformity. The selected configuration has a number of other advantages. The large workpiece contains sufficient area to measure the seating of the workpiece on the vacuum chuck using either an LVDT or a capacitance probe, which is required to obtain the required metrology of the targets. And finally, a large number of $4 \mathrm{~mm}$ diameter targets could be fabricated from a single $100 \mathrm{~mm}$ disk, which appeared to be a significant advantage when this plan was being developed and the shot schedule called for dozens of EOS targets. 


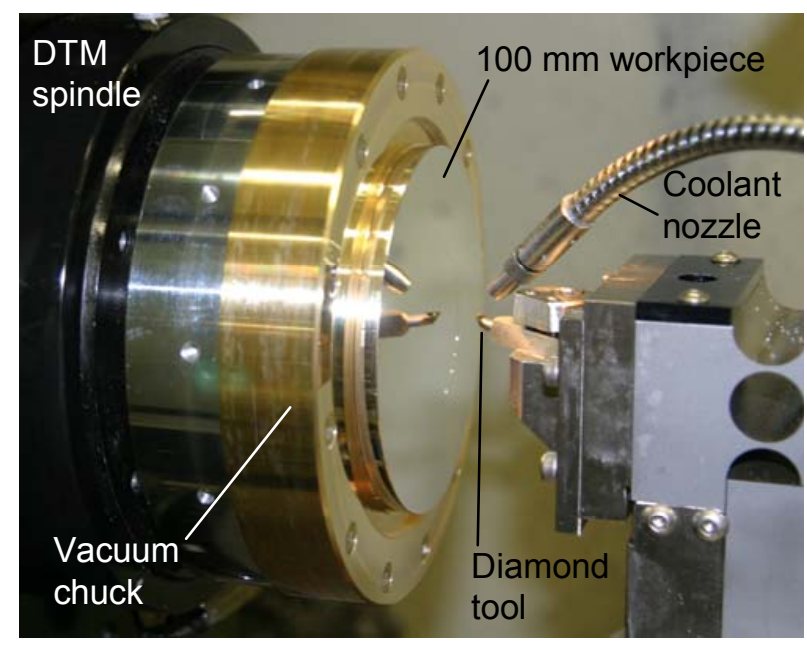

Figure 4. Machining of a $100 \mathrm{~mm}$ diameter workpiece on a "narrow land" vacuum chuck

\section{Outline of Manufacturing Plan}

The basic outline of the manufacturing plan for these targets is illustrated in the following figure. A number of details were added to this plan since its inception and will be discussed later, but this basic premise was used when designing the manufacturing process for the targets. A $100 \mathrm{~mm}$ diameter disk of $1100 \mathrm{Al}$ as the primary workpiece. This Al disk is machined to create the baseplate of the target, and the sample, pre-heat shield, and ablator are added during the manufacturing process.

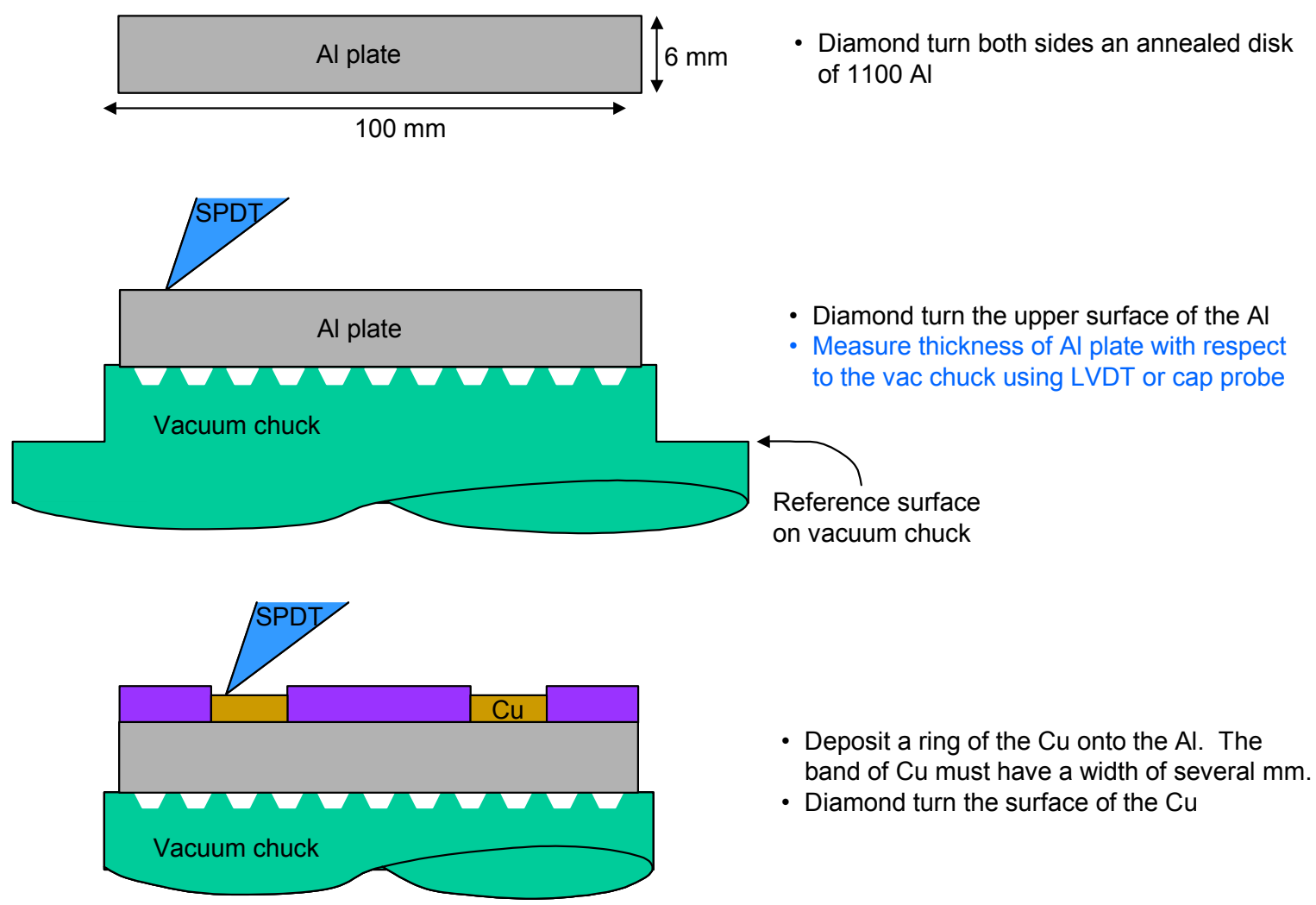



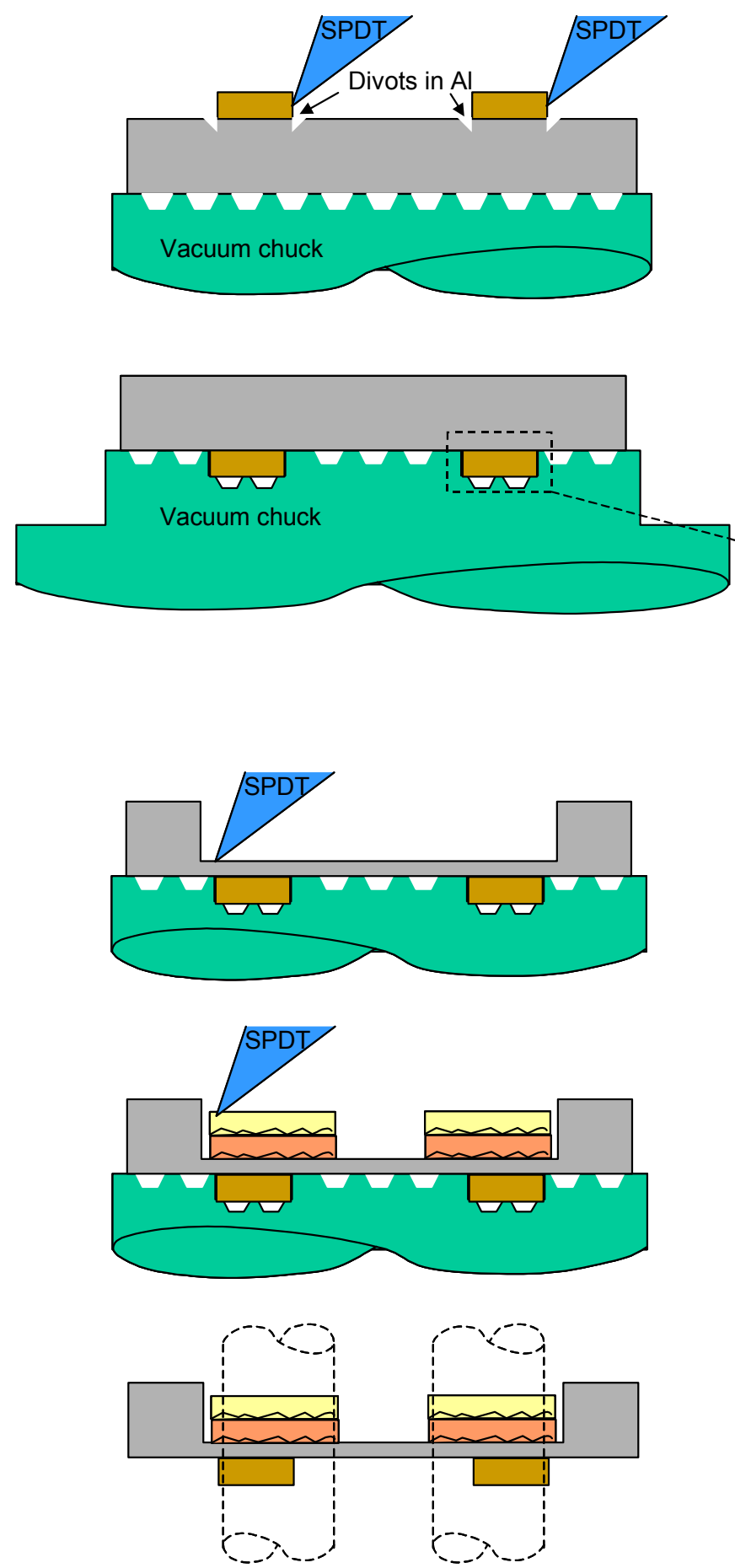

- Remove the mask used for the $\mathrm{Cu}$ deposition process

- Machine the inner and outer edges of the $\mathrm{Cu}$

- Measure Cu thickness using Wyko or probe mounted to DTM

- Custom machine a vacuum chuck to conform to the Cu-Al surface. This step requires that the ring of $\mathrm{Cu}$ be concentric to the OD of the disk to within 5-10 $\mu \mathrm{m}$.

- Use cap probe over surface to verify the part is seated correctly on the vac chuck

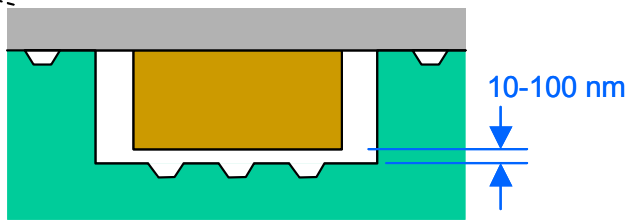

- Diamond turn into the Al, machining it to the correct thickness

- Use LVDT / cap probe to measure Al thickness

- Glue a layer of $\mathrm{ICH}$ to the $\mathrm{Al}$

- Diamond turn the $\mathrm{ICH}$

- Measure thickness of ICH

- Glue a layer of $\mathrm{CH}$ to the $\mathrm{ICH}$

- Diamond turn the $\mathrm{CH}$

- Measure thickness of $\mathrm{CH}$

- Laser cut several $4 \mathrm{~mm}$ targets

Figure 5. Schematic illustration of the basic outline for the manufacturing process for the EOS targets

At each step of the this manufacturing process, the fixturing of the workpiece is crucial to obtaining the required precision. Each time the $100 \mathrm{~mm}$ disk is placed on the vacuum chuck, its seating on the chuck is carefully checked by measuring the axial runout using a capacitance probe. This step is not illustrated in Figure 5, but it is crucial to meeting the specifications for the targets. Each of the steps in this process was carefully designed to be consistent with the 
required overall precision of the targets. One of the challenging steps in this process was depositing the $\mathrm{Cu}$ onto the $\mathrm{Al}$ baseplate with adequate adhesion without damaging the $100 \mathrm{~mm}$ Al disk.

\section{Interface between the $\mathrm{Cu}$ sample and the $\mathrm{Al}$ baseplate}

When this target fabrication effort began, the required interface between the $\mathrm{Cu}$ sample and the Al baseplate of the targets could not be manufactured using the available standard fabrication practices. An adhesive bond created with the Target Fabrication Groups's standard bonding methods using epoxy or cyanoacrylate was known to have a thickness on the order of a few $\mu \mathrm{m}$, so a different means of attaching the $\mathrm{Cu}$ to the $\mathrm{Al}$ had to be devised. A research effort was required to develop a method of joining the $\mathrm{Cu}$ to the $\mathrm{Al}$ in a manner consistent with the subsequent precision manufacturing steps. The difficulty in this task was to bond the $\mathrm{Cu}$ and the Al with an interface thickness less than $0.5 \mu \mathrm{m}$ using a method that maintained all of the reference surfaces and workpiece form and accuracy, so the subsequent steps in the manufacturing process produced targets with the required $0.1 \mu \mathrm{m}$ thickness uniformity and allowed the targets to be metrologized with an accuracy of $0.1 \mu \mathrm{m}$. Developing such a method for bonding the $\mathrm{Cu}$ to the $\mathrm{Al}$ required several months of effort.

Several different bonding methods were considered for bonding the $\mathrm{Cu}$ sample and $\mathrm{Al}$ baseplate of the target. Initial efforts focused on using a low-viscosity hydroxide solution, which formed a joint by attaching to the oxide resident on the $\mathrm{Cu}$ and the $\mathrm{Al}$ and bonding them together. This method was shown to produce bondlines of thickness $1 \mu \mathrm{m}$ or smaller. However, difficulties in controlling the amount of adhesive dispensed resulted in excess solution being applied that completely covered the workpiece components and did not maintain the required environment for producing precision targets. Therefore, this method initially showed good potential for producing sub- $\mu \mathrm{m}$ bonds, but it was not pursued beyond the preliminary investigations in favor of other methods.

Several different methods of directly depositing $\mathrm{Cu}$ onto Al were investigated in detail. Depositing sub- $\mu \mathrm{m}$ layers of $\mathrm{Cu}$ onto an $\mathrm{Al}$ substrate using sputtering, electroplating, and e-beam evaporation were all standard practices for which the capability existed at LLNL. Each of these methods had several advantages and disadvantages, and it was not initially known which of them was best suited for fabricating the EOS targets. Therefore, several tests were performed to investigate each of the processes. To reduce the time and cost of the experiments, investigations were performed by applying $\mathrm{Cu}$ to disks of $1100 \mathrm{Al}$ of thickness $6 \mathrm{~mm}$ and diameter $25 \mathrm{~mm}$. These smaller Al disks could be prepared fairly quickly. The following paragraphs summarize the most important findings of these experiments.

\section{E-beam evaporation}

An experiment was performed in which $82 \mu \mathrm{m}$ of $\mathrm{Cu}$ was deposited on a $25 \mathrm{~mm}$ diameter $\mathrm{Al}$ disk using an E-beam evaporation process. The roughness of the as-deposited $\mathrm{Cu}$ was $\mathrm{R}_{\mathrm{t}}=80$ $\mathrm{nm}$. The $\mathrm{Cu}$ did not experience any problems with adhesion while being diamond turned. The interface between the $\mathrm{Cu}$ and the $\mathrm{Al}$ appeared to have met the specifications for the targets. Unfortunately, SEM pictures of this interface were not made available to the Target Fabrication Group. This process appeared to be a good method of obtaining adequate adhesion with an acceptable interface. One of the major drawbacks to this method is that it is performed at a temperature of several hundred ${ }^{\circ} \mathrm{C}$. The temperature is too high for a Kapton mask, so a metal 
hardmask must be used, which introduces the problem of aligning the hardmask with the reference surfaces on the workpiece to within 5 to $10 \mu \mathrm{m}$.

\section{Zincated electroplating}

Several attempts were made to electroplate $\mathrm{Cu}$ onto $25 \mathrm{~mm} \mathrm{Al} \mathrm{disks.} \mathrm{Because} \mathrm{of} \mathrm{the}$ oxide layer on $\mathrm{Al}, \mathrm{Cu}$ will not adhere to the $\mathrm{Al}$ unless the $\mathrm{Al}$ surface is prepared properly. One quick and easy method of preconditioning the $\mathrm{Al}$ is to zincate the surface, which involves chemically removing the oxide and then electroplating $\mathrm{Zn}$ onto the newly cleaned surface. $\mathrm{Cu}$ can then be electroplated onto the $\mathrm{Zn}$. Unfortunately, the zincating process creates a surface roughness of $\mathrm{Rt}=120$ to $600 \mathrm{~nm}$, depending on the process parameters. In addition, up to $200 \mathrm{~nm}$ of $\mathrm{Al}$ can be removed during the process. Therefore, if a section of the $\mathrm{Al}$ disk is masked with tape, then a step of up to $200 \mathrm{~nm}$ will be formed between the zincated surface and the masked Al surface. Because of the roughness created by this process, it could not be used to produce targets that met the specifications.

\section{Sputter-seeded electroplating}

Several trials were performed by sputtering a few $\mu \mathrm{m}$ of $\mathrm{Cu}$ onto the $\mathrm{Al}$ disk to provide a conduction path for an electroplating process. After masking a portion of a $25 \mathrm{~mm} \mathrm{Al} \mathrm{disk} \mathrm{with}$ Kapton tape, the oxide was removed with an ion mill, and $20 \mathrm{~nm}$ of Ti were sputtered followed by $3 \mu \mathrm{m}$ of $\mathrm{Cu}$. The sputtering was done in B231. Then an additional $30 \mu \mathrm{m}$ of $\mathrm{Cu}$ were electroplated onto the sputtered $\mathrm{Cu}$ in LLNL's Metal Finishing Shop. This $\mathrm{Cu}$ did not experience any problems with adhesion while being diamond turned. One advantage of this process is that Kapton tape can be applied directly to the Al surface to create an effective mask. A sample that was prepared using this method was sectioned and examined with an SEM, as shown in Figure 6. These images were taken from a sample that was prepared several months after this preliminary study, as described in Appendix B, but it was prepared in a very similar manner and should be representative of the condition of the samples that were prepared during these preliminary tests. The images reveal that the interface between the $\mathrm{Cu}$ and the $\mathrm{Al}$ meets the specifications for the targets.

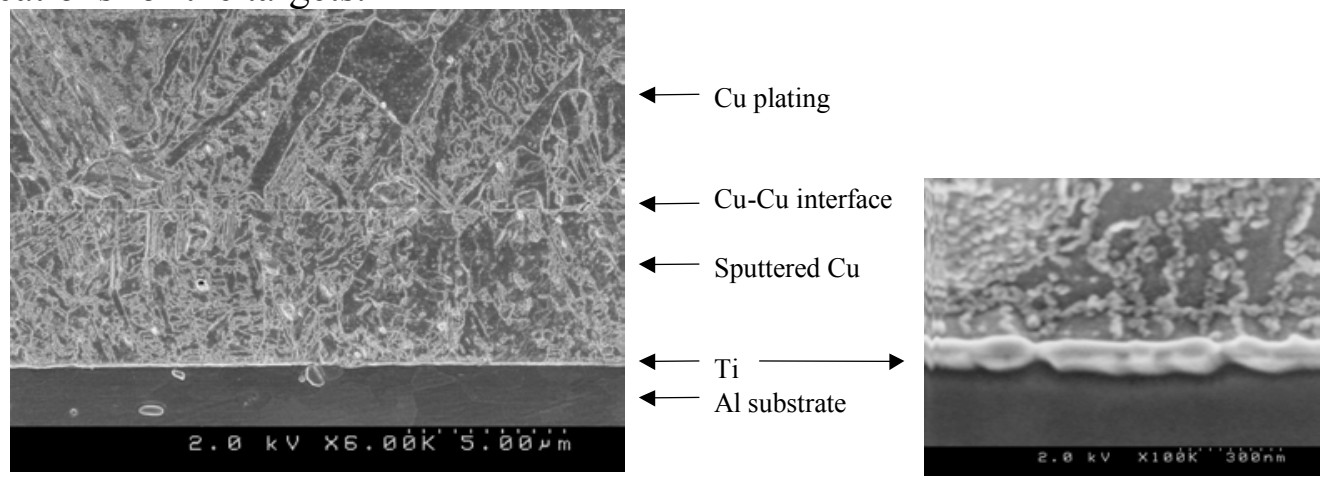




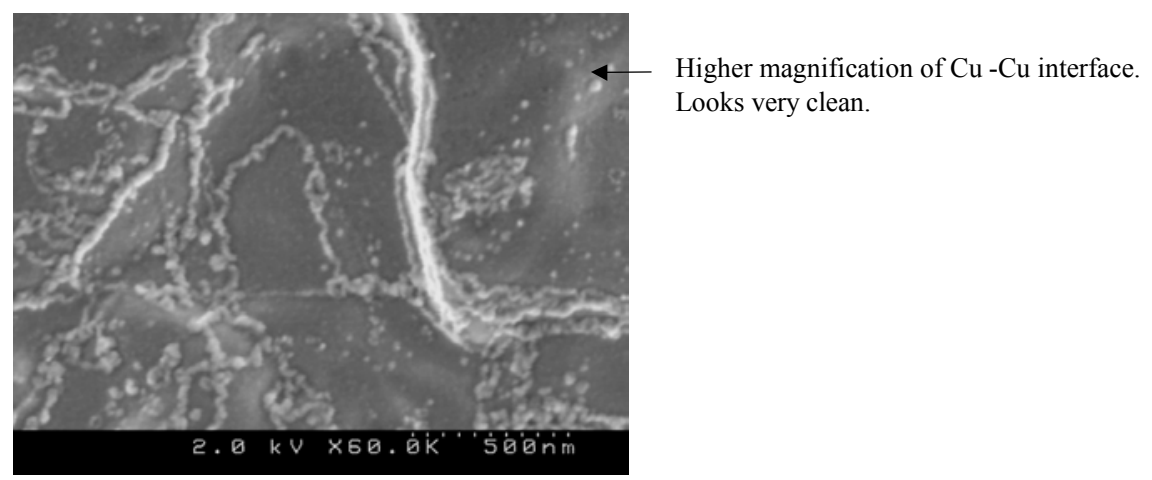

Figure 6. SEM images of a sample prepared by sputter-seeded electroplating

\section{Sputtering $\mathrm{Cu}$ to the required thickness}

A trial was also performed in which $30 \mu \mathrm{m}$ of $\mathrm{Cu}$ was sputtered directly onto a $25 \mathrm{~mm} \mathrm{Al}$ disk in B231. This sputtering process took several days to complete. The sputtered $\mathrm{Cu}$ did not experience any problems with adhesion while being diamond turned. However, there was some concern that the stresses in sputtered $\mathrm{Cu}$ could be very large and could eventually lead to delamination. Delamination was not actually observed in this test, but the concerns that were voiced caused this potential method to be abandoned in favor of other methods. Note that this project did not find any direct evidence to indicate whether or not sputtering $\mathrm{Cu}$ to the required thickness would be a successful process, and it is possible that it could have worked.

These preliminary investigations indicated that E-beam evaporation and sputter-seeded electroplating were good candidates for depositing the $\mathrm{Cu}$ onto the $100 \mathrm{~mm} \mathrm{Al}$ disk. Therefore, both of these processes were attempted on full-scale $100 \mathrm{~mm} \mathrm{Al} \mathrm{disks.}$

\section{0 mm AI DISKS MACHINED WITH MINERAL OIL}

\section{First Attempt at Sputter-Seeded Electroplating (5/26/04)}

The first attempt to fabricate a batch of targets used a sputter-seeded electroplating process to deposit a $4 \mathrm{~mm}$ wide ring of $\mathrm{Cu}$ on the $100 \mathrm{~mm} \mathrm{Al} \mathrm{disk.} \mathrm{The} 100 \mathrm{~mm} \mathrm{Al}$ disk was prepared by diamond turning both sides using mineral oil as the cutting fluid. After machining the disk, it was cleaned with an alcohol rinse. A layer of Kapton tape was then laid onto one surface of the disk. Two circular score marks were made through the Kapton using the diamond tool on the diamond turning machine, and the resulting ring of Kapton tape was peeled up to create a $4 \mathrm{~mm}$ wide circular band of exposed $\mathrm{Al}$, as shown in Figure 7. Because this scoring was done directly on the diamond turning machine, the circular band of exposed $\mathrm{Al}$ was concentric to the outer diameter of the disk, which was critical for the future step in the manufacturing process where the $100 \mathrm{~mm}$ disk must be inserted into a vacuum chuck with the $\mathrm{Cu}$ face seated against the vacuum chuck. 

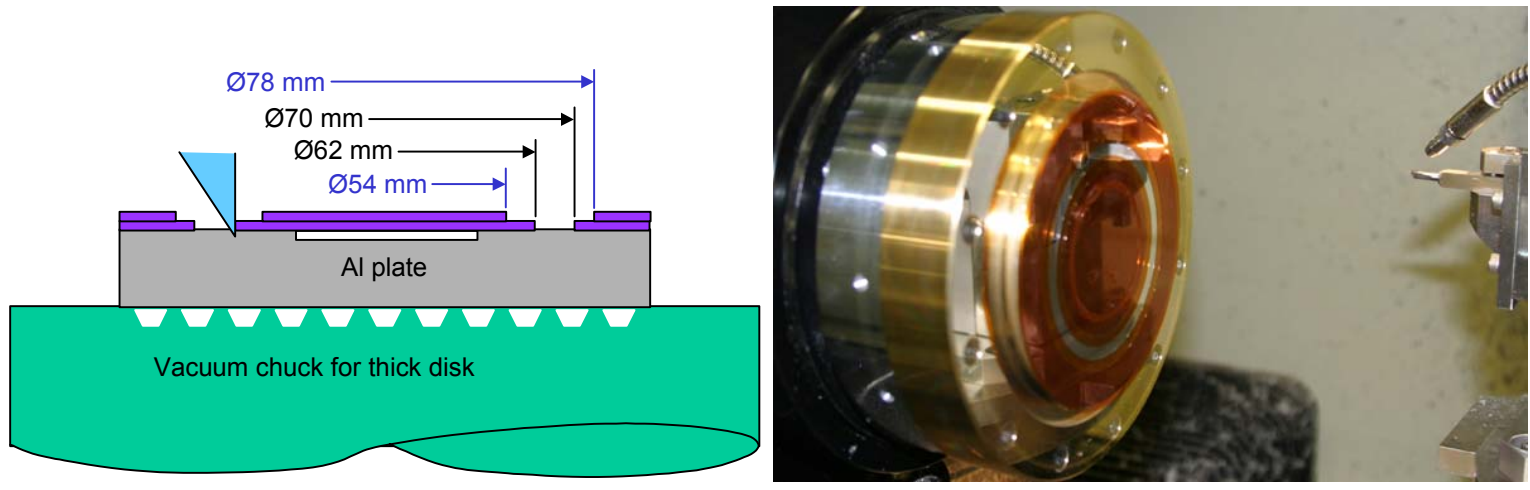

Figure 7. Schematic illustration and photograph of the scoring and removal of the Kapton ring

The disk was then sputtered in B235 with $10 \mathrm{~nm}$ of Ti followed by $3 \mu \mathrm{m}$ of $\mathrm{Cu}$. Note that the sputtering chamber in B235 was not equipped with an ion mill, so this process differed from the initial sputter-seeded electroplating tests performed on the $25 \mathrm{~mm}$ diameter Al sample.

Additional $\mathrm{Cu}$ was then electroplated onto the sputtered $\mathrm{Cu}$. The $\mathrm{Cu}$ that had been electroplated onto the part was visibly blistered and appeared to have delaminated from the $100 \mathrm{~mm} \mathrm{Al} \mathrm{disk.}$ A scalpel was used to pick through the blistered $\mathrm{Cu}$. Photographs of the area in which flakes of $\mathrm{Cu}$ were removed appear in Figure 8.

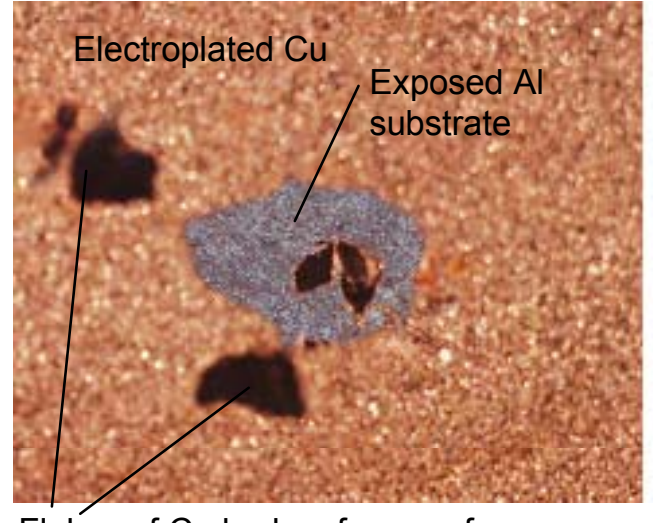

Flakes of Cu broken from surface

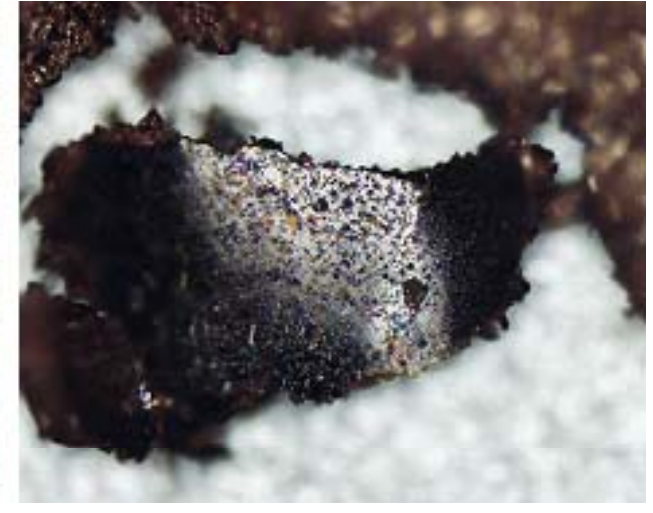

Back surface of a flake of $\mathrm{Cu}$

Figure 8. Flakes of the blistered electroplated $\mathrm{Cu}$ and the underlying Al substrate

The underside of the flake of material pried from the surface was silver in color, not copper. Therefore, it appeared that the sputtered Ti was well bonded to the sputtered $\mathrm{Cu}$, and the delamination occurred at the interface between the Ti and the Al. The left side of Figure 9 depicts a portion of the $\mathrm{Al}$ disk that was protected by Kapton during sputtering and electroplating. This image reveals that residual traces of the adhesive from the Kapton tape remained on the surface of the Al after the Kapton was removed. The right side of Figure 9 depicts the $\mathrm{Al}$ substrate in the area in which the flake of $\mathrm{Cu}$ was removed. This image reveals a texture and some contaminants on the Al. The features on this surface could have been related to the Kapton residue that was left after the $4 \mathrm{~mm}$ wide ring of Kapton tape was removed from this area. 

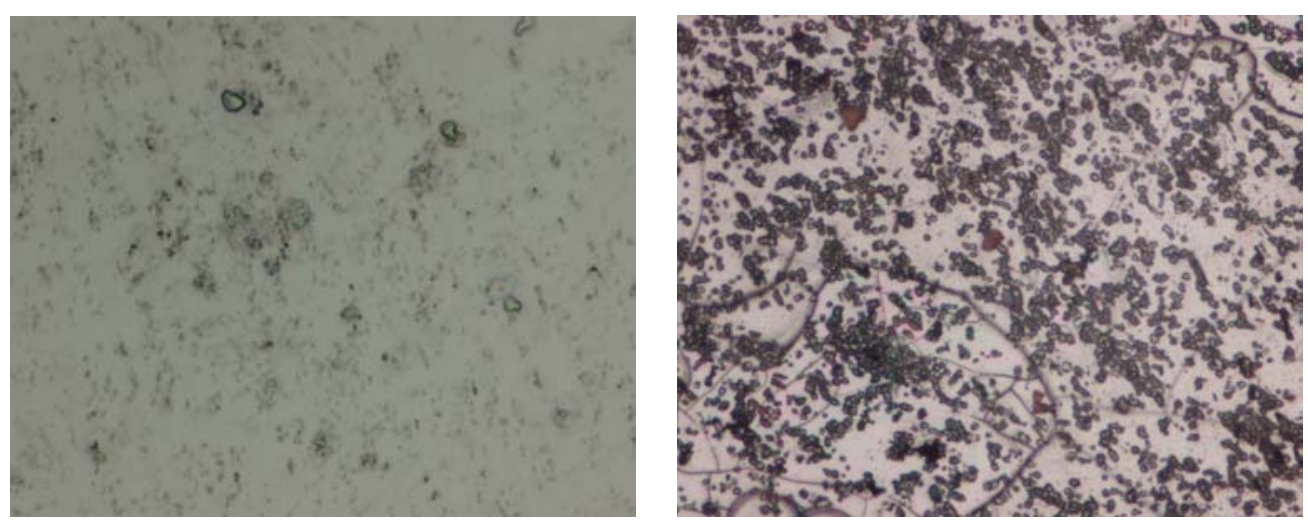

Figure 9. Microscope images at $500 \times$ of a portion of the Al disk that was protected by Kapton during sputtering and electroplating (left) and the Al beneath the delaminated $\mathrm{Cu}$ (right)

\section{First Attempt at E-Beam Evaporation of $\mathrm{Cu}(6 / 10 / 04)$}

Another attempt was made to deposit $\mathrm{Cu}$ onto a $100 \mathrm{~mm} \mathrm{Al}$ disk using an E-beam evaporation process. This process was more complicated than the sputtering process, because it required a precision hardmask. This hardmask had to withstand a temperature of several hundred ${ }^{\circ} \mathrm{C}$, and it had to locate the deposited $\mathrm{Cu}$ on the $100 \mathrm{~mm} \mathrm{Al}$ disk very precisely. The ring of deposited $\mathrm{Cu}$ had to be concentric to the $\mathrm{OD}$ of the $100 \mathrm{~mm}$ disk to within approximately 5 to $10 \mu \mathrm{m}$. This requirement was very important, because the disk was later flipped over into a vacuum chuck with the $\mathrm{Cu}$ side against the vacuum chuck, and the OD of the disk was used as a reference surface during this operation. If the $\mathrm{Cu}$ was not concentric to the OD of the disk, then the $\mathrm{Cu}$ would have been damaged during this step, or the Al disk could have been scratched, which would have eliminated a crucial precision reference surface. The stainless steel precision hardmask made for the E-beam evaporation of $\mathrm{Cu}$ onto the $100 \mathrm{~mm} \mathrm{Al} \mathrm{disk} \mathrm{is} \mathrm{shown} \mathrm{in} \mathrm{Figure}$ 10 .
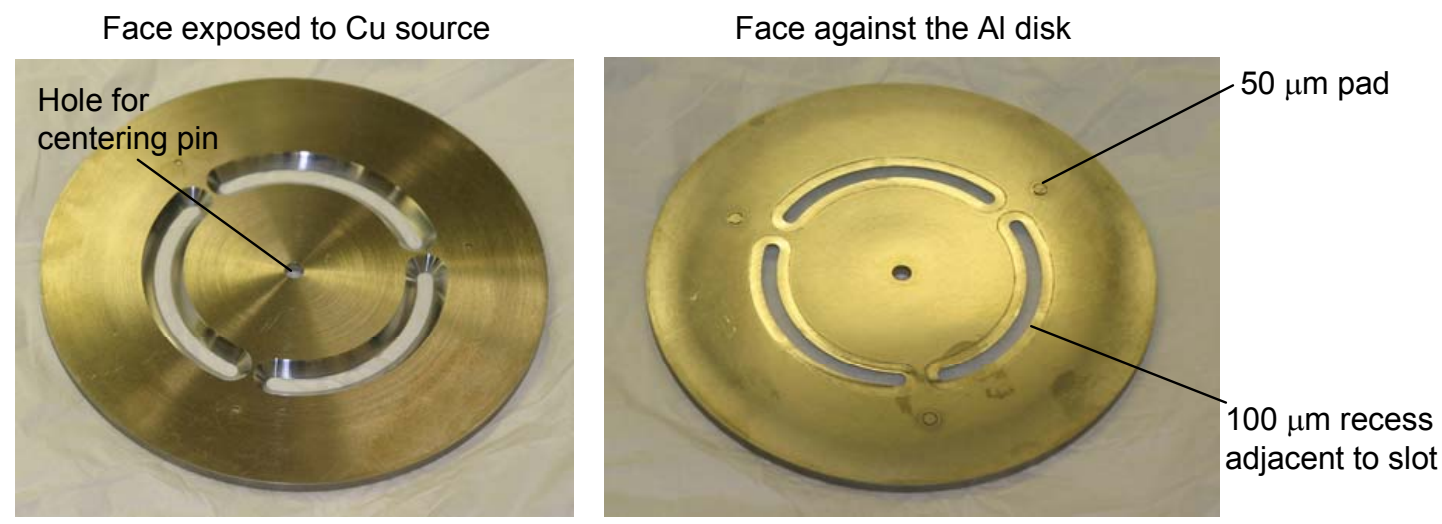

Figure 10. Precision hardmask used for E-beam evaporation of $\mathrm{Cu}$ onto the $100 \mathrm{~mm}$ Al disk

Prior to doing the deposition of the $\mathrm{Cu}$, the hardmask was placed in the deposition chamber in the configuration shown in the right side of Figure 10. The Al disk was placed on top of the hardmask, where it rested on three pads of height $50 \mu \mathrm{m}$. These pads supported the disk above the surface of the hardmask and ensured that the Al disk was scratched only at the location of the pads. The hardmask contained three tapered grooves of width $4 \mathrm{~mm}$, through which the $\mathrm{Cu}$ was deposited. A recess of depth $100 \mu \mathrm{m}$ adjacent to each groove prevented the newly deposited $\mathrm{Cu}$ from sticking to the hardmask. The required concentricity of the deposited 
$\mathrm{Cu}$ with respect to the $\mathrm{OD}$ of the $\mathrm{Al}$ disk was obtained by using a precision centering pin that had been press-fit into the center of the Al disk and diamond turned to be concentric to the OD of the disk, as shown in Figure 11. This pin was only a few $\mu \mathrm{m}$ smaller than the hole machined in the center of the hardmask. Thus, when the disk was assembled into the mask as shown in the figure, the precision centering pin provided the required concentricity.
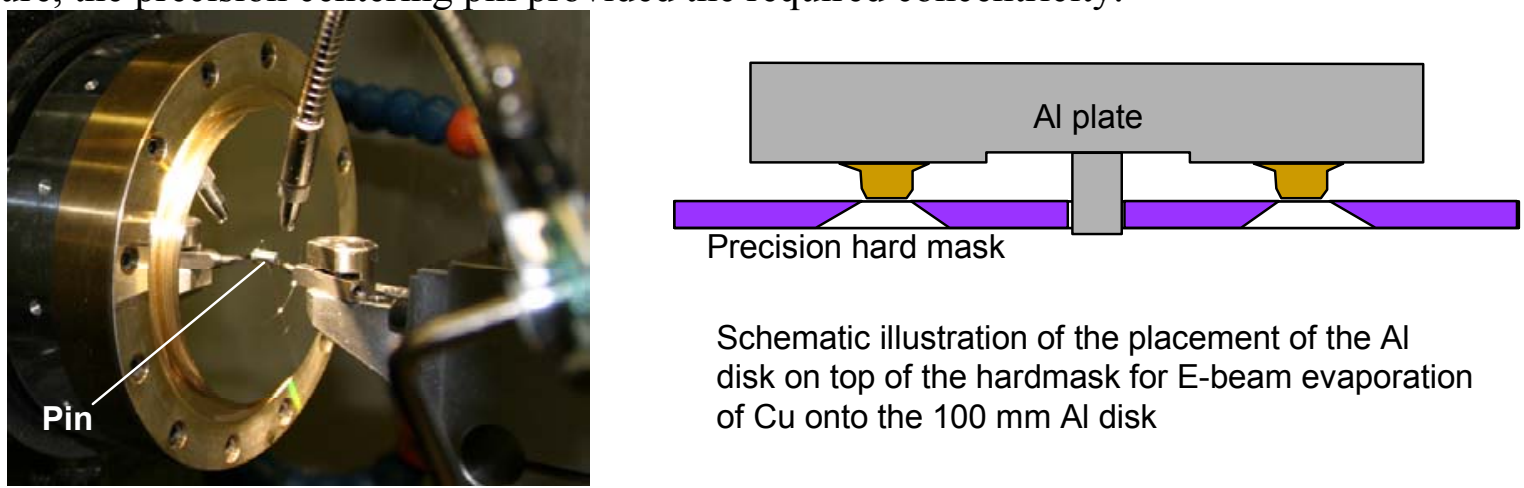

Precision hard mask

Schematic illustration of the placement of the Al disk on top of the hardmask for E-beam evaporation of $\mathrm{Cu}$ onto the $100 \mathrm{~mm} \mathrm{Al} \mathrm{disk}$

Figure 11. Machining of the precision locating pin and installation of the disk onto the hardmask

Upon receiving the disk back from the E-beam evaporation process, several flaws were apparent on the disk. Some $\mathrm{Cu}$ had been deposited on the OD of the $\mathrm{Al}$ disk. Although the $\mathrm{Cu}$ deposited on this reference surface was less than $1 \mu \mathrm{m}$ in thickness and was not itself a problem, it indicated that the process had not been executed as planned. A much larger flaw was also evident on the surface of the $\mathrm{Al}$ disk onto which the $\mathrm{Cu}$ had been deposited. This precision reference surface had been damaged during the deposition and contained a dent that raised the surface by several $\mu \mathrm{m}$ in a localized area. Therefore, one of the required precision reference surfaces was lost, and the disk could not be used to make acceptable targets.
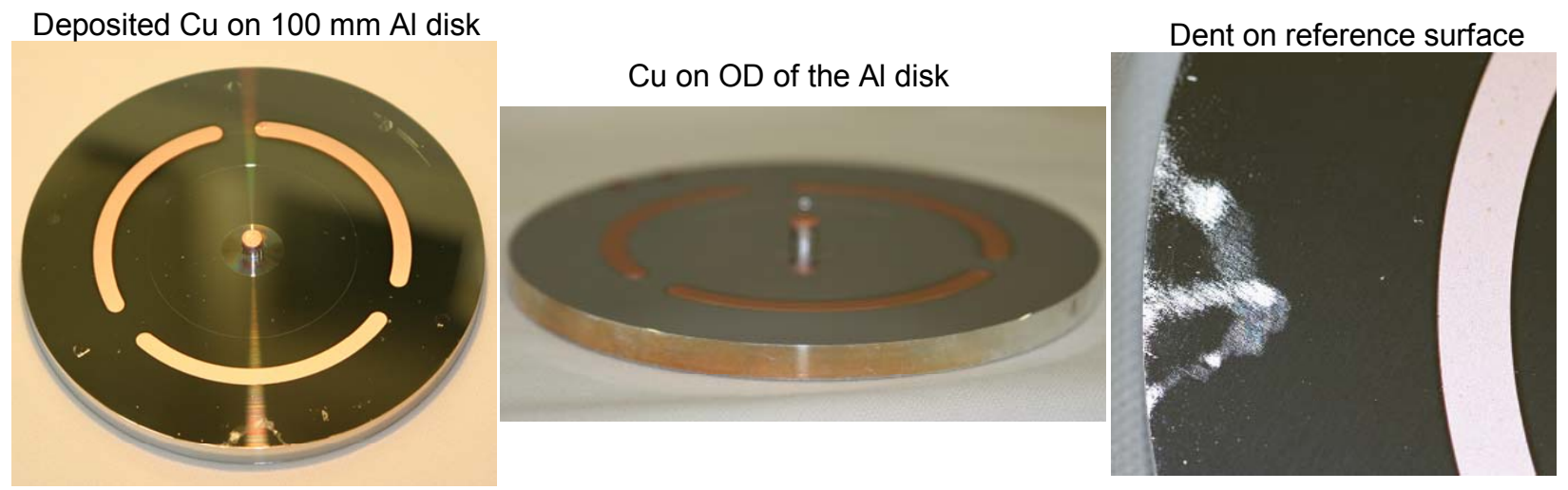

It was later discovered that an error occurred while installing the $100 \mathrm{~mm}$ disk in the hardmask. The locating pin on the disk caught in the hole in the hardmask, so the disk did not seat properly onto the mask during the deposition. This problem is illustrated in Figure 12. The temperatures reached in the deposition process could easily have caused the $100 \mathrm{~mm} \mathrm{Al}$ disk to warp due to creep. 


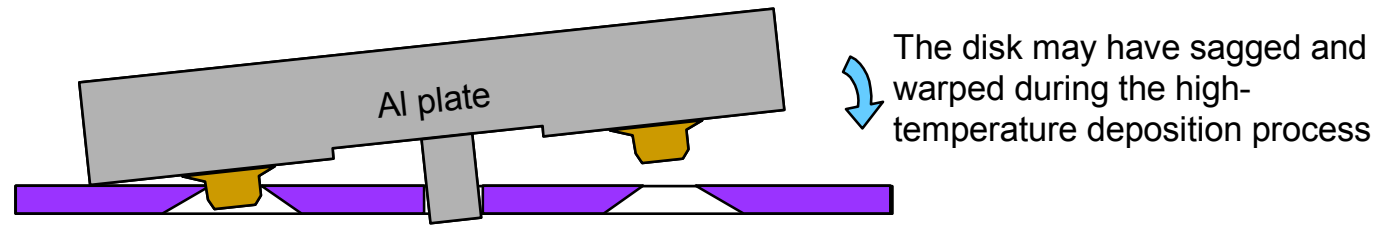

Figure 12. Misalignment of the $100 \mathrm{~mm}$ disk and the hardmask

To determine the quality of the $\mathrm{Cu}$ edge created by the E-beam evaporation process with this hardmask, the edge of the deposited Cu was measured with the Wyko NT 8000 optical profiling system. A profile trace taken through the measured dataset appears in Figure 13. The profile trace reveals that the deposited $\mathrm{Cu}$ had a height of approximately $53 \mu \mathrm{m}$. The sidewall of the deposited $\mathrm{Cu}$ was not perfectly vertical, and there was a "shadow" where the thickness of the $\mathrm{Cu}$ tapered toward zero. This "shadow" had a height of approximately $1 \mu \mathrm{m}$ at a radial distance of $100 \mu \mathrm{m}$ from the edge of the $\mathrm{Cu}$, and the "shadow" disappeared at a distance of approximately $150 \mu \mathrm{m}$ from the edge of the $\mathrm{Cu}$.
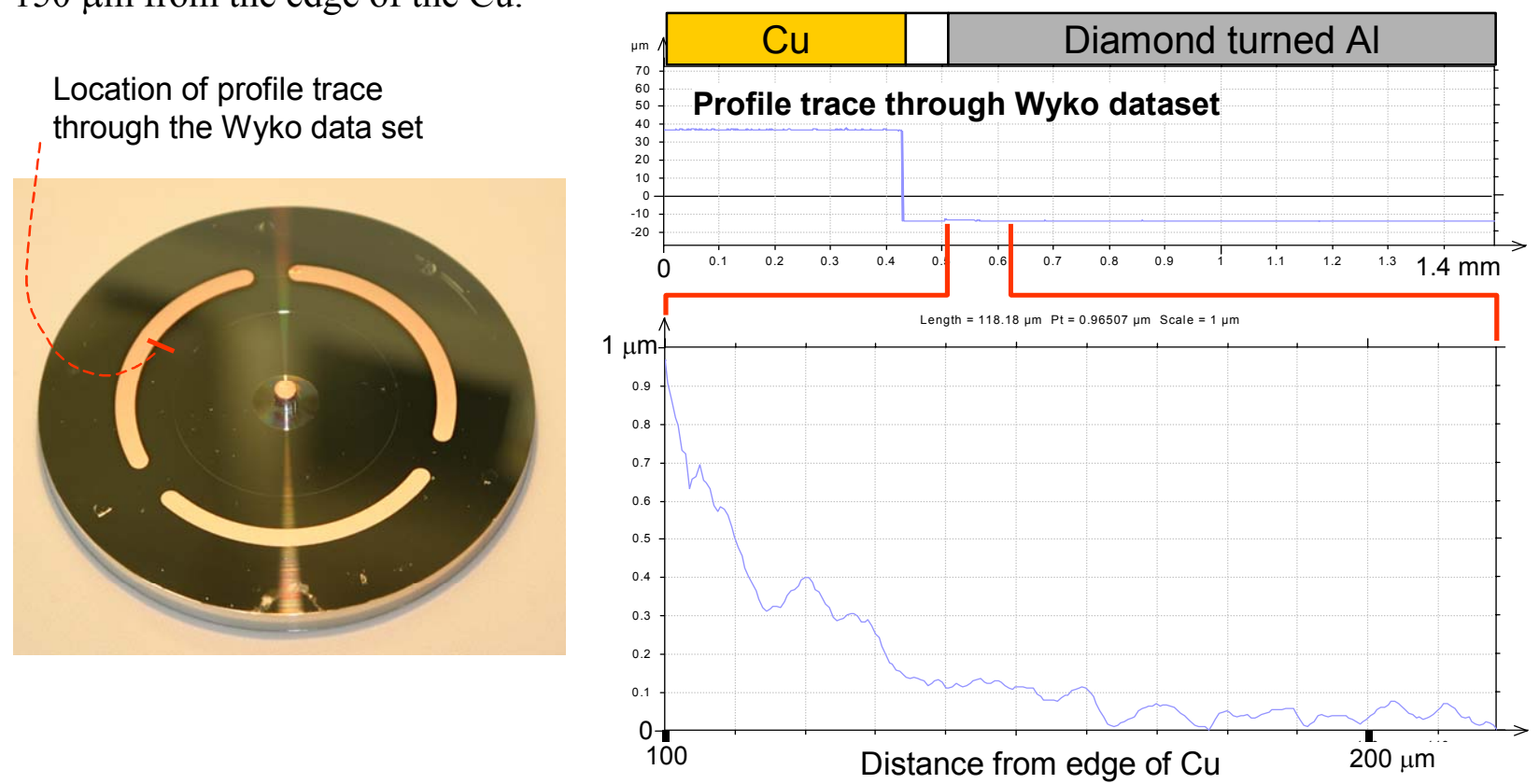

Figure 13. Wyko measurement of the shadow at the edge of the deposited $\mathrm{Cu}$

\section{Second Attempt at Sputter-Seeded Electroplating (6/23/04)}

The problem that was believed to have occurred with the first attempt at sputter-seeded electroplating of the $\mathrm{Cu}$ was poor adhesion of the sputtered Ti caused by residual adhesive on the surface of the $\mathrm{Al}$ from the Kapton tape. In an attempt to fix the problem and obtain better adhesion, another $100 \mathrm{~mm} \mathrm{Al} \mathrm{disk} \mathrm{was} \mathrm{processed.} \mathrm{This} \mathrm{disk} \mathrm{was} \mathrm{prepared} \mathrm{by} \mathrm{diamond} \mathrm{turning}$ both sides using mineral oil as the cutting fluid. After machining the disk, it was cleaned with an alcohol rinse, and a layer of Kapton tape was then applied to one surface. As with the previous disk, two circular score marks were made through the Kapton using the diamond tool on the diamond turning machine, and the resulting ring of Kapton tape was then peeled off to create a 4 $\mathrm{mm}$ wide circular band of exposed Al. In an attempt to remove any residual adhesive from the Kapton tape, the $4 \mathrm{~mm}$ wide circular band of exposed $\mathrm{Al}$ was washed with acetone. To perform the acetone rinse, the disk was mounted on the spindle of the diamond turning machine and 
rotated at several hundred rpm. A squirt bottle of acetone was then used to apply a stream of acetone to the exposed Al for several seconds, and a squirt bottle of isopropyl alcohol was used to rinse off the acetone. The disk was then sputtered in B235 with $10 \mathrm{~nm}$ of Ti followed by $3 \mu \mathrm{m}$ of $\mathrm{Cu}$. Several hundred $\mu \mathrm{m}$ of $\mathrm{Cu}$ were then electroplated onto the sputtered layer of $\mathrm{Cu}$.

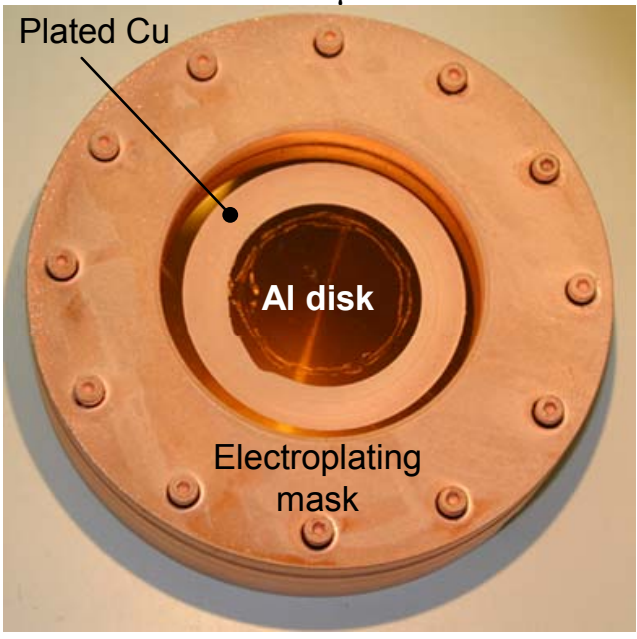

Figure 14. Electroplated disk

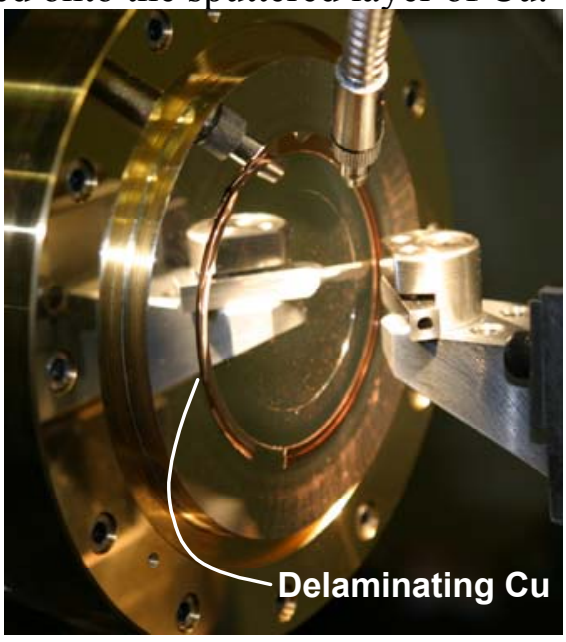

Figure 15. Delaminating $\mathrm{Cu}$

Figure 14 depicts the Kapton-masked $100 \mathrm{~mm}$ Al disk inside the hardmask used for the electroplating process. This photograph was taken just after removing the disk and the electroplating mask from the plating bath. After removing the disk from this hardmask, the Kapton was removed, and the disk was placed back on the vacuum chuck on the diamond turning machine. The $\mathrm{Cu}$ was then diamond turned to reduce its thickness. At the time, this disk was intended for $16 \mathrm{~kJ}$ Omega EOS targets, which required a Cu sample of thickness $25 \mu \mathrm{m}$. As the $\mathrm{Cu}$ was being machined to the correct thickness, it began to delaminate and peel away from the $\mathrm{Al}$ disk, as shown in Figure 15. At a thickness of $27 \mu \mathrm{m}$, a portion of the $\mathrm{Cu}$ completely fell off of the $\mathrm{Al}$ disk. The backside of the $\mathrm{Cu}$ strip was silver in appearance, which indicated that once again, the sputtered Ti had delaminated from the Al substrate.

\section{Second Attempt at E-Beam Evaporation of Cu (7/20/04)}

One of the problems that occurred during the first attempt to deposit $\mathrm{Cu}$ using E-beam evaporation was that the locating pin on the disk caught in the hole in the hardmask, so the disk did not seat properly onto the mask during the deposition. Another attempt was made to deposit $\mathrm{Cu}$ onto a $100 \mathrm{~mm} \mathrm{Al}$ disk using E-beam evaporation, but this time the precision locating pin was machined differently. Rather than machining a simple cylindrical pin, the pin was machined in a barrel shape. The curved edges of the pin allowed the disk to be correctly inserted onto the hardmask in the E-beam evaporation chamber.

By this point in time, the $16 \mathrm{~kJ}$ Omega EOS shots had been cancelled. Therefore, this disk was intended to be used to make 23 MBar NIF EOS targets, which required a Cu sample of thickness $43 \mu \mathrm{m}$. It was well known that material deposited by E-beam evaporation can have a surface roughness of several hundred $\mathrm{nm}$, and the upper and lower surfaces of the deposited material can be crowned or "shadowed" as shown in Figure 13. Therefore, excess material must always be deposited so it can be diamond turned to the desired thickness. Therefore, the Target Fabrication Group requested that 50 to $60 \mu \mathrm{m}$ of $\mathrm{Cu}$ be deposited using the E-beam evaporation process. 
The disk received from the E-beam evaporation process did not have sufficient $\mathrm{Cu}$. The thickness of the deposited $\mathrm{Cu}$ ranged from 38 to $44 \mu \mathrm{m}$. The disk was mounted back on the diamond turning machine, and the $\mathrm{Cu}$ was machined to a thickness of $41.5 \mu \mathrm{m}$. This machining process removed $\mathrm{Cu}$ from a portion of the disk, but in some areas, the $\mathrm{Cu}$ was not touched by the cutting tool, as shown in Figure 16.

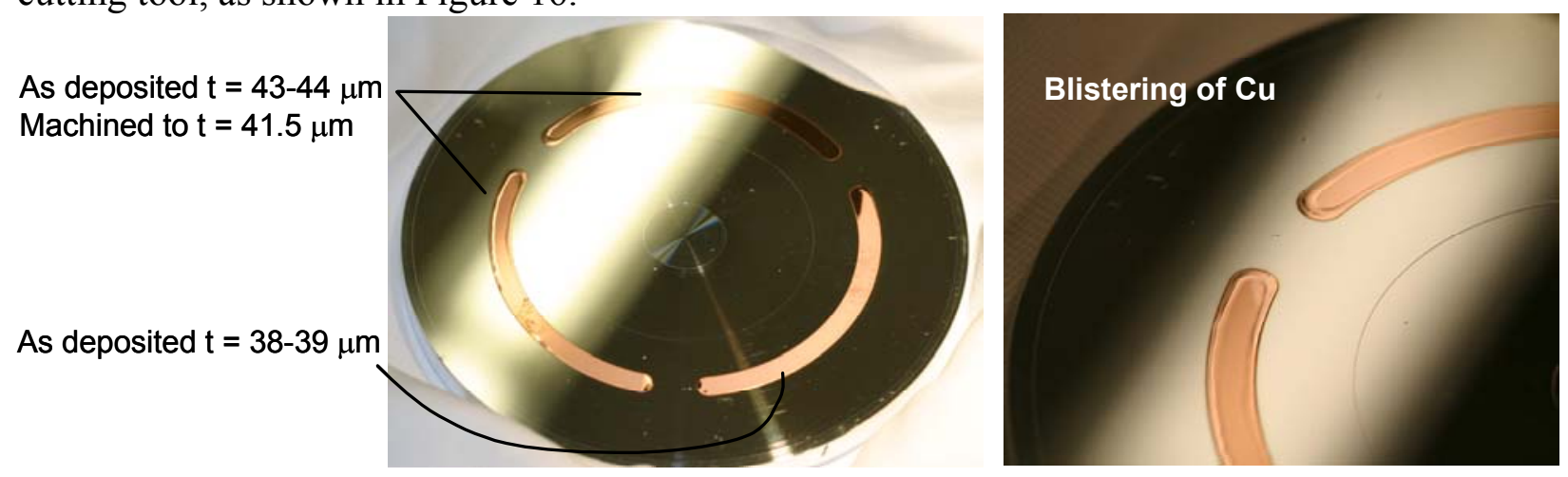

Figure 16. Cu deposited by E-beam evaporation after machining it to a thickness of $41.5 \mu \mathrm{m}$

The $\mathrm{Cu}$ deposited in this process was not adequately adhered to the $\mathrm{Al}$ disk. The right side of Figure 16 reveals that the $\mathrm{Cu}$ began to blister near the edges and delaminate from the Al. The $4 \mathrm{~mm}$ wide band of deposited $\mathrm{Cu}$ was inspected with the Wyko NT8000 optical profiling system. A profile trace made through the dataset revealed that the diamond turned surface of the $\mathrm{Cu}$ had a profile of approximately $0.5 \mu \mathrm{m}$ over the $4 \mathrm{~mm}$ width, as shown in Figure 17 . This profile was caused by $\mathrm{Cu}$ that blistered from the $\mathrm{Al}$ after the machining process.

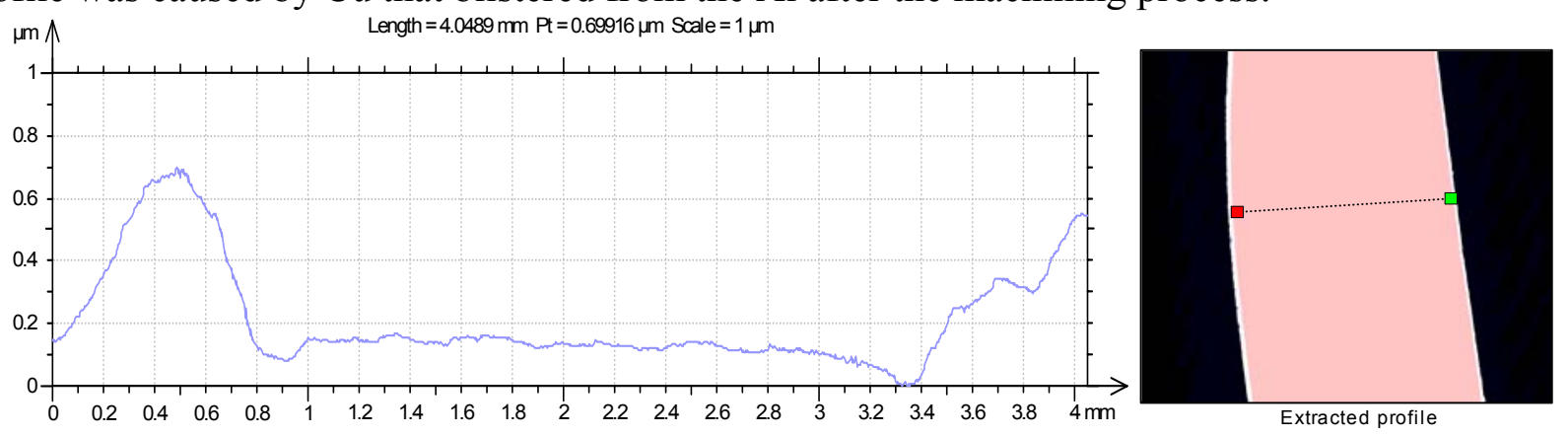

Figure 17. Profile trace across the $4 \mathrm{~mm}$ wide band of $\mathrm{Cu}$

\section{CLEANING TESTS}

After attempts to deposit $\mathrm{Cu}$ onto the $\mathrm{Al}$ disk using both sputter-seeded electroplating and E-beam evaporation suffered from delamination of the $\mathrm{Cu}$, it was apparent that the processes needed to be changed to obtain better adhesion. Therefore, attempts to produce targets were put on hold, and a research effort was performed to determine how adhesion of the $\mathrm{Cu}$ to the $\mathrm{Al}$ could be improved.

It was hypothesized that the delamination of the $\mathrm{Cu}$ could have been related to inadequate cleaning of the Al disk. The research effort used samples of diameter $25 \mathrm{~mm}$ to perform tests on different cleaning processes. Examples of the $25 \mathrm{~mm}$ disks are depicted in Figure 18. The left side of the figure depicts a $25 \mathrm{~mm}$ disk in the sputtering chamber in B231 immediately after it had been sputtered with $5 \mu \mathrm{m}$ of $\mathrm{Cu}$. The right side of the figure depicts a $25 \mathrm{~mm}$ disk that was coated with $\mathrm{Cu}$ using E-beam evaporation. The Kapton mask had been peeled off of this disk. 

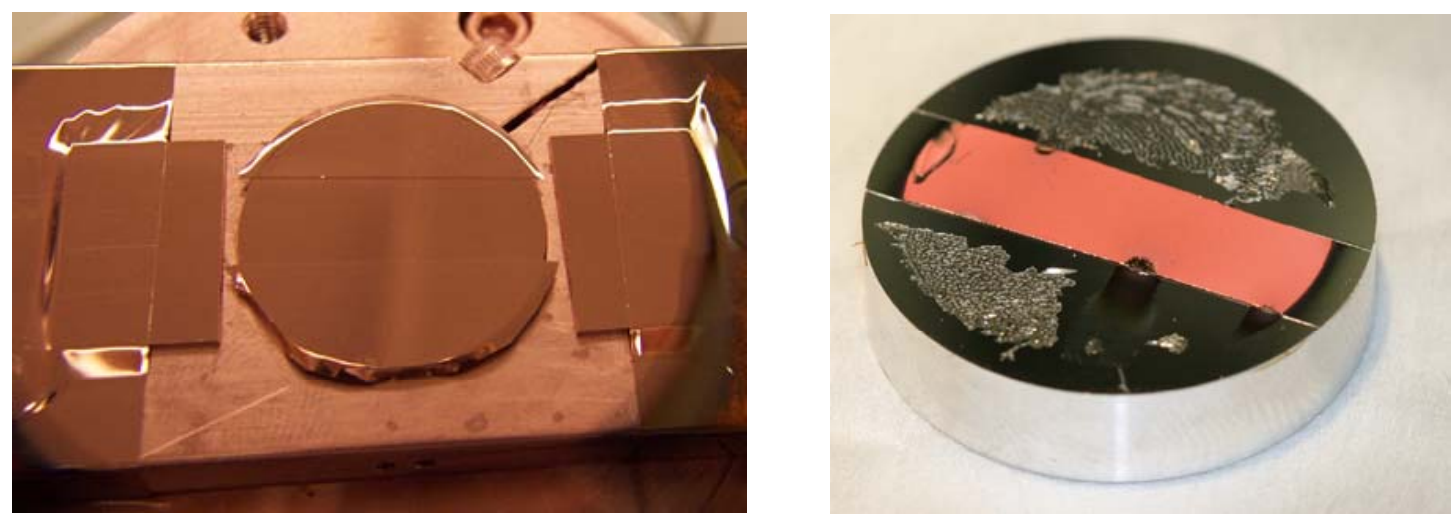

Figure 18. Disks of diameter $25 \mathrm{~mm}$ used for cleaning tests

The tests performed on these $25 \mathrm{~mm}$ disks yielded a great deal of valuable information on the procedures exercised prior to and during the $\mathrm{Cu}$ deposition operations. Complete details of the tests are available in Appendix B. A summary of some of the important observations is given below.

- Mineral spirits can be used as a cutting fluid to machine diamond turned surfaces on Al 1100 . Because mineral spirits is much more volatile than mineral oil, it evaporates more quickly and is more easily removed from the surface. Therefore, it is recommended that all machining be performed using mineral spirits as the cutting fluid.

- Pentane is an excellent solvent for cleaning mineral spirits off of diamond turned surfaces. One cleaning method that led to adequate adhesion of the $\mathrm{Cu}$ to the $\mathrm{Al}$ was to clean the diamond turned surface by rinsing it with pentane, followed by acetone, followed by clean ethanol. This sequence should be repeated three times. This cleaning method does not have any noticeable adverse effect on the surface finish of diamond turned Al. After machining a sample using mineral spirits and cleaning it three times with pentane, acetone, and ethanol, a SIMS analysis did not identify any peaks representative of mineral spirits, pentane, acetone, or ethanol.

- Pentane should not be stored in polyethylene bottles. The pentane will become contaminated and deposit crystals on the Al that are not easily removed. A microscope image of these crystals appears in Figure 19. Pentane should be stored in a glass bottle and can be applied using a syringe with a syringe filter or with a glass pipette.
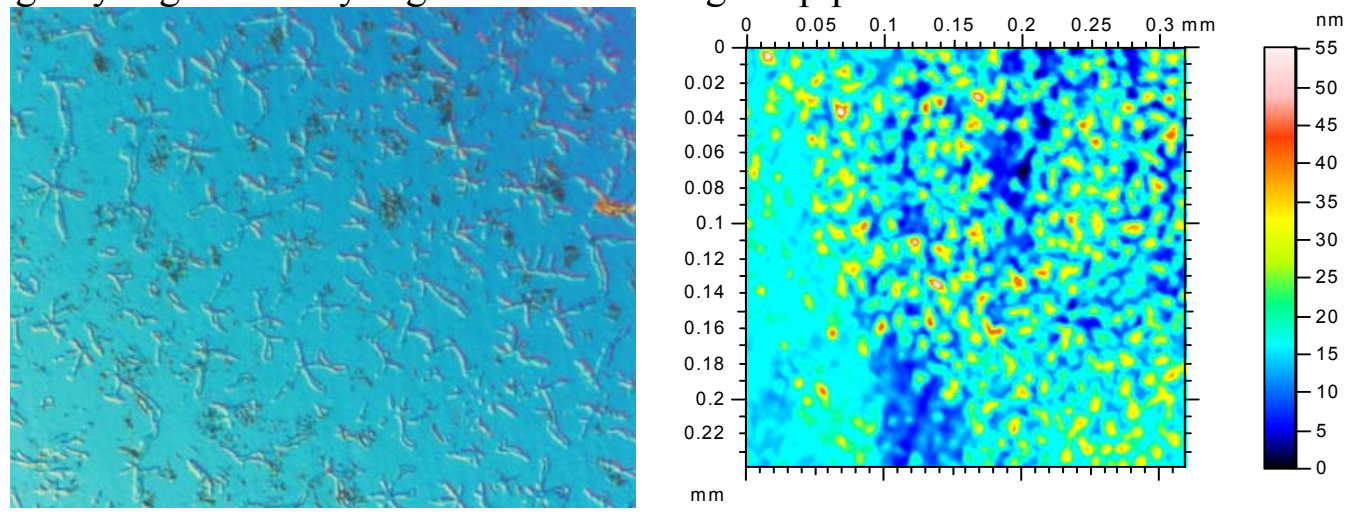

Figure 19. Microscope image $(500 \times)$ and Wyko dataset (PSI $20 \times$ ) of debris left by pentane that had been stored in a polyethylene bottle 
- Prior to being sputtered, parts should not be stored in polyethylene boxes, because the outgassing of the plastic can contaminate the Al. Instead, parts should be stored in Fluoroware trays, which are commonly used as wafer shipping trays and do not outgas significantly.

- Alcohol and acetone should not be used in the vicinity of Kapton tape. They can dissolve the adhesive on the tape and transport a white residue over the surface of the parts. This white residue can be very detrimental to the adhesion of deposited $\mathrm{Cu}$.

- Bob Dively Liquid Masking Film can be applied as a barrier between the Al and the Kapton tape. This masking film can be peeled up, and SIMS analyses indicated that it does not leave any significant residue on the surface.

- Performing a SIMS analysis does produce any noticeable detrimental effect on surface finish

- A 30 second swirl in dilute Oakite solution has a small detrimental effect on surface finish.

In one test on a diamond turned $\mathrm{Al}$ surface, the Oakite cleaning process increased $\mathrm{S}_{\mathrm{t}}$ from 30 $\mathrm{nm}$ to $40 \mathrm{~nm}$.

- $\mathrm{Cu}$ should not be directly E-beam evaporated onto Kapton tape. (The parameters used for this test were not made available to the Target Fabrication Group). At the test conditions used for this single test, the Kapton warped and peeled off of the Al, leaving a significant amount of adhesive residue behind. This residue was easily removed with acetone.

\section{0 mm AI DISKS MACHINED WITH MINERAL SPIRITS}

The cleaning tests identified some procedural changes that should have promoted adhesion of the deposited $\mathrm{Cu}$ to the $\mathrm{Al}$. The most important discovery was that mineral spirits makes an excellent cutting fluid and can be removed by rinsing the part with pentane, acetone, and clean ethanol. This cleaning process appeared to lead to excellent adhesion of the deposited $\mathrm{Cu}$ to the Al. This information was incorporated into resumed production attempts on $100 \mathrm{~mm}$ Al disks.

\section{Test Disk for Sputter-Seeded Electroplating (9/30/04)}

While the cleaning tests were taking place, several $100 \mathrm{~mm}$ diameter Al disks were diamond turned such that the two faces were parallel to within $100 \mathrm{~nm}$. Because more than one month had elapsed since a $100 \mathrm{~mm}$ disk was run through the sputtering and electroplating processes, a non-precision test disk was run through the process with the intent of working out any bugs in the different steps.

This test disk was machined using mineral spirits as the cutting fluid. It was then rinsed with pentane, acetone, and ethanol. The cleaning process was repeated three times. The disk was then masked with Kapton tape. However, rather than applying the tape directly to the Al surface, a layer of Bob Dively Liquid Masking Film was first applied to the disk, as illustrated in Figure 20. 

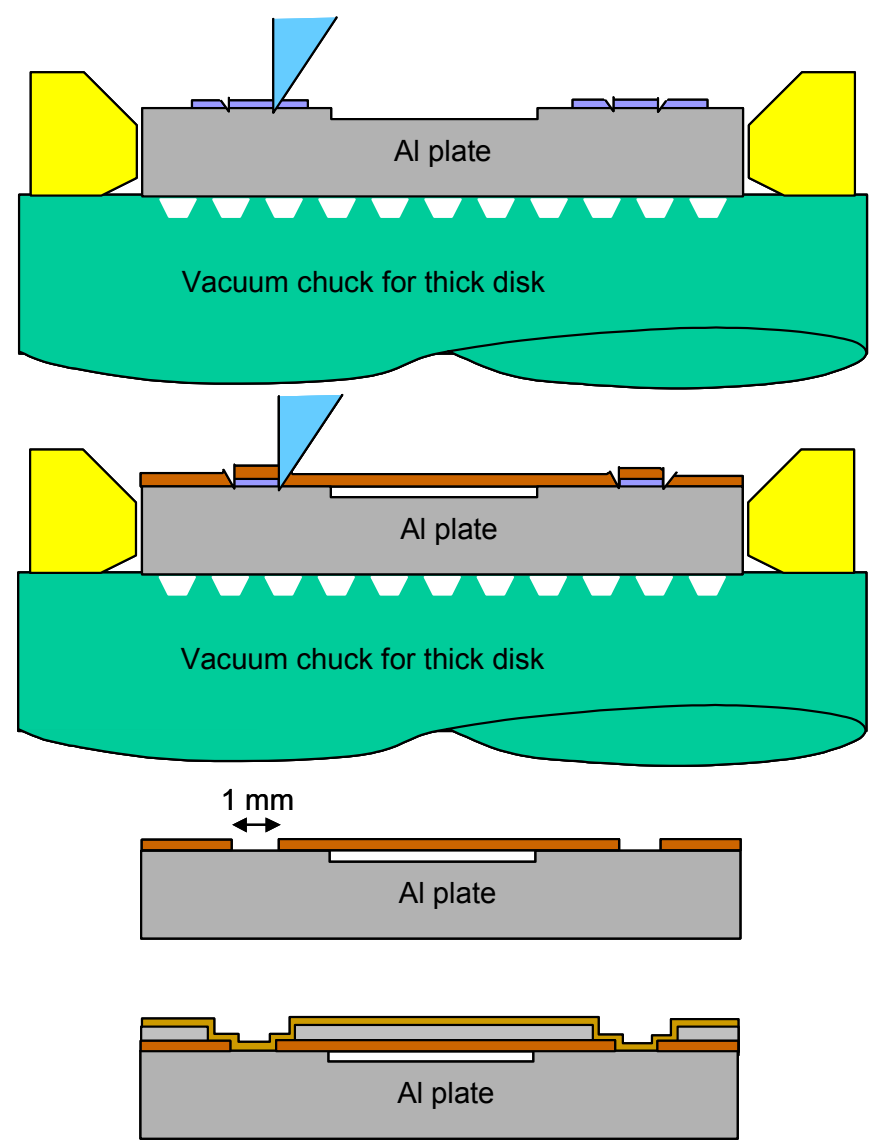

-Apply a layer of Bob Dively Liquid Masking

Film over a portion of the disk.

-Allow the masking film to dry for a few hours, and then score it with a diamond tool. The tool may cut up to $2 \mu \mathrm{m}$ into the Al. -Peel up the outer and inner sections of paint, leaving only a $1 \mathrm{~mm}$ wide band of paint.

-Apply Kapton tape over the entire surface of the disk

-Score through the tape, being careful to retrace the previous score marks.

-Peel up the $1 \mathrm{~mm}$ wide ring of Kapton and masking film to expose a $1 \mathrm{~mm}$ wide band of Al

-Place a mask of Al foil over the surface of the Kapton, leaving only a few $\mathrm{mm}$ of exposed Kapton adjacent to the exposed $\mathrm{Al}$ -Place the disk in the sputtering chamber -Ion mill the surface for several minutes, then sputter $20 \mathrm{~nm}$ of Ti followed by $5 \mu \mathrm{m}$ of $\mathrm{Cu}$ on the surface

Figure 20. Masking of the Test Disk using Bob Dively Liquid Masking film as a barrier beneath the Kapton

The disk was then placed in the sputtering chamber in B231, ion milled for several minutes, and sputtered with $20 \mathrm{~nm}$ of Ti followed by $5.4 \mu \mathrm{m}$ of $\mathrm{Cu}$. Figure 21 depicts the setup of the Test Disk in the sputtering chamber. The foil masks that have been placed over the Kapton prevent the ion milling process from ablating too much of the Kapton. The right side of the figure depicts the disk after it was sputtered with $\mathrm{Cu}$ and the foil masks were removed.
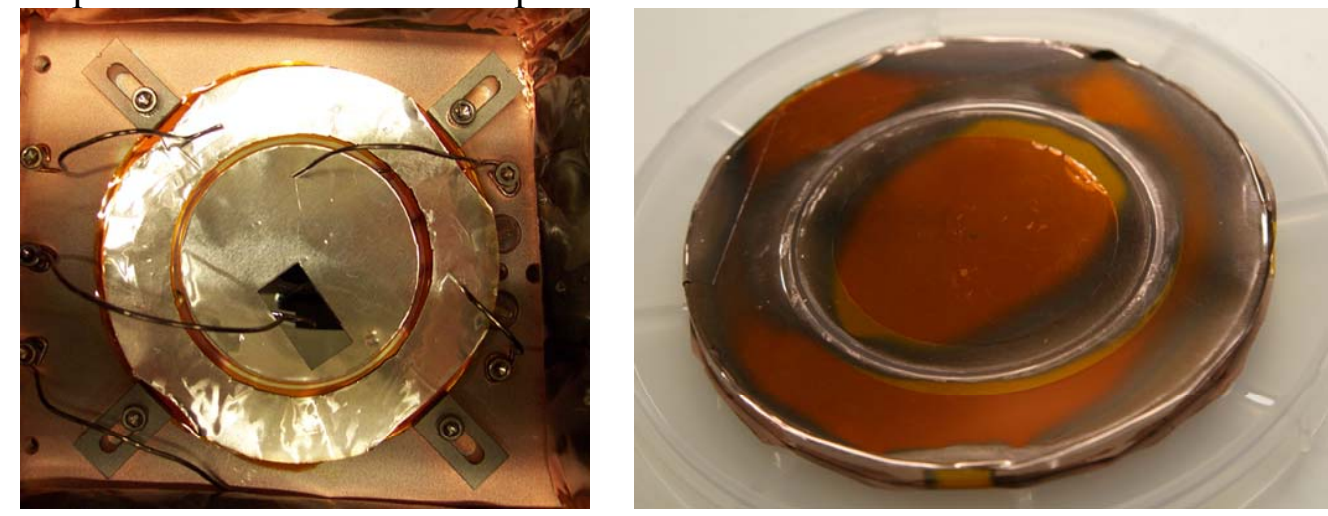

Figure 21. Setup for sputtering the Test Disk (left) and the sputtered disk after removing the Al foil masks (right)

While sputtering the Test Disk, a shutter in the sputtering chamber had been inadvertently left closed, so the first $0.5 \mu \mathrm{m}$ of $\mathrm{Cu}$ was deposited very slowly, which had the effect of 
significantly reducing the sputtering power. After sputtering the disk, the Kapton mask used during the sputtering process was left in place, and the disk was placed into the electroplating mask and electroplated with an additional several hundred $\mu \mathrm{m}$ of $\mathrm{Cu}$. The disk was placed back on the diamond turning machine, and the $\mathrm{Cu}$ was machined with the diamond tool so that the Kapton could be removed without tearing the $\mathrm{Cu}$. The electroplated $\mathrm{Cu}$ was then machined to a thickness of $43 \mu \mathrm{m}$. The $\mathrm{Cu}$ showed no signs of delaminating when attempting to pry up the edge with a razor blade. A picture of the machined $\mathrm{Cu}$ appears in Figure 22. Note that the band of $\mathrm{Cu}$ had a width of only $1 \mathrm{~mm}$, because the design for the target changed. The edge of the $\mathrm{Cu}$ looked relatively clean, but there were a few places where the $\mathrm{Al}$ had been pitted adjacent to the $\mathrm{Cu}$, which may have been a result of electroplating chemicals penetrating beneath the Kapton mask.
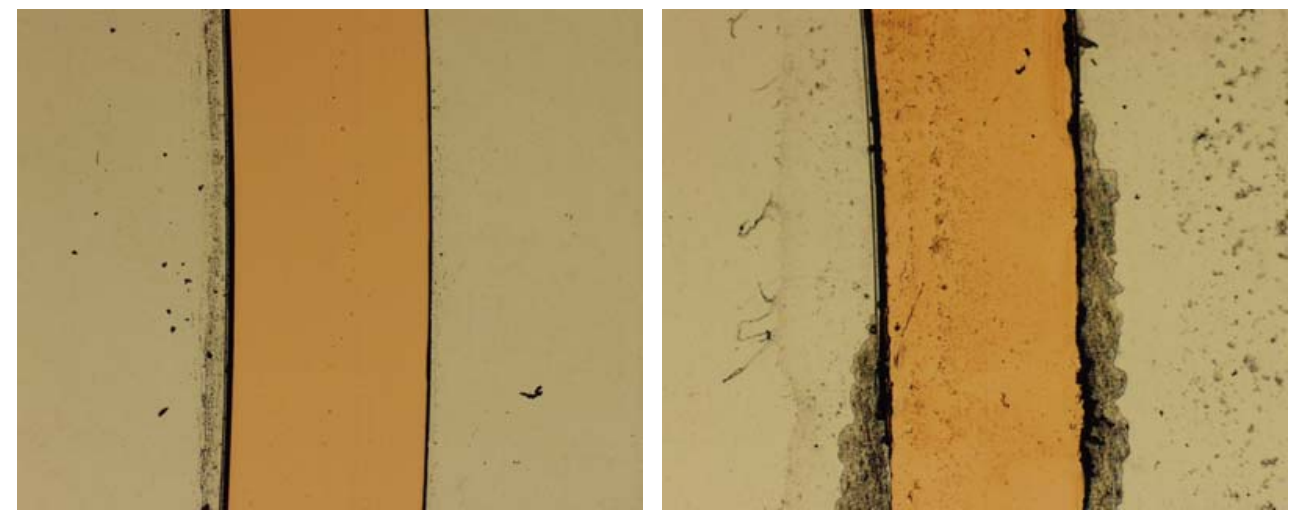

Figure 22. Machined $\mathrm{Cu}$ on the Test Disk with clean regions (left) and pitted regions (right)

\section{SPUT1 - Masked with Electroplating Paint (10/05/04)}

After successfully depositing a band of $\mathrm{Cu}$ on the Test Disk, an attempt was made to repeat the process on a precise $100 \mathrm{~mm} \mathrm{Al} \mathrm{disk} \mathrm{with} \mathrm{parallel} \mathrm{surfaces.} \mathrm{This} \mathrm{disk,} \mathrm{labeled}$ "SPUT1" was diamond turned using mineral spirits and cleaned with pentane, acetone, and ethanol. It was then masked with Bob Dively Liquid Masking Film and Kapton in the manner illustrated in Figure 20. The Kapton was scored with the diamond tool, and after peeling the 1 $\mathrm{mm}$ wide ring of Kapton tape and masking film from the surface, the machinist noticed a small piece of debris on the surface. In an attempt to clean off this debris, it was rinsed with ethanol. The alcohol appeared to have dissolved some of the adhesive on the Kapton tape and left a white residue on the $1 \mathrm{~mm}$ wide band of exposed Al. This residue was wiped with a cotton swab in an attempt to remove it.

The disk was then placed in the sputtering chamber in B231, ion milled for several minutes, and sputtered with $20 \mathrm{~nm}$ of Ti followed by several $\mu \mathrm{m}$ of $\mathrm{Cu}$. Upon examining the disk with a microscope, it appeared that the Kapton tape had lifted slightly around the inner and outer perimeters of the $1 \mathrm{~mm}$ groove, as shown in Figure 23. This peeling of the Kapton may have been related to the fact that ethanol had dissolved some of the adhesive on the Kapton tape. It is possible that ethanol removed so much of the adhesive from the Kapton that there was not enough adhesive left to keep the Kapton down on the surface of the Al. There was concern that electroplating solution could easily have penetrated beneath the Kapton and damaged the Al surface of the disk, so the disk was not electroplated in this condition. Instead, the Kapton mask was removed, and the disk was coated with commercial electroplating masking paint. Special 
care was taken to ensure that the edges of the $1 \mathrm{~mm}$ wide band of sputtered $\mathrm{Cu}$ were well covered.
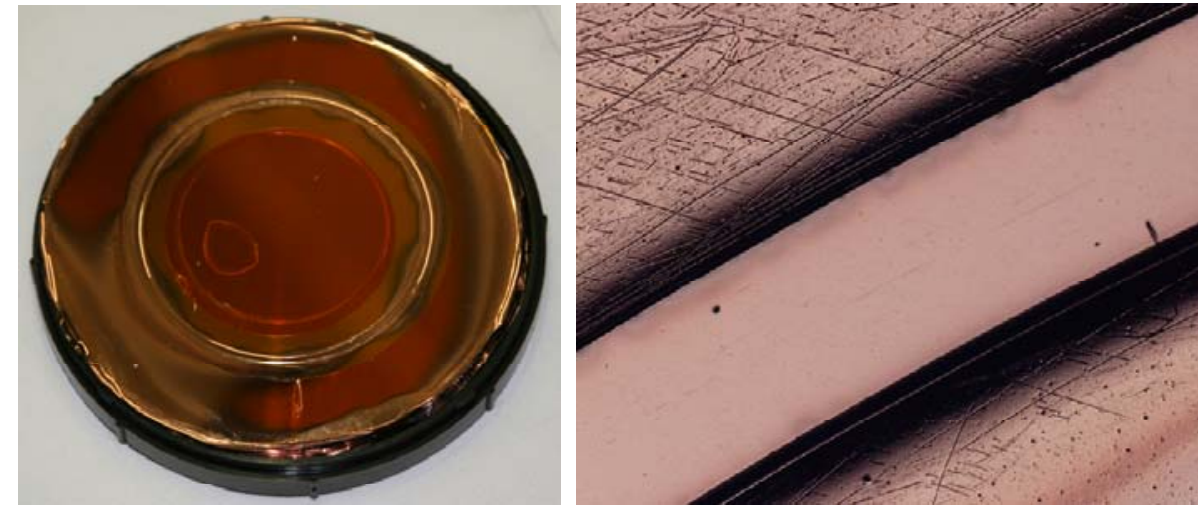

Figure 23. Sputtered disk SPUT1 and a microscope image of the Kapton peeling up

Once the electroplating paint had dried, the disk was mounted back on the diamond turning machined. The paint was then scored with the diamond tool on either side of the $1 \mathrm{~mm}$ band of sputtered $\mathrm{Cu}$, and this $1 \mathrm{~mm}$ wide strip of paint was peeled up to reveal the sputtered $\mathrm{Cu}$, as shown in Figure 24.
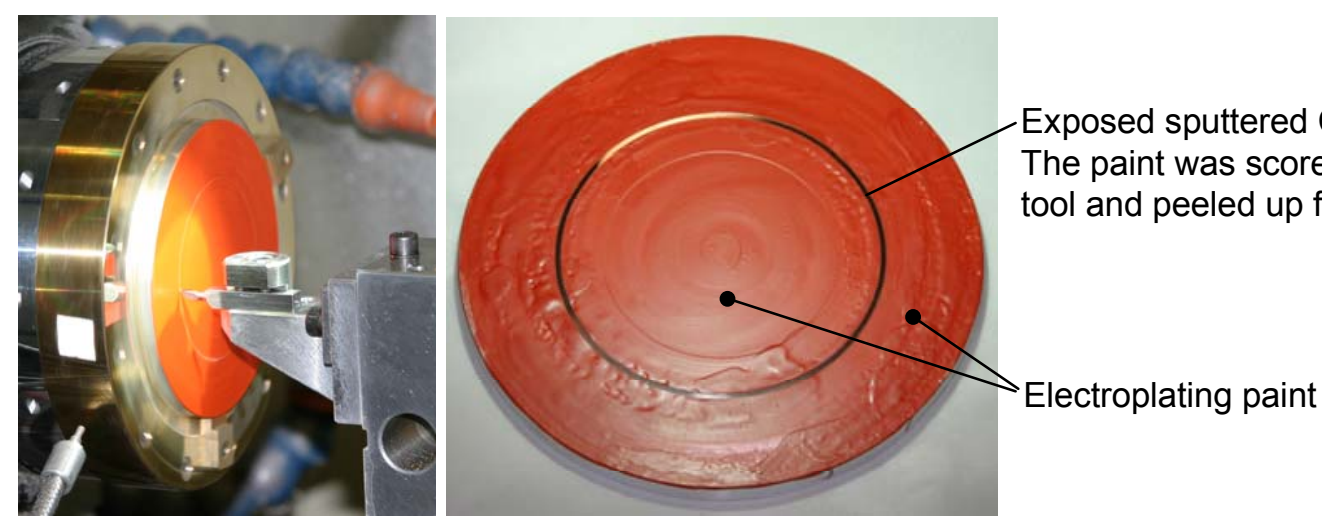

Figure 24. Scoring of the electroplating paint with the diamond tool (left) and the masked disk SPUT1 after peeling off the $1 \mathrm{~mm}$ wide section of scored paint (left)

The disk was then placed in the electroplating mask, and several hundred $\mu \mathrm{m}$ of $\mathrm{Cu}$ were deposited using a current density of $30 \mathrm{Amp} / \mathrm{ft}^{2}$. The electroplating paint was then peeled off of the disk. The surface of the Al had been severely damaged during the electroplating process, as shown in the photograph and microscope image in Figure 25. The pitting of the Al was probably caused by electroplating chemical penetrating through the electroplating paint. Despite the fact that this electroplating masking paint is a commercial product that is commonly used to mask parts while they are being electroplated, it failed to adequately protect the Al disk. 

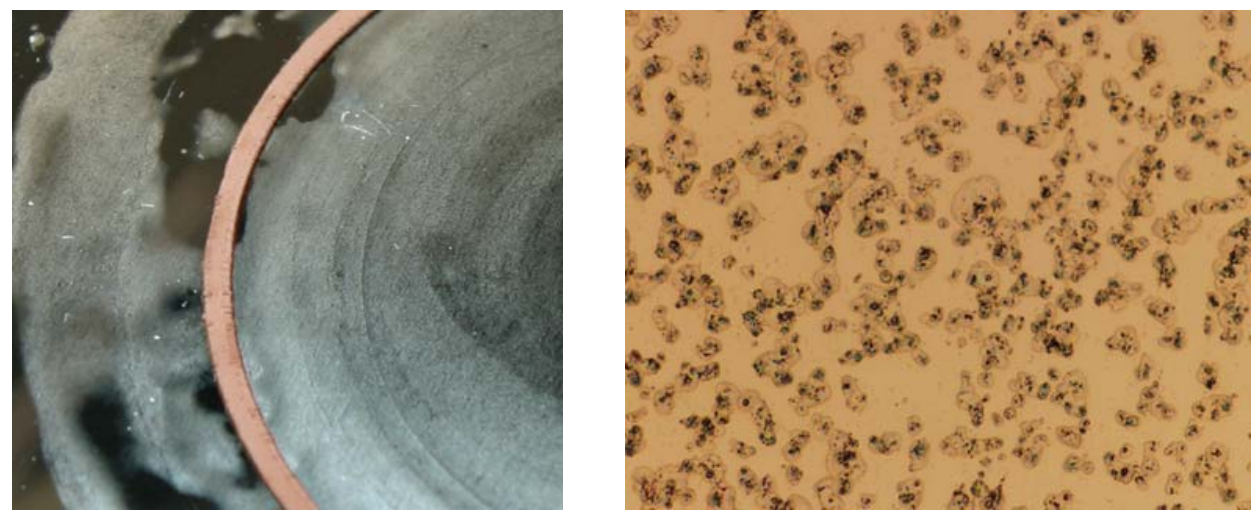

Figure 25. Damaged Al surface of SPUT1 caused by the electroplating process

\section{SPUT3 - Masked with Kapton and Electroplating Paint (10/18/04)}

Before processing another $100 \mathrm{~mm} \mathrm{Al}$ disk, a simple test was performed to determine if electroplating chemicals can penetrate the commercial electroplating masking paint. The tests indicated that more than one coat of the electroplating paint is required to adequately protect the Al. Work continued with this electroplating paint, because it could be machined more nicely than Kapton tape, and at the time, it seemed like an attractive option that was expected to produce clean edges on the deposited $\mathrm{Cu}$.

Another $100 \mathrm{~mm}$ Al disk, labeled "SPUT3" was diamond turned using mineral spirits and cleaned with pentane, acetone, and ethanol. The disk was prepared using the process illustrated in Figure 26. The disk was masked with Bob Dively Liquid Masking Film and Kapton. The Kapton was scored with the diamond tool, and the $1 \mathrm{~mm}$ wide ring of Kapton tape and masking film was peeled up. The disk was ion milled and sputtered in B231 with $20 \mathrm{~nm}$ of Ti followed by $5 \mu \mathrm{m}$ of $\mathrm{Cu}$.

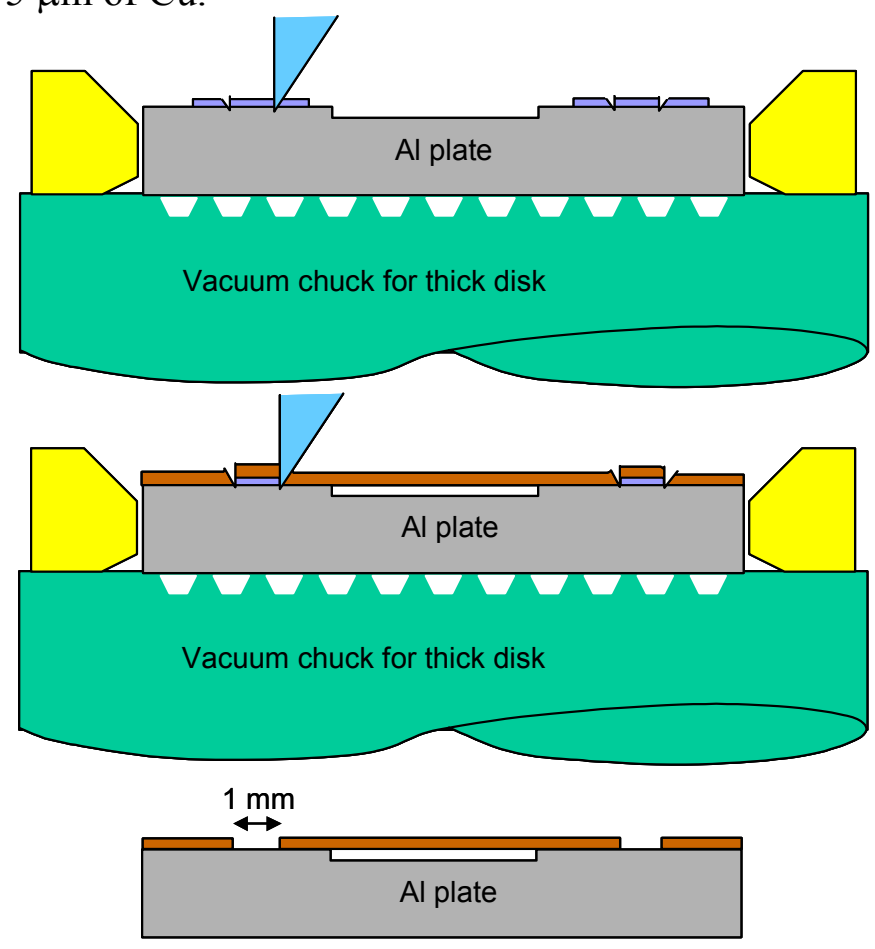

-Apply a layer of Bob Dively Liquid Masking Film over a portion of the disk. -Allow the masking film to dry for a few hours, and then score it with a diamond tool. The tool may cut up to $2 \mu \mathrm{m}$ into the Al. -Peel up the outer and inner sections of paint, leaving only a $1 \mathrm{~mm}$ wide band of paint.

-Apply Kapton tape over the entire surface of the disk

-Score through the tape, being careful to retrace the previous score marks.

-Peel up the $1 \mathrm{~mm}$ wide ring of Kapton and masking film to expose a $1 \mathrm{~mm}$ wide band of $\mathrm{Al}$ 

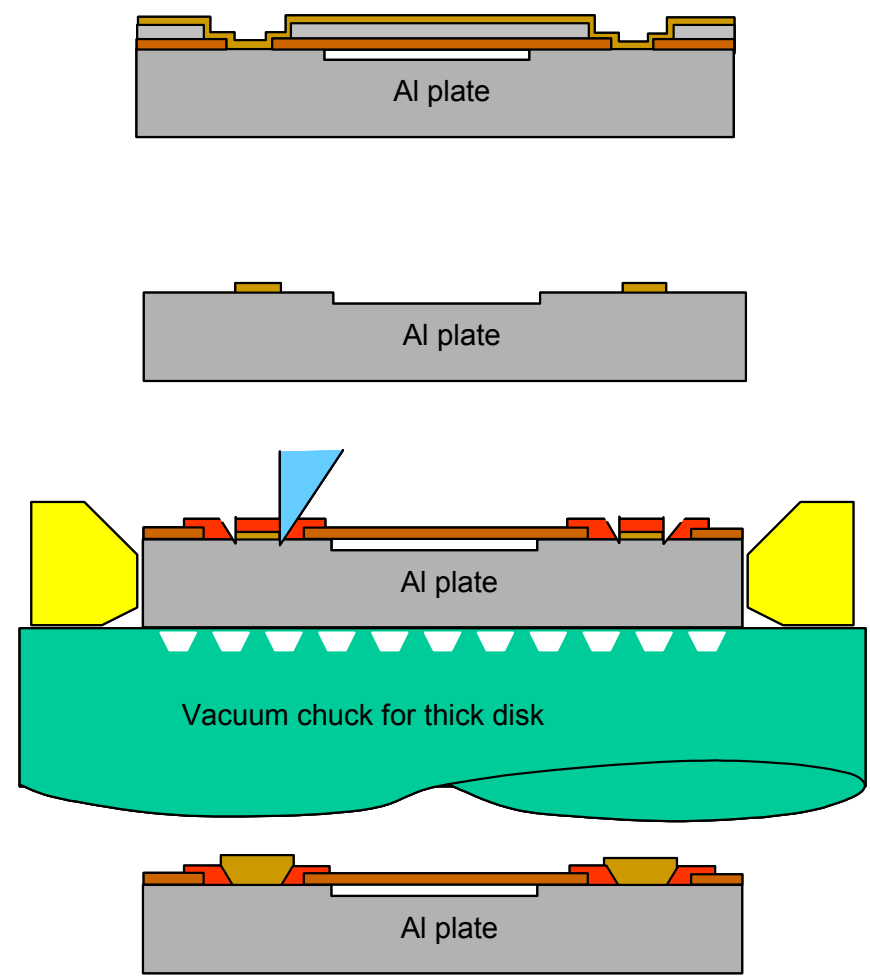

-Place a mask of Al foil over the surface of the Kapton, leaving only a few $\mathrm{mm}$ of exposed Kapton adjacent to the exposed $\mathrm{Al}$ - Place the disk in the sputtering chamber - Ion mill the surface for several minutes, then sputter $20 \mathrm{~nm}$ of Ti followed by $5 \mu \mathrm{m}$ of $\mathrm{Cu}$ on the surface

-Remove the Al mask

-Remove the Kapton, which will leave only a $1 \mathrm{~mm}$ wide band of sputtered $\mathrm{Cu}$ on the surface of the Al

-Rinse the disk with alcohol to remove any Kapton adhesive residue

-Place a Kapton mask over the majority of the surface of the disk, leaving several $\mathrm{mm}$ of exposed $\mathrm{Al}$ adjacent to the $\mathrm{Cu}$

-Paint the exposed $\mathrm{Al}$ and the $\mathrm{Cu}$ with electroplating masking paint. Apply 3 thin coats of the paint.

- Once the paint has dried, score through the paint with a diamond tool and peel up the 1 $\mathrm{mm}$ wide band of paint to expose the $\mathrm{Cu}$.

-Place the disk in the hardmask and electroplate an additional $100 \mu \mathrm{m}$ of $\mathrm{Cu}$ onto the sputtered $\mathrm{Cu}$.

Figure 26. Processing of disk SPUT3

After sputtering the disk, the Kapton was peeled from the disk, and precut pieces of fresh Kapton were placed on the disk, leaving several $\mathrm{mm}$ of $\mathrm{Al}$ exposed adjacent to the sputtered $\mathrm{Cu}$. The exposed $\mathrm{Al}$ and $\mathrm{Cu}$ were then covered with three coats of the commercial electroplating masking paint, as shown in Figure 27. Once the paint had dried, the disk was mounted back on the diamond turning machined. The paint was then scored with the diamond tool on either side of the $1 \mathrm{~mm}$ band of sputtered $\mathrm{Cu}$, and this $1 \mathrm{~mm}$ wide strip of paint was peeled up to reveal the sputtered $\mathrm{Cu}$. 

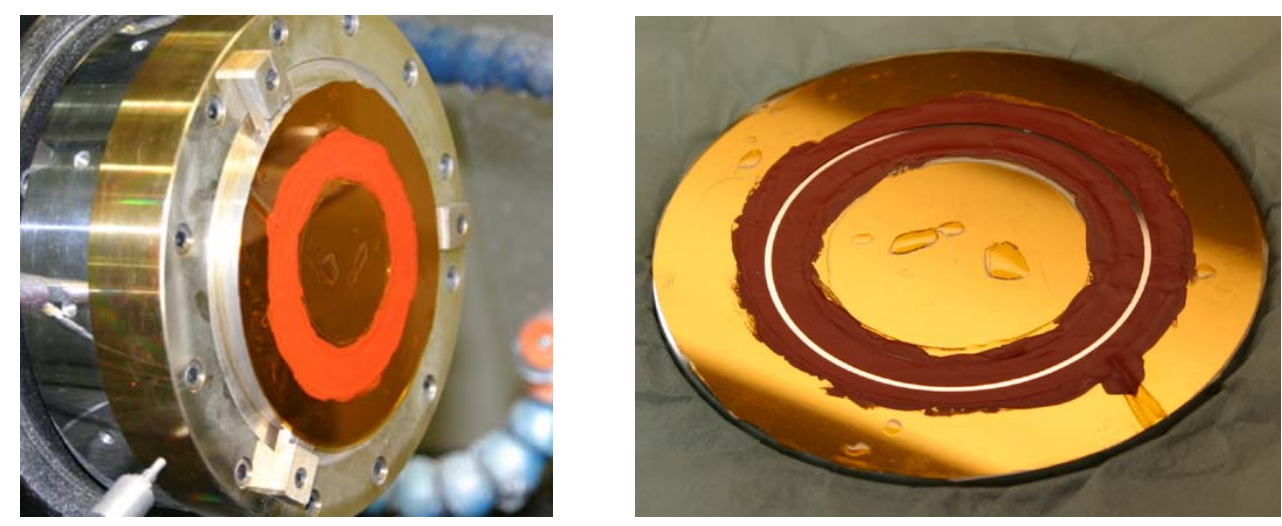

Figure 27. Disk SPUT3 after coating the $\mathrm{Al}$ and $\mathrm{Cu}$ with electroplating paint (left) and after scoring and peeling up the $1 \mathrm{~mm}$ wide section of paint that had covered the sputtered $\mathrm{Cu}$ (right)

The disk was then placed in the electroplating mask, and several hundred $\mu \mathrm{m}$ of $\mathrm{Cu}$ were deposited using a current density of $30 \mathrm{Amp} / \mathrm{ft}^{2}$. The electroplating paint and Kapton were then peeled off of the disk. Once again, the surface of the Al was damaged during the electroplating process, as shown in Figure 28. The Al was pitted over portions of the area that had been covered by the electroplating paint, but it was clean in the area that had been covered by Kapton. The electroplating chemicals appeared to have leaked through or beneath the electroplating paint. At this point, it was obvious that despite the fact that the commercial electroplating paint was designed specifically for the purpose for which it was being used, it did not function well enough to meet the requirements for these targets.

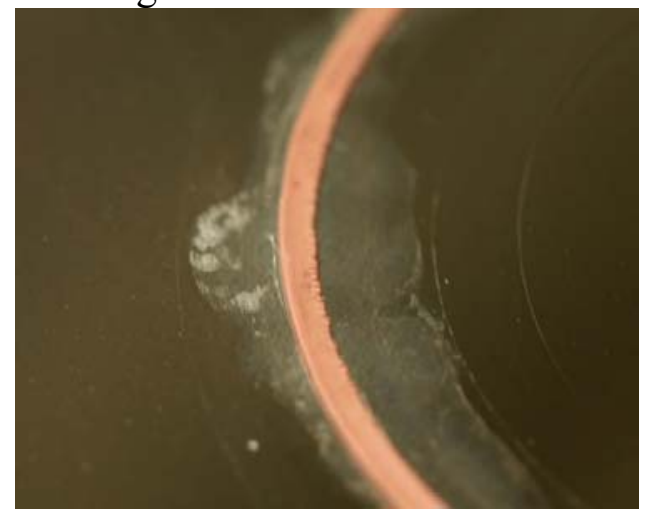

Figure 28. Damaged Al surface of SPUT3 caused by the electroplating process

Note that initial tests with the electroplating paint revealed that three coats of the paint adequately protected an Al substrate. However, when performing these tests, the Al was simply coated with the paint and then placed in the electroplating solution. The paint on this Al substrate was never machined with a diamond tool. In contrast, the paint on disk SPUT3 was machined with a diamond tool. It is possible that the process of machining the paint with the diamond cutting tool created a path for the electroplating chemicals to penetrate beneath the paint.

\section{SPUT10 - Masked with Fresh Kapton Prior to Electroplating (11/03/04)}

Because the electroplating paint did not function as expected, it was eliminated from consideration. Continued attempts to produce targets used Kapton tape to mask the $100 \mathrm{~mm} \mathrm{Al}$ disk. Another $100 \mathrm{~mm} \mathrm{Al} \mathrm{disk,} \mathrm{labeled} \mathrm{"SPUT10"} \mathrm{was} \mathrm{diamond} \mathrm{turned} \mathrm{using} \mathrm{mineral} \mathrm{spirits} \mathrm{and}$ 
cleaned with pentane, acetone, and ethanol. The disk was prepared using the process illustrated in Figure 29. The disk was masked with Bob Dively Liquid Masking Film and Kapton. The Kapton was scored with the diamond tool, and the $1 \mathrm{~mm}$ wide ring of Kapton tape and masking film was peeled up. The disk was ion milled and sputtered with $20 \mathrm{~nm}$ of Ti followed by several $\mu \mathrm{m}$ of $\mathrm{Cu}$ in $\mathrm{B} 231$.

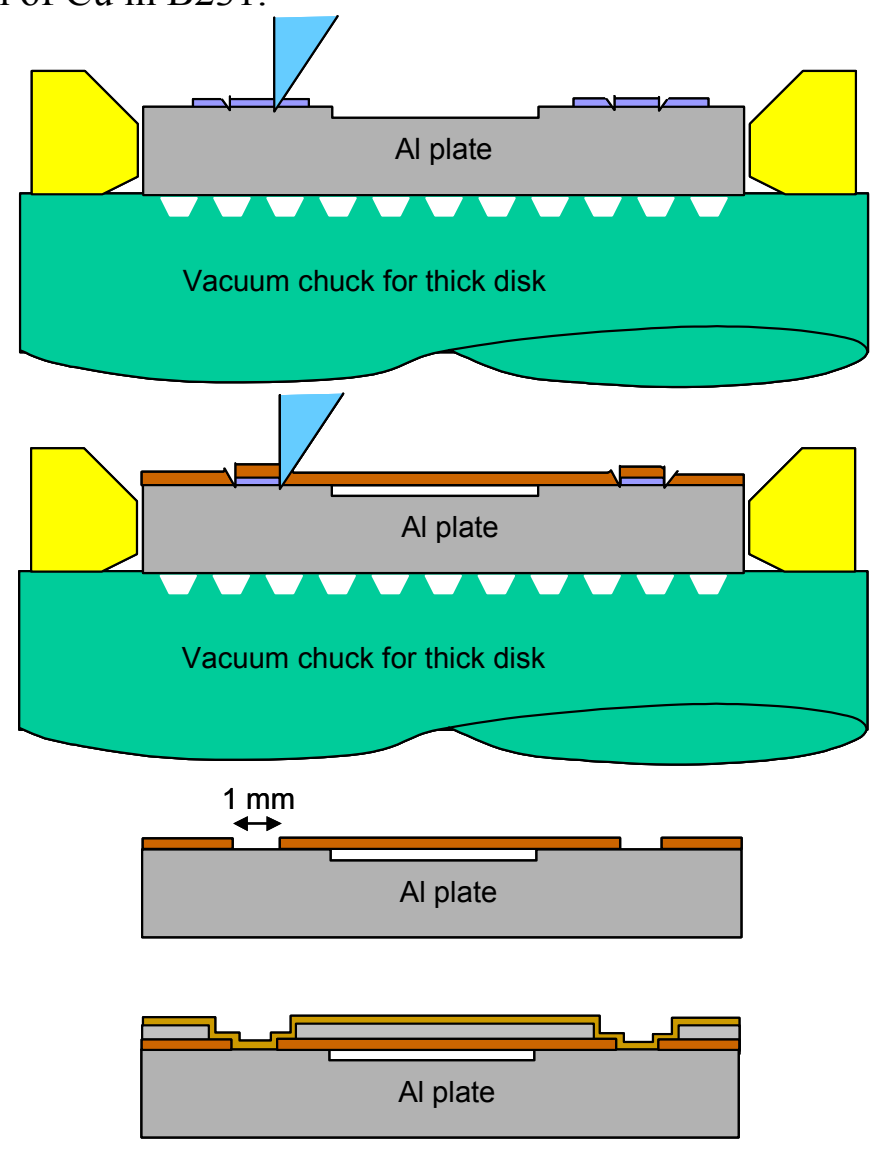

-Apply a layer of Bob Dively Liquid Masking Film over a portion of the disk. -Allow the masking film to dry for a few hours, and then score it with a diamond tool. The tool may cut up to $2 \mu \mathrm{m}$ into the Al. -Peel up the outer and inner sections of paint, leaving only a $1 \mathrm{~mm}$ wide band of paint.

-Apply Kapton tape over the entire surface of the disk

-Score through the tape, being careful to retrace the previous score marks.

-Peel up the $1 \mathrm{~mm}$ wide ring of Kapton and masking film to expose a $1 \mathrm{~mm}$ wide band of $\mathrm{Al}$

-Place a mask of Al foil over the surface of the Kapton, leaving only a few $\mathrm{mm}$ of exposed Kapton adjacent to the exposed $\mathrm{Al}$ - Place the disk in the sputtering chamber - Ion mill the surface for several minutes, then sputter $20 \mathrm{~nm}$ of Ti followed by $5 \mu \mathrm{m}$ of $\mathrm{Cu}$ on the surface

- Remove the Al mask

-Remove the Kapton, which will leave only a $1 \mathrm{~mm}$ wide band of sputtered $\mathrm{Cu}$ on the surface of the Al

-Rinse the disk with alcohol to remove any Kapton adhesive residue

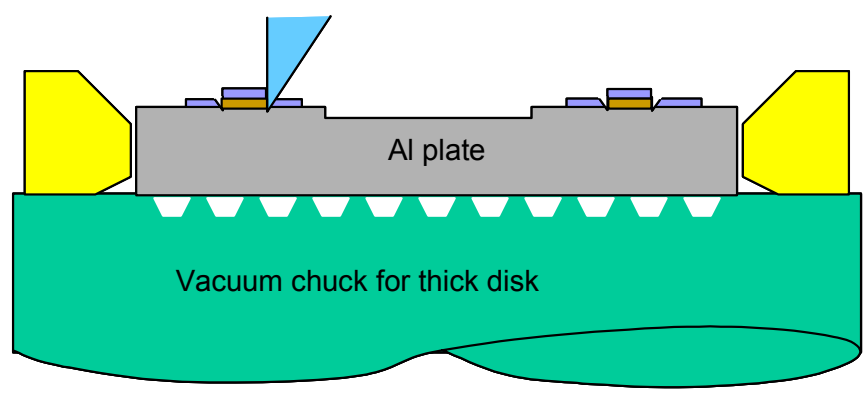

-Repeat the procedure of applying Bob Dively Liquid masking film, scoring the dried film, and peeling up the inner and outer portions to leave a $1 \mathrm{~mm}$ wide strip of masking film that covers the sputtered $\mathrm{Cu}$. 


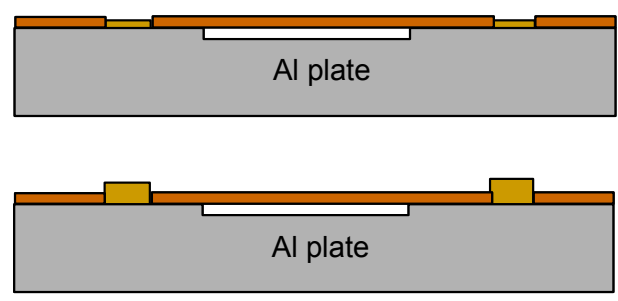

-Place a sheet of Kapton over the entire disk - Score the Kapton along the score marks -Peel up the $1 \mathrm{~mm}$ wide strip of Kapton and masking film to expose the $1 \mathrm{~mm}$ band of sputtered $\mathrm{Cu}$

-Place the disk in the hardmask and electroplate an additional $100 \mu \mathrm{m}$ of $\mathrm{Cu}$ onto the sputtered $\mathrm{Cu}$.

Figure 29. Processing of disk SPUT10

Because disk SPUT1 had experienced problems with the Kapton peeling up from the surface of the Al after sputtering, disk SPUT10 was processed slightly differently. Future discoveries would later indicate that the problem with SPUT1 was caused by the fact that ethanol had dissolved some of the adhesive from the Kapton tape, and the problem was not caused exclusively by the nature of the Kapton itself. However, at the time that disk SPUT10 was processed, this information had not been discovered yet.

After sputtering $\mathrm{Cu}$ onto the disk, the Kapton was removed. Bob Dively Liquid Masking Film was then applied over the sputtered $\mathrm{Cu}$. Once it had dried, the Bob Dively Liquid Masking Film was scored with the diamond tool, and a $1 \mathrm{~mm}$ wide strip was peeled up to reveal the sputtered $\mathrm{Cu}$. A fresh layer of Kapton tape was then placed over the entire surface of the disk. The Kapton was then scored, and a $1 \mathrm{~mm}$ wide strip was peeled up to reveal the sputtered $\mathrm{Cu}$. The disk was then placed in the electroplating mask, and several hundred $\mu \mathrm{m}$ of $\mathrm{Cu}$ were deposited using a current density of $30 \mathrm{Amp} / \mathrm{ft}^{2}$.

The Kapton was peeled off of the disk to reveal that once again, the Al was damaged adjacent to the electroplated $\mathrm{Cu}$, as shown in Figure 30. It appeared that once again, chemicals from the electroplating process reached the $\mathrm{Al}$ and caused pitting of the surface. In this case, the chemicals probably penetrated beneath the edge of the Kapton tape.
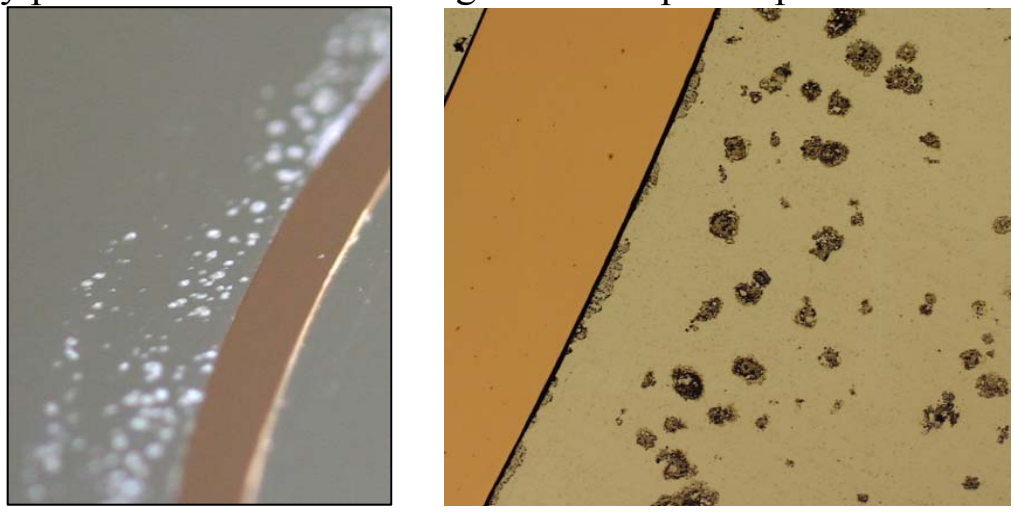

Figure 30. Pitting of Al on disk SPUT10 after electroplating

\section{SPUT11 - Same Kapton Mask Used for Both Sputtering and Electroplating (11/19/04)}

The only $100 \mathrm{~mm} \mathrm{Al} \mathrm{disk} \mathrm{that} \mathrm{did} \mathrm{not} \mathrm{experience} \mathrm{severe} \mathrm{pitting} \mathrm{during} \mathrm{electroplating} \mathrm{was}$ the Test Disk. For this disk, the same Kapton mask was used for both sputtering and electroplating, and it did not peel up significantly during sputtering. The masking of the disk for the electroplating process had the configuration illustrated in Figure 31. 


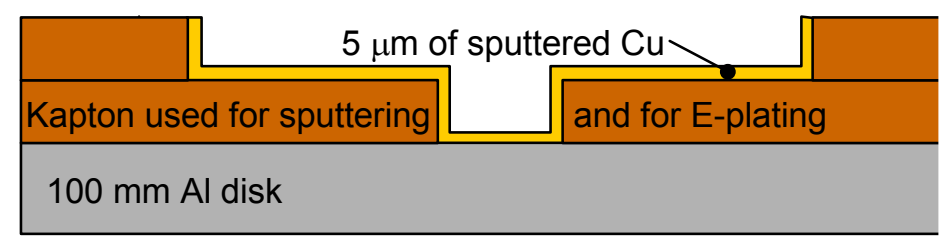

Figure 31. Masking of Test Disk during electroplating.

One possible explanation for why the Kapton did not peel up during the sputtering process was that the initial $0.5 \mu \mathrm{m}$ of $\mathrm{Cu}$ was sputtered very slowly, so it did not heat the Kapton and cause it to lift from the surface. This bit of $\mathrm{Cu}$ sealed the Kapton to the Al, and subsequent $\mathrm{Cu}$ built up on the sidewall of the Kapton, which protected the Al disk from the electroplating chemicals. It may also have been relevant that the area onto which $\mathrm{Cu}$ was electroplated had a width of $11 \mathrm{~mm}$ on the Test Disk, but it was only $1 \mathrm{~mm}$ for SPUT1, SPUT3, and SPUT10.

The procedure used to prepare the Test Disk for sputtering was repeated for another disk, which was labeled SPUT11. This disk was machined using mineral spirits as the cutting fluid. It was then rinsed with pentane, acetone, and ethanol. The cleaning process was repeated three times. The disk was then coated with Bob Dively Liquid Masking Film, which was scored and peeled to leave only a $1 \mathrm{~mm}$ wide band on the surface of the disk. The entire surface of the disk was masked with Kapton tape, which was then scored with the diamond tool. The $1 \mathrm{~mm}$ wide ring of Kapton was peeled up to expose a $1 \mathrm{~mm}$ wide band of Al, as illustrated in Figure 20.

Prior to sputtering this disk, the edges of the Kapton were examined very carefully. Some images of the edge of the Kapton appear in Figure 32. Over the majority of the part, the Kapton appeared to be fairly well adhered to the Al, but there were some areas where the Kapton did not appear to be well adhered. The inspection also revealed that the diamond tool did not always cut a nice smooth edge in the Kapton, and burrs or stips of material could be created in the Kapton by the cutting tool.
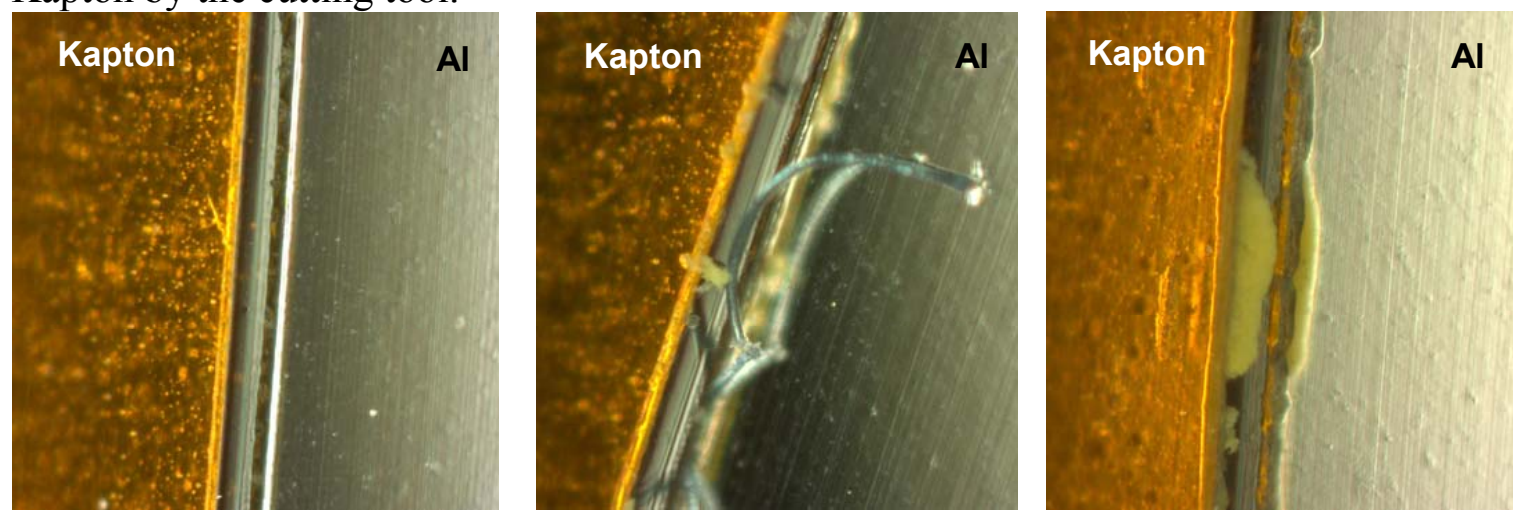

Figure 32. Disk SPUT11 masked with Kapton prior to sputtering

This part was placed in the sputtering chamber in B231, ion milled for several minutes, and then sputtered with $20 \mathrm{~nm}$ of Ti followed by $3 \mu \mathrm{m}$ of $\mathrm{Cu}$. The deposition rate, which is a function of the sputtering power, was reduced to $50 \%$ of that used for the previous disks. Some images of the edge of the sputtered Kapton appear in Figure 33. 

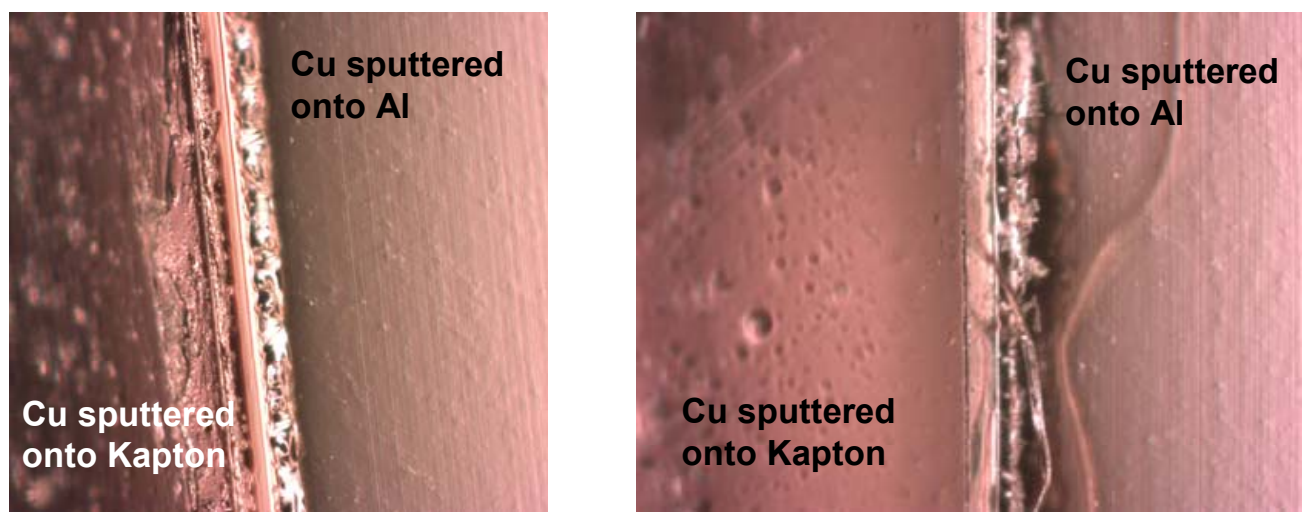

Figure 33. Disk SPUT11 after being sputtered with $3 \mu \mathrm{m}$ of $\mathrm{Cu}$

The disk was then placed in the electroplating mask, and approximately $100 \mu \mathrm{m}$ of $\mathrm{Cu}$ was plated onto the sputtered $\mathrm{Cu}$. The sputtering was done at $5 \mathrm{Amp} / \mathrm{ft}^{2}$ and required approximately 8 hours to deposit $100 \mu \mathrm{m}$ of $\mathrm{Cu}$. When the electroplating was complete, the Kapton was removed from the disk, and the $\mathrm{Cu}$ was diamond turned to a thickness of $45 \mu \mathrm{m}$. Microscope images of the machined $\mathrm{Cu}$ and the $\mathrm{Al}$ appear in Figure 34. The majority of the $\mathrm{Al}$ surface had the original diamond turned finish. However, there were some areas in which the Al adjacent to the $\mathrm{Cu}$ had been pitted. Focusing the microscope in and out of the plane of the $\mathrm{Al}$ indicated that there may be some Al material near the pit that had been redeposited on top of the original Al surface. Therefore, it is not known how well this part would fit into a vacuum chuck with the $\mathrm{Cu}$ side against the face of the chuck.
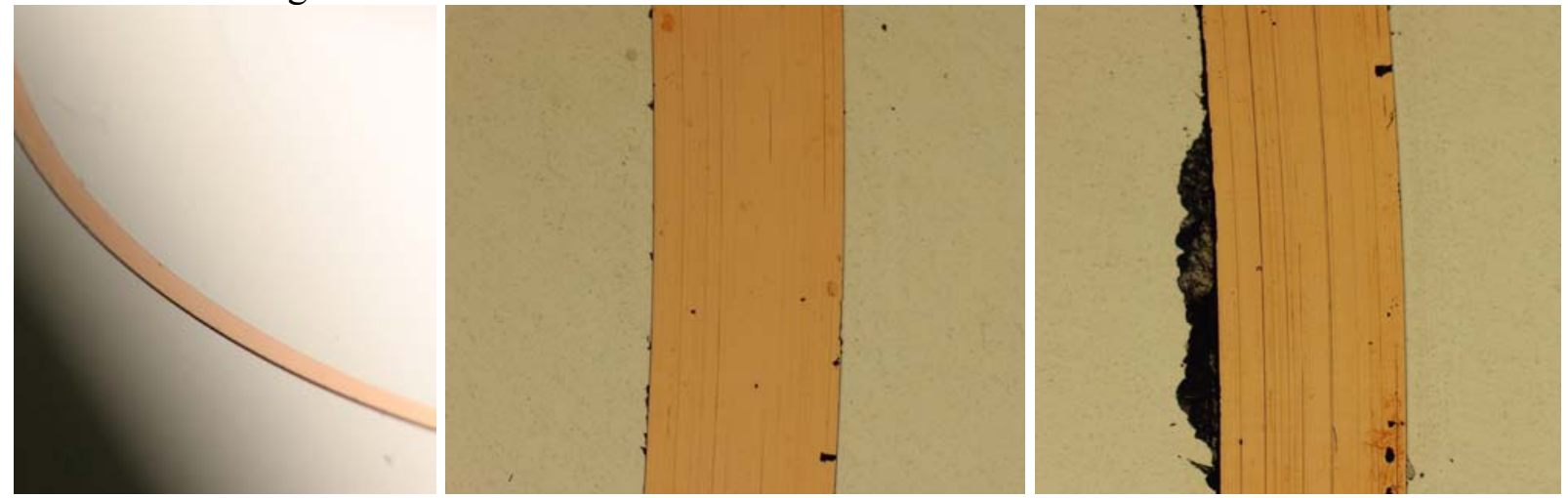

Figure 34. Disk SPUT11 after diamond turning the electroplated Cu

\section{Robin2 - Masked with Lithographic Photoresist that was Exposed with a Glass Photomask $(\mathbf{1 1} / \mathbf{2 3} / \mathbf{0 4})$}

At the same time disk SPUT11 was being processed, an alternate means of masking 100 $\mathrm{mm} \mathrm{Al}$ disks was being pursued. This alternate method used a lithographic photoresist to mask the part while sputtering the $\mathrm{Cu}$. Lithographic masks are known to produce edges with sub- $\mu \mathrm{m}$ accuracy when sputtering or evaporating layers of materials with a thickness of several dozen $\mathrm{nm}$. However, it was not known at the time of this effort how these masks would perform when attempting to make EOS targets via sputter-seeded electroplating of $\mathrm{Cu}$.

Another $100 \mathrm{~mm} \mathrm{Al} \mathrm{disk,} \mathrm{labeled} \mathrm{"Robin2"} \mathrm{was} \mathrm{diamond} \mathrm{turned} \mathrm{using} \mathrm{mineral} \mathrm{spirits.}$ Two fiducial marks were then machined onto the surface of the disk. The disk was then rinsed with pentane, acetone, and ethanol. The cleaning process was repeated three times. $14 \mu \mathrm{m}$ of 
lithographic photoresist was spin-coated onto the surface of this disk in B153, and the resist was then soft-baked. The disk was then placed into a machine that aligned a glass photomask with the fiducial marks that had been machined on the disk. After exposing and developing the photoresist, it was hard-baked. This process removed a ring of the photoresist, so that a $1 \mathrm{~mm}$ wide ring of Al was exposed through the photoresist, as shown in Figure 35.

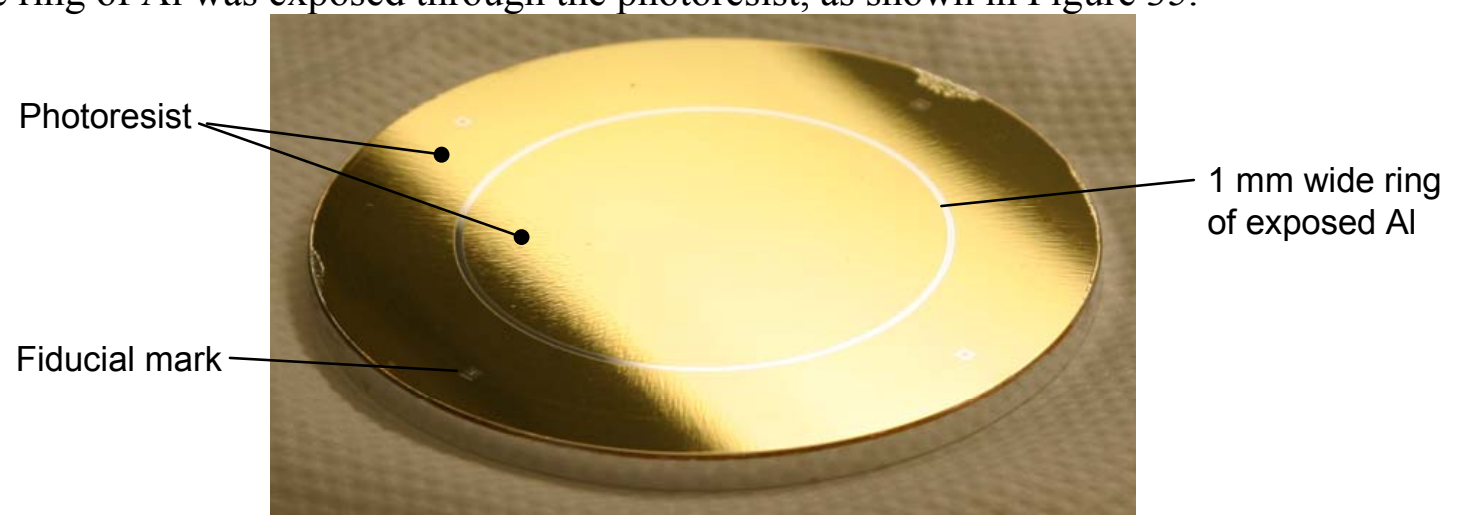

Figure 35. Disk Robin2 masked with photoresist

The exposed Al was measured with the Wyko NT8000 optical profiling system using PSI mode at 20×. Some features were apparent on the exposed Al, as shown in Figure 36. The lithographic process appeared to have changed the surface finish of the $\mathrm{Al}$ from $\mathrm{S}_{\mathrm{t}}=40-50 \mathrm{~nm}$ to $\mathrm{S}_{\mathrm{t}}=90-100 \mathrm{~nm}$ when measured in PSI mode at $20 \times$.

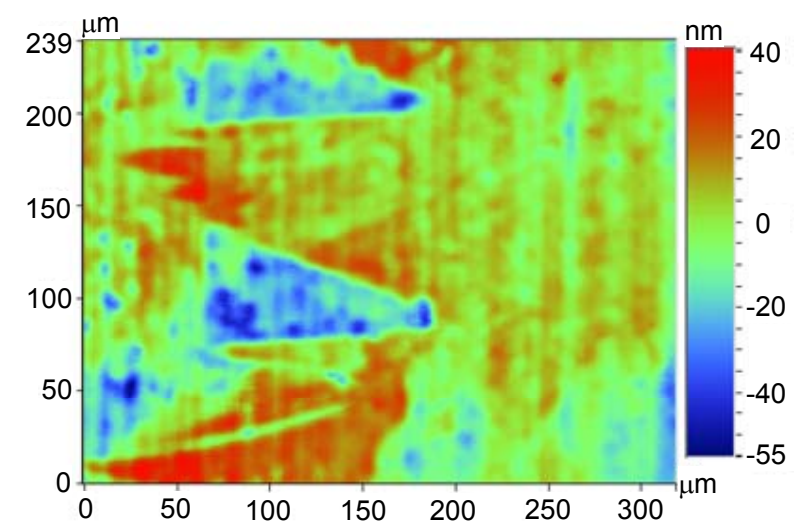

Figure 36. Wyko measurement of exposed Al on disk Robin2

The disk was placed into the sputtering chamber, where it was ion milled for several minutes and then sputtered with $3.8 \mu \mathrm{m}$ of $\mathrm{Cu}$ at $50 \%$ power. When the disk was taken out of the sputtering chamber, the photoresist had curled up and delaminated from the $\mathrm{Al}$, as shown in Figure 37. The photoresist may not have maintained adhesion to the Al due to the heat from the sputtering process. It is also possible that the photoresist was not rigid enough to withstand the residual stress formed in $3.8 \mu \mathrm{m}$ of sputtered $\mathrm{Cu}$. Photoresists such as this are normally used to sputter only a few dozen nm of material, and a coating of $3.8 \mu \mathrm{m}$ may have simply been too thick for the resist. 


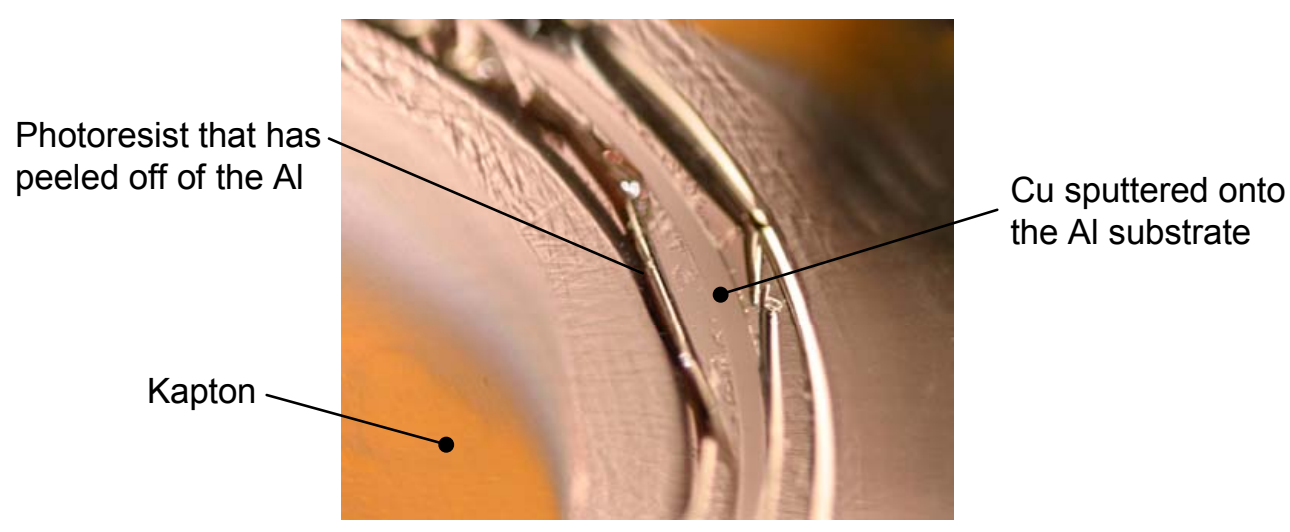

Figure 37. Delaminating photoresist on disk Robin 2 after sputtering $3.8 \mu \mathrm{m}$ of $\mathrm{Cu}$ onto the photoresist

\section{Robin1 - Masked with Lithographic Photoresist that was Exposed with an E-Beam Evaporated Cr Photomask (12/10/04)}

At the same time disk Robin 2 was being processed, another $100 \mathrm{~mm}$ Al disk was being prepared using a slightly different type of lithographic masking process. This different masking process is illustrated in Figure 38. This other $100 \mathrm{~mm} \mathrm{Al} \mathrm{disk,} \mathrm{labeled} \mathrm{"Robin1"} \mathrm{was} \mathrm{diamond}$ turned using mineral spirits. The disk was then rinsed with pentane, acetone, and ethanol. The cleaning process was repeated three times. $14 \mu \mathrm{m}$ of lithographic photoresist was spin-coated onto the surface of this disk in B153, and the resist was then soft-baked.

$100 \mathrm{~mm}$ diam Al disk, $\mathrm{t}=5-6 \mathrm{~mm}$

$14 \mu \mathrm{m}$

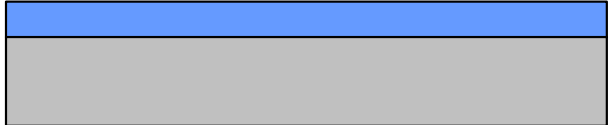

$200 \mathrm{~nm}$

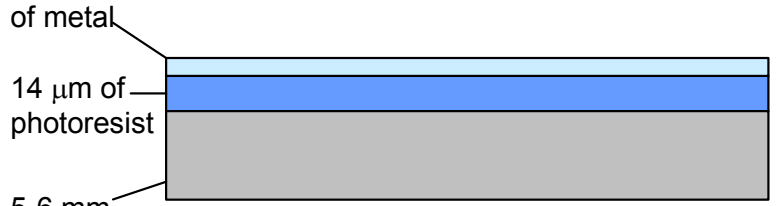

Al disk

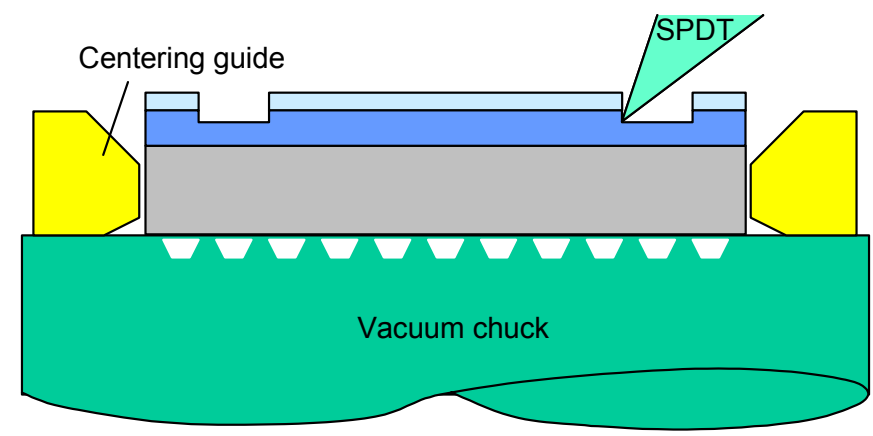

-Diamond turn both sides of a 100 mm Al 1100 disk

-Spin coat a $14 \mu \mathrm{m}$ layer of photoresist on the Al The photoresist must be compatible with $\mathrm{Al}$, and it must be compatible with sputtering $\mathrm{Cu}$

-Soft-bake the photoresist $\left(90^{\circ} \mathrm{C}\right.$ for $15 \mathrm{~min}$ )

-Deposit $200 \mathrm{~nm}$ or more of a metal onto the softbaked photoresist. This metal will be the photomask for the exposure process.

The metal must be opaque to UV light, and the deposition process must not cause too much damage to the photoresist.
-Diamond turn a $1 \mathrm{~mm}$ wide ring in the part, cutting through the metal mask and into the soft-baked photoresist. 

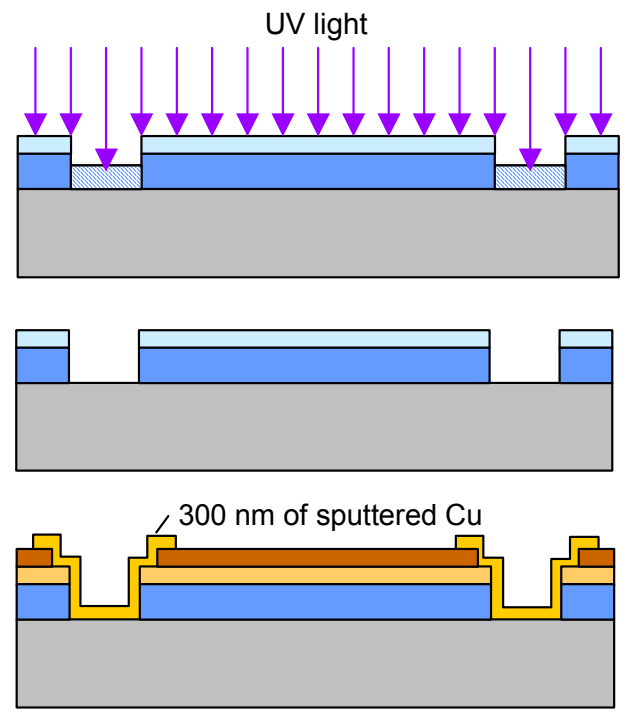

$100 \mu \mathrm{m}$ of electroplated $\mathrm{Cu}$
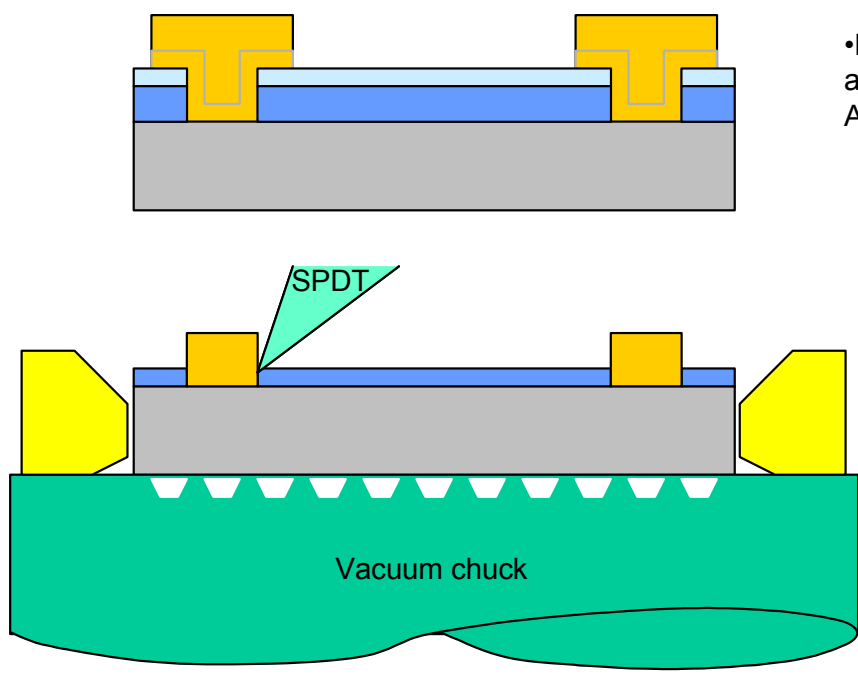

$43 \mu \mathrm{m}$ of $\mathrm{Cu}$
-Expose the resist with UV light. The deposited metal acts as a mask during the exposure.

-Wash off the exposed photoresist

-Hard-bake the photoresist $\left(110^{\circ} \mathrm{C}\right.$ for $\left.30 \mathrm{~min}\right)$

-Mask the disk with Kapton, leaving only a few mm of exposed resist on either side of the exposed Al - Place Al foil masks over the Kapton and ion mill the disk for several minutes

-Sputter $20 \mathrm{~nm}$ of Ti followed by $300 \mathrm{~nm}$ of Cu using reduced power to minimize temperature during the sputtering process

-Place the disk in the hardmask and electroplate an additional $100 \mu \mathrm{m}$ of $\mathrm{Cu}$ onto the sputtered $\mathrm{Cu}$ at 5 Amp/ft ${ }^{2}$
-Diamond turn the Cu to a thickness of $43 \mu \mathrm{m}$ -Machine the deposited metal mask from the photoresist

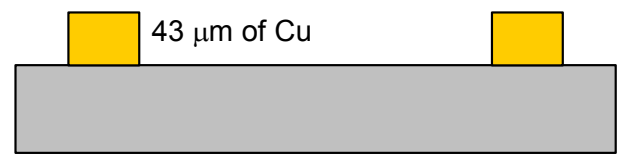

-Dissolve the remaining photoresist

Figure 38. Processing of disk Robin1

$200 \mathrm{~nm}$ of Cr was then evaporated onto the surface of the photoresist. After evaporating the $\mathrm{Cr}$ onto the resist, the surface began to crack and looked like a dried lake bed. The disk was placed back on the diamond turning machine, and a groove of width $1 \mathrm{~mm}$ was machined through the $\mathrm{Cr}$ and into the underlying resist. Microscope images of the $1 \mathrm{~mm}$ groove in the $\mathrm{Cr}$ appear in Figure 39. The cracked surface of the $\mathrm{Cr}$ is clearly visible in these images. 

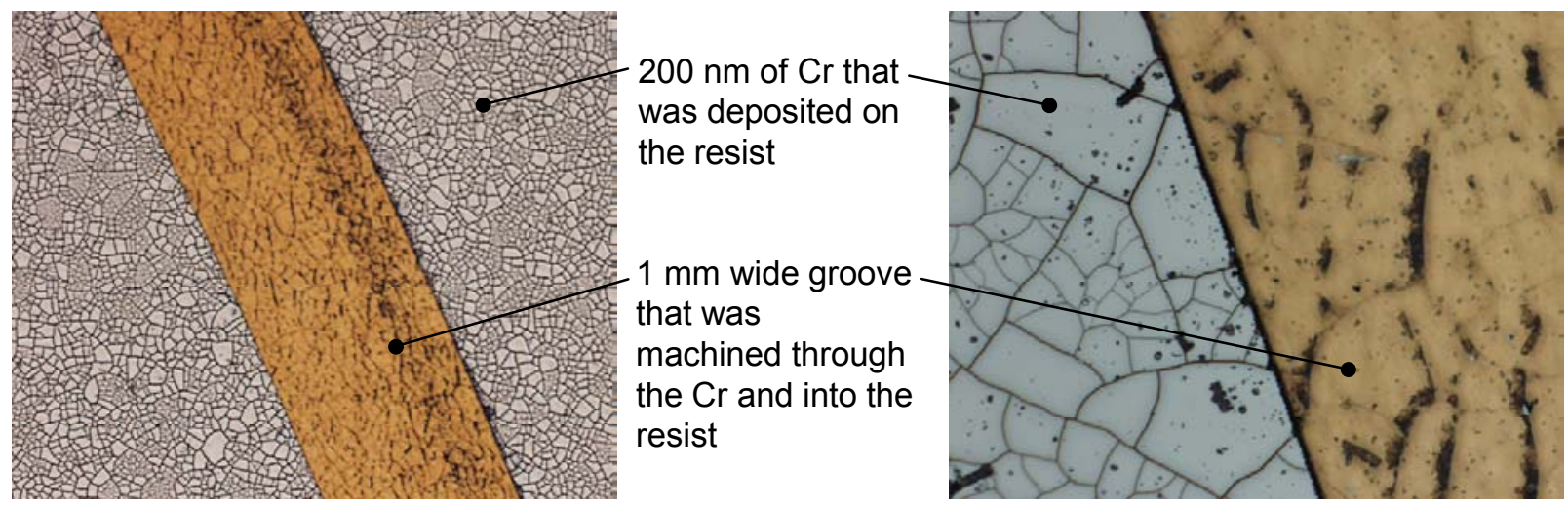

Figure 39. Surface of disk Robin 2 after machining a $1 \mathrm{~mm}$ groove through the $200 \mathrm{~nm}$ of $\mathrm{Cr}$ on the resist

The disk was then placed under a UV light source to expose the resist. Note that the 200 $\mathrm{nm}$ of $\mathrm{Cr}$ acted as a photomask during the exposure, so only a $1 \mathrm{~mm}$ section of the photoresist was exposed to the UV light. The exposed resist was then washed off. The remaining photoresist was then hard-baked, and the disk was masked with Kapton. The disk was then ion milled for several minutes and sputtered with $20 \mathrm{~nm}$ of Ti followed by $300 \mathrm{~nm}$ of Cu in B231. In this case, the photoresist did not delaminate from the Al substrate. The disk was then placed in the electroplating mask, as shown in Figure 40.
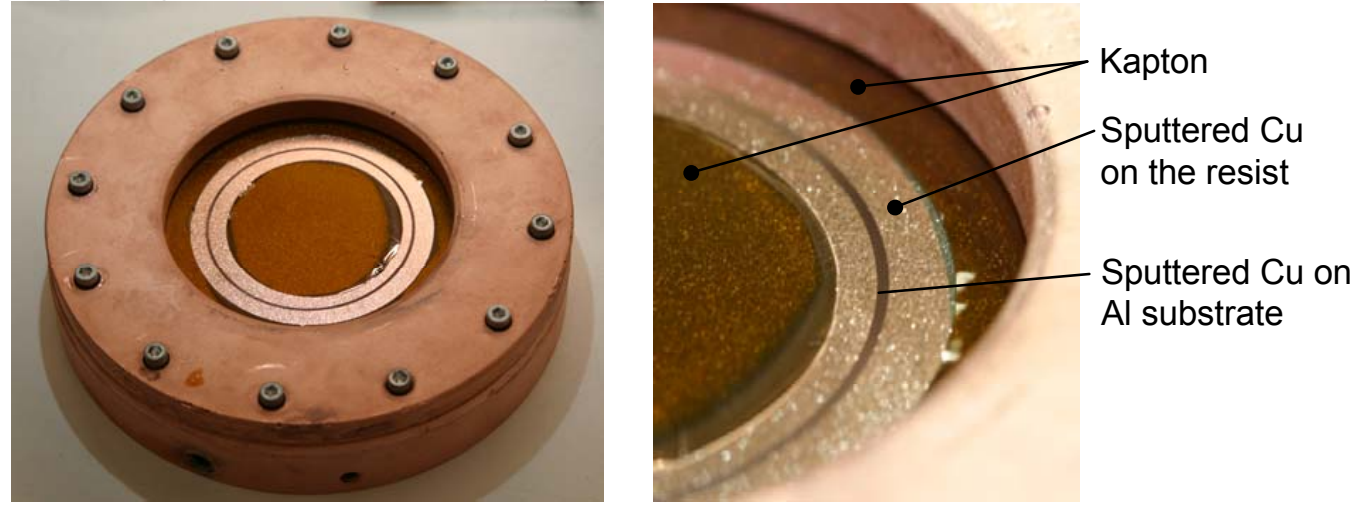

Figure 40. Disk Robin1 in the electroplating mask

The disk was then electroplated at $5 \mathrm{Amp} / \mathrm{ft}^{2}$ for 8 hours. The disk was placed back on the diamond turning machine, and the excess electroplated $\mathrm{Cu}$ was machined off with the diamond tool. The disk was then rinsed with acetone to remove the remaining photoresist.

After washing away all of the photoresist with acetone, islands of $\mathrm{Cu}$ were evident on the Al. The Al was not pitted as it had been with SPUT1, SPUT3, and SPUT10, and it was not damaged near the edge of the mask as it had been with SPUT11. Instead, the Al surface was partially covered with small islands of $\mathrm{Cu}$. The images in Figure 41 were taken after machining the $\mathrm{Cu}$ islands to a height of approximately $2 \mu \mathrm{m}$ from the surface of the Al. The $1 \mathrm{~mm} \mathrm{Cu}$ band had a height of $50 \mu \mathrm{m}$. 

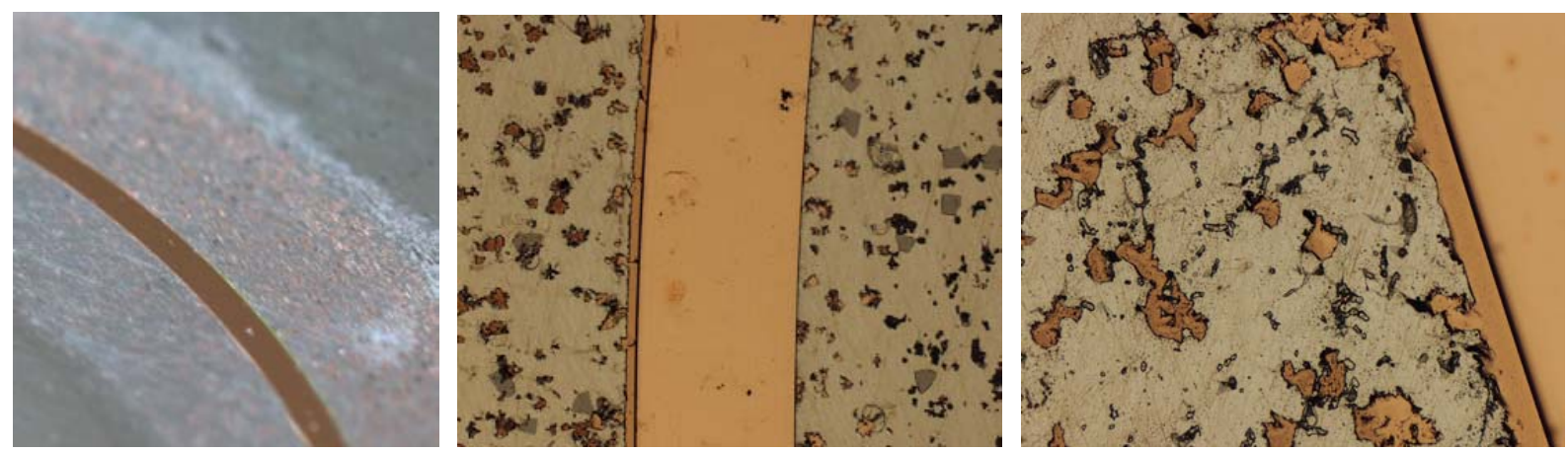

Figure 41. Robin1 after electroplating and removing the lithographic mask (center $=25 \times$, right=100 $\times$ )

The islands of $\mathrm{Cu}$ on the $\mathrm{Al}$ could have resulted from the cracks in the $\mathrm{Cr}$ photomask and underlying photoresist. It is possible that during the sputtering process, $\mathrm{Cu}$ penetrated through the $\mathrm{Cr}$ and the photoresist (possibly through the cracks) and reached the Al surface. Additional $\mathrm{Cu}$ was then deposited during the electroplating processes to create the islands seen in Figure 41. Note that if the photoresist had not contained the cracks seen in Figure 39, this process might have been successful. However, at this point in the development process, resources were not available to make another attempt with a lithographic mask.

\section{D1, D2, and D3 - Cu Deposited into a Machined Recess in the Al Disk (12/13/04)}

Rather than attempting to avoid pitting of the $100 \mathrm{~mm} \mathrm{Al}$ disk adjacent to the $\mathrm{Cu}$ during electroplating, a process was developed to remove the pitted material from the Al so that it would not be present on the finished targets. This change in direction in the development of the manufacturing process resulted from a relaxation of some of the specifications by the physicists. The original specifications for the targets required that the Al baseplate have no shortwavelength features with a peak-to-valley height larger than $0.1 \mu \mathrm{m}$. This specification was relaxed to allow a step of up to $1 \mu \mathrm{m}$ in the $\mathrm{Al}$ baseplate at the edge of the $\mathrm{Cu}$ sample, provided the height of any step was measured to better than $0.2 \mu \mathrm{m}$. This change in the specifications allowed a completely different means of depositing and machining the $\mathrm{Cu}$ sample to be pursued.

Three additional $100 \mathrm{~mm} \mathrm{Al} \mathrm{disks} \mathrm{were} \mathrm{prepared.} \mathrm{After} \mathrm{diamond} \mathrm{turning} \mathrm{both} \mathrm{sides} \mathrm{of}$ each disk and cleaning them with pentane, acetone, and ethanol, a specific profile was machined into the surface of each disk. This profile included a recess of width $1 \mathrm{~mm}$ and depth $25 \mu \mathrm{m}$. This recess was carefully measured with an LVDT mounted to the B-axis of the diamond turning machine. After masking each disk with Kapton tape, several $\mu \mathrm{m}$ of $\mathrm{Cu}$ was sputtered into the 1 $\mathrm{mm} \times 25 \mu \mathrm{m}$ recess, and additional $\mathrm{Cu}$ was then electroplated on the sputtered $\mathrm{Cu}$, as described in Figure 42.

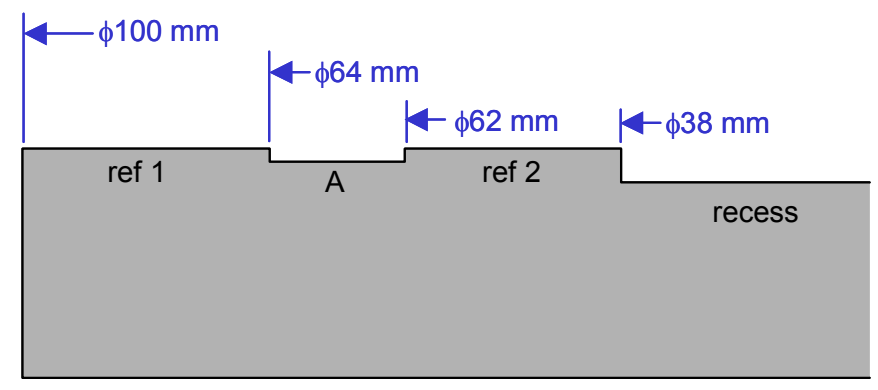

Surfaces ref1 and ref2 are reference surfaces.

Surface $A$ is machined $25 \mu \mathrm{m}$ below the reference surfaces. The $\mathrm{Cu}$ will be sputtered onto this surface.

The recessed surface is machined $58 \mu \mathrm{m}$ below the reference surfaces and will be used to make the $\mathrm{Al}$ characterization targets.

Depth of $A=25 \mu \mathrm{m}$

Depth of recess $=58 \mu \mathrm{m}$

Using LVDT, measure actual

-Depth of A below ref2

-Depth of recess below ref2 


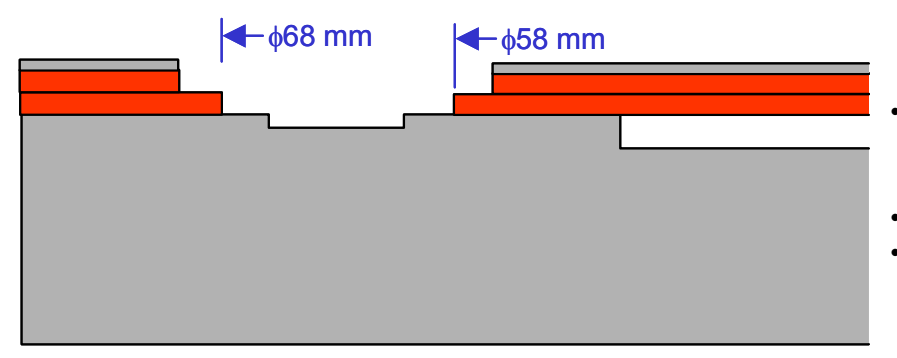

-Place Kapton on each side of surface A, leaving a few $\mathrm{mm}$ of exposed $\mathrm{Al}$ on ref1 and ref2.

-Place an additional layer of Kapton on the disk -Place Al foil masks on the Kapton and insert the disk in the sputtering chamber.

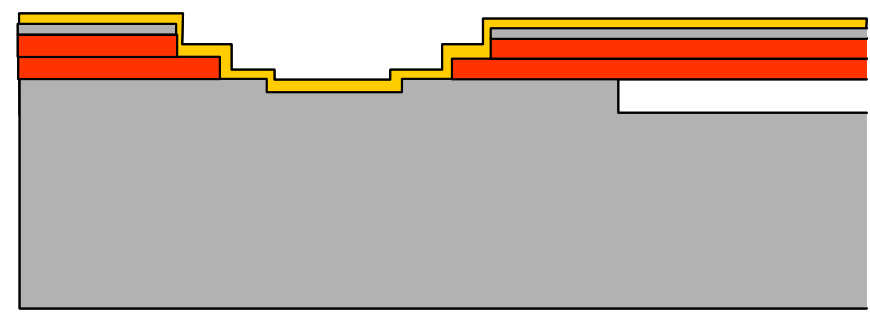

- Ion mill for 3 minutes and then sputter an adhesion layer of $20 \mathrm{~nm}$ of Ti followed by 3-5 $\mu \mathrm{m}$ of $\mathrm{Cu}$.

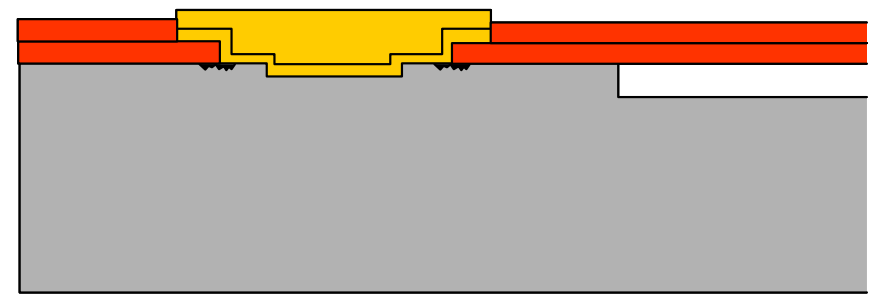

-Place disk in a hardmask and electroplate additional $\mathrm{Cu}$ at $5 \mathrm{Amp} / \mathrm{sq} \mathrm{ft}$ for 8 hours. The plating chemicals might cause some pitting on ref1 and ref2 at the edge of the Kapton.

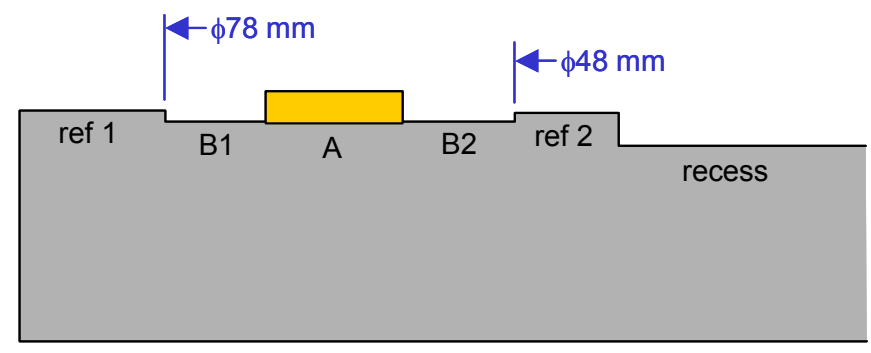

- Machine the Cu to a height of $43 \mu \mathrm{m}$.

- Machine into ref1 and ref2 to create surfaces $\mathrm{B} 1$ and B2. Attempt to machine B1 and B2 to be level with surface $A$.

Ideally,

Depth of $A=$

Depth of $\mathrm{B} 1=$

Depth of B2 $=25 \mu \mathrm{m}$

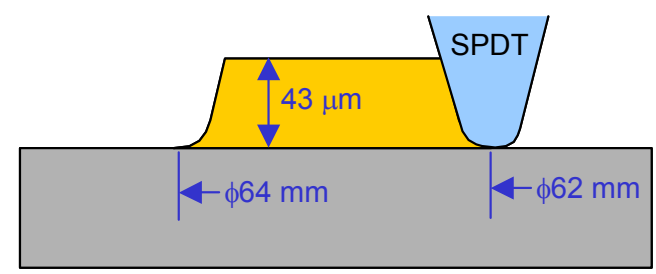

Using LVDT, measure actual

-Depth of B2 below ref2

-Height of $\mathrm{Cu}$ above ref2

Figure 42. Processing of D1, D2, and D3 by sputter-seeded electroplating the $\mathrm{Cu}$ into a recess in the Al

When the electroplated $\mathrm{Cu}$ was diamond turned to its final form, the pitted $\mathrm{Al}$ adjacent to the $\mathrm{Cu}$ was machined at the same time. A special method was developed to diamond turn surfaces B1 and B2 coplanar with the interface of the Al and the $\mathrm{Cu}$ (surface A in Figure 42). This method involved making several intermittent measurements of the Al using the LVDT mounted to the B-axis of the diamond turning machine. By intermittently measuring the step height between surface B2 and the reference surface ref2, the amount of material remaining to be removed could be determined, as shown in Figure 43. The final machining pass had a depth of cut of $2 \mu \mathrm{m}$. Surface A was measured to be flush to surface B2 to within approximately $20 \mathrm{~nm}$, where the uncertainty of this measurement was approximately $\pm 50 \mathrm{~nm}$. 

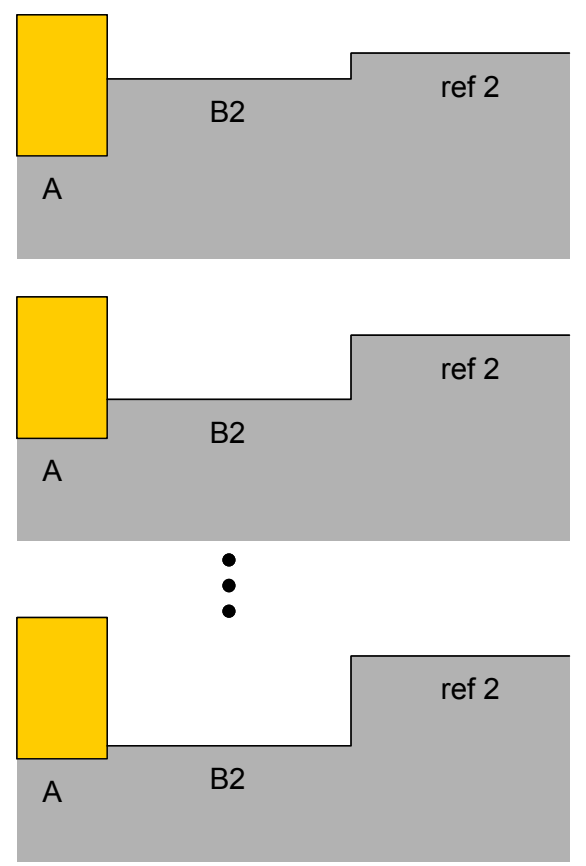

Figure 43. Method for machining the Al flush with the bottom surface of the $\mathrm{Cu}$

Photographs of disk D2 at various stages in the process appear in Figure 44.

Unfortunately, the diamond tool was mistakenly plunged into the $\mathrm{Cu}$ of disk D1, which ruined this disk. Therefore, processing continued using disk D2.
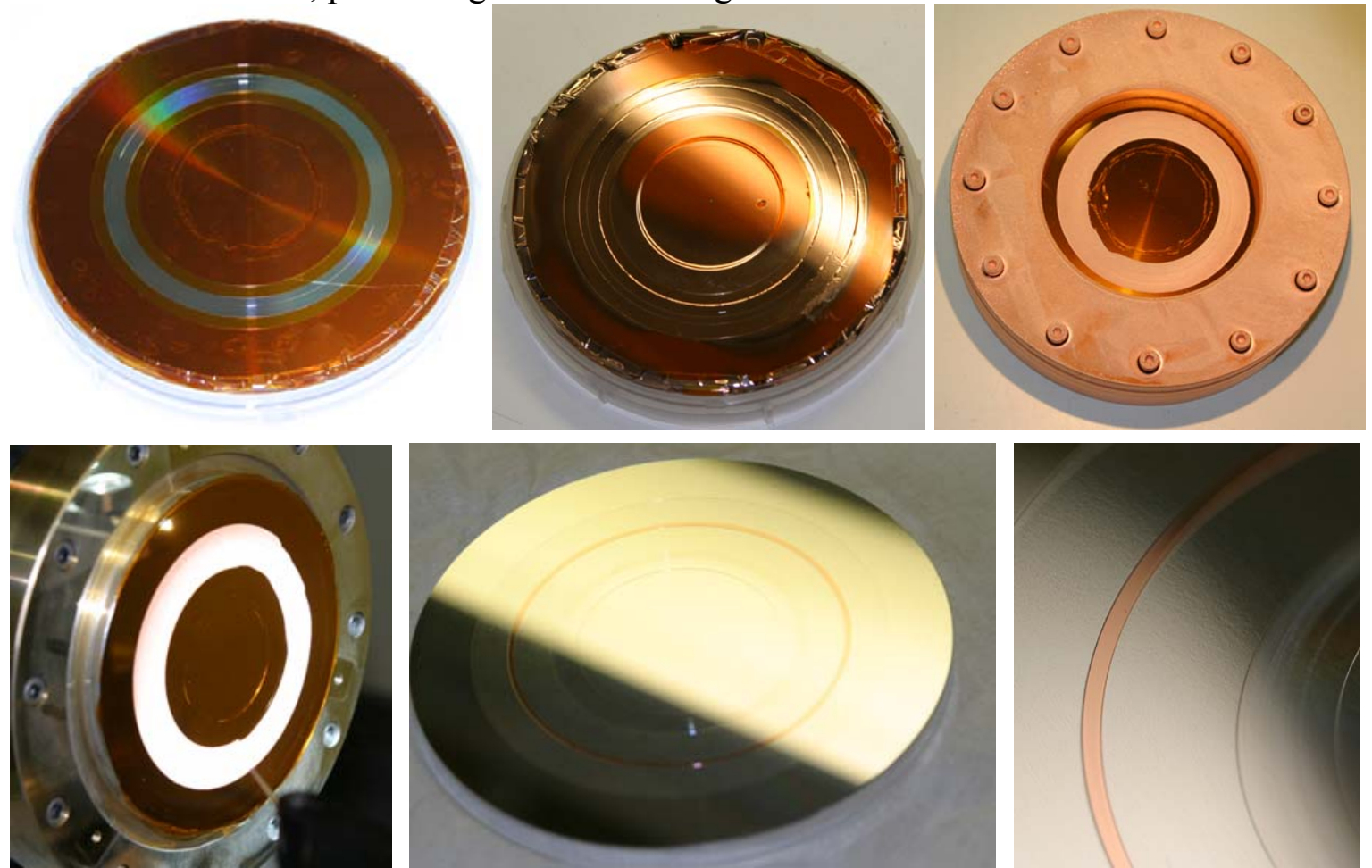

Figure 44. Photographs of disk D2 after being masked with Kapton (top left), sputtered with Cu (top center), placed in the hardmask for electroplating (top right), electroplated with additional $\mathrm{Cu}$ and mounted on the vacuum chuck (bottom left), and diamond turned (bottom center and bottom right) 
Once the $1 \mathrm{~mm}$ band of $\mathrm{Cu}$ had been deposited onto the surface of the $\mathrm{Al}$ disk and diamond turned to a thickness of $43 \mu \mathrm{m}$, a vacuum chuck was fabricated to hold the $100 \mathrm{~mm} \mathrm{Al}$ disk so it could be machined from a thickness of $6 \mathrm{~mm}$ to $62 \mu \mathrm{m}$. This vacuum chuck included a $1 \mathrm{~mm} \times 43 \mu \mathrm{m}$ recess for the band of $\mathrm{Cu}$, and a $58 \mu \mathrm{m}$ step, so the vacuum chuck would match the profile of the Al disk. To reduce the likelihood of the thin Al pulling away from the vacuum chuck during machining, the Al was reduced to a thickness of $62 \mu \mathrm{m}$ only in the regions of the disk in which the targets would be made. In these regions, the vacuum chuck was diamond turned with vacuum grooves of width $100 \mu \mathrm{m}$ and lands of width $50 \mu \mathrm{m}$. Elsewhere on the disk, the Al was left thicker, so it would have additional structural stability. In these regions, the grooves on the vacuum chuck had a larger width, but all of the lands on the chuck were $50 \mu \mathrm{m}$ wide. The $\mathrm{Al}$ around the perimeter of the $100 \mathrm{~mm}$ disk was left at a thickness of $6 \mathrm{~mm}$, so the disk could be handled easily. The profile that was machined into the Al disk is illustrated in Figure 45. The purple numbers in the figure indicate the thickness of the $\mathrm{Al}$ in the different regions, and the red numbers indicate the width of the grooves used in each region of the vacuum chuck. The vacuum grooves were connected together by eight radial grooves, which were machined by placing a diamond tool on its side and machining linear grooves from the inside toward the outer perimeter of the chuck. These radial grooves were intended to have a depth of $25 \mu \mathrm{m}$.

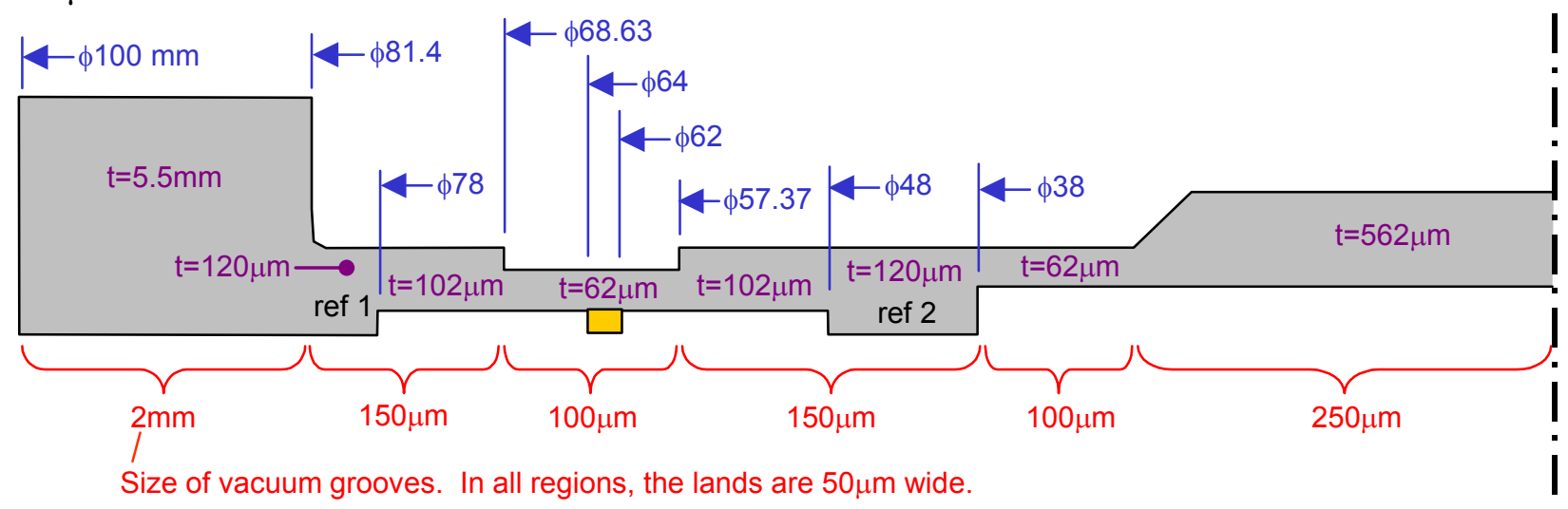

Figure 45. Schematic illustration of the profile machined into the $100 \mathrm{~mm}$ Al disk and the widths of the grooves on the vacuum chuck. The figure is not drawn to scale.

Several weeks were required to plan the fabrication of this chuck, write the machine tool programs, debug the programs, machine the vacuum grooves, cut radial channels to connect each of the vacuum grooves, and reface the chuck.

Upon placing one of the disks into this vacuum chuck, the axial runout of the disk measured by the capacitance probe was approximately $1.5 \mu \mathrm{m}$. However, after squirting the perimeter of the disk with alcohol, the axial runout dropped to $200 \mathrm{~nm}$. Apparently, the alcohol sealed off the perimeter of the disk, so the vacuum could pull the entire disk flush against the vacuum chuck, as shown in Figure 46. 


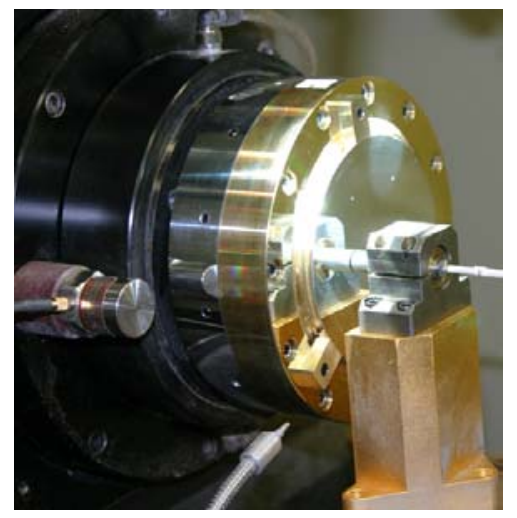

Figure 46. Cap probe measuring axial runout on disk D2 with $\mathrm{Cu}$ against the vacuum chuck

When machining the Al disk from a thickness of $6 \mathrm{~mm}$ to thin foil, a HSS tool was used to make the initial cuts. HSS was used because it can be ground to have a sharper cutting edge than a carbide tool. When spray mist mineral spirits are used as a cutting fluid, the Al does not build up on the tool, and the HSS has adequate tool life. After removing several $\mathrm{mm}$ of $\mathrm{Al}$, the HSS tool was replaced with a diamond tool of nose radius $125 \mu \mathrm{m}$, which machined the Al with a depth of cut of $1.5 \mu \mathrm{m}$. Note that a smaller depth of cut caused the Al to burnish rather than producing clean chips.

When the Al had reached a thickness of $90 \mu \mathrm{m}$, a failure occurred. The workpiece began making an odd noise, so the machine tool program was halted. The tool had cut through the Al at the outer edge of the $\mathrm{Cu}$. However, the cut did not extend a full $360^{\circ}$ around the part. One damaged area extended over an included angle of approximately $60^{\circ}$, over which the $\mathrm{Al}$ baseplate appeared to have been cut cleanly by the diamond tool. Over another $40^{\circ}$ to $50^{\circ}$ length, a portion of the $\mathrm{Cu}$ appeared to have been ripped off by the diamond tool.

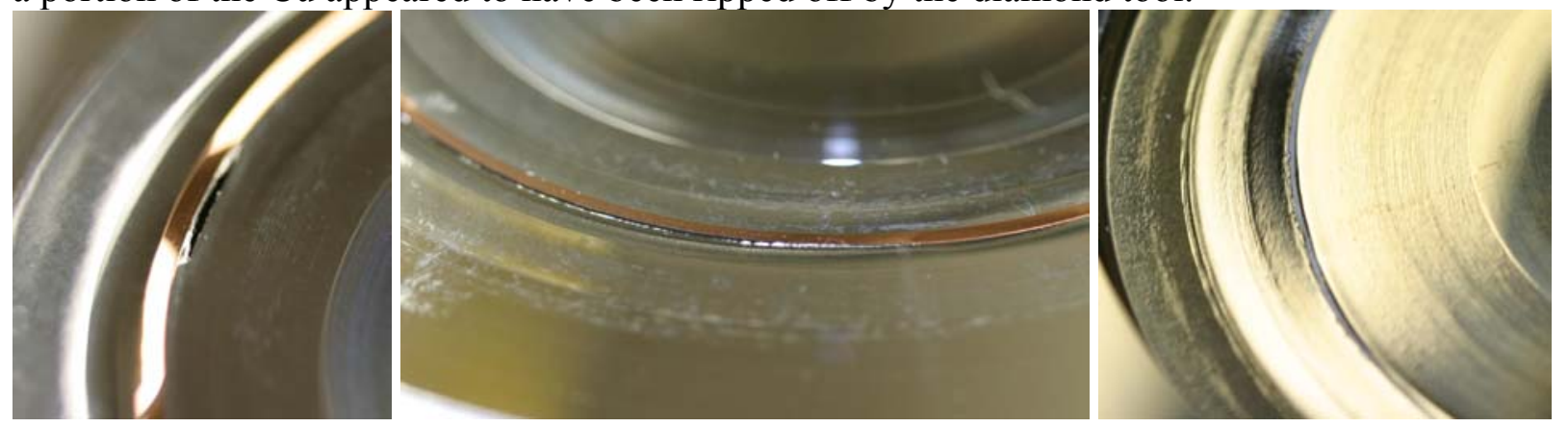

Figure 47. Disk D2 after being machined to a thickness of $90 \mu \mathrm{m}$. Small rip on inside of $\mathrm{Cu}$ (left), large clean cut through outside of $\mathrm{Cu}$ (center), large rough cut $1 \mathrm{~mm}$ inside the $\mathrm{Cu}$ on the machined face of the $\mathrm{Al}$ (right)

There were also some damaged areas on the inner edge of the $\mathrm{Cu}$. One cut extended over a fairly short arclength, as shown in the left side of Figure 47. The Al was also cut in several places several $\mathrm{mm}$ inside the $\mathrm{Cu}$. None of the damaged areas extended a full $360^{\circ}$ around the part.

The cause of this failure was traced to the radial grooves on the vacuum chuck in the location of the outer edge of the $1 \mathrm{~mm} \times 43 \mu \mathrm{m} \mathrm{Cu}$ band (the same location where disk D2 first failed while being machined to thickness). It was discovered that the radial grooves in the outermost land that supported the $\mathrm{Cu}$ were incomplete and did not extend fully through the land. Therefore, there was no continuous path for the vacuum to reach outside this land. The clearance between the bottom surface of the $\mathrm{Cu}$ and upper surface of the lands in the $43 \mu \mathrm{m}$ recess in the 
vacuum chuck was nominally only $50 \mathrm{~nm}$. Therefore, because the radial grooves were incomplete and did not properly create a vacuum path through this particular land, any vacuum feed would be restricted to this $50 \mathrm{~nm}$ clearance. Note that because of uncertainties in the process and in the measurements, the $\mathrm{Cu}$ could possibly have actually bottomed out on these lands, in which case there would actually have been no clearance and no path for the vacuum. The thin Al may have pulled away from the vacuum chuck, where it was severed by the diamond tool.

A diamond tool was placed on its side to machine radial grooves in the vacuum chuck that connect each of the vacuum channels. The tool machined from the center to the perimeter of the chuck.

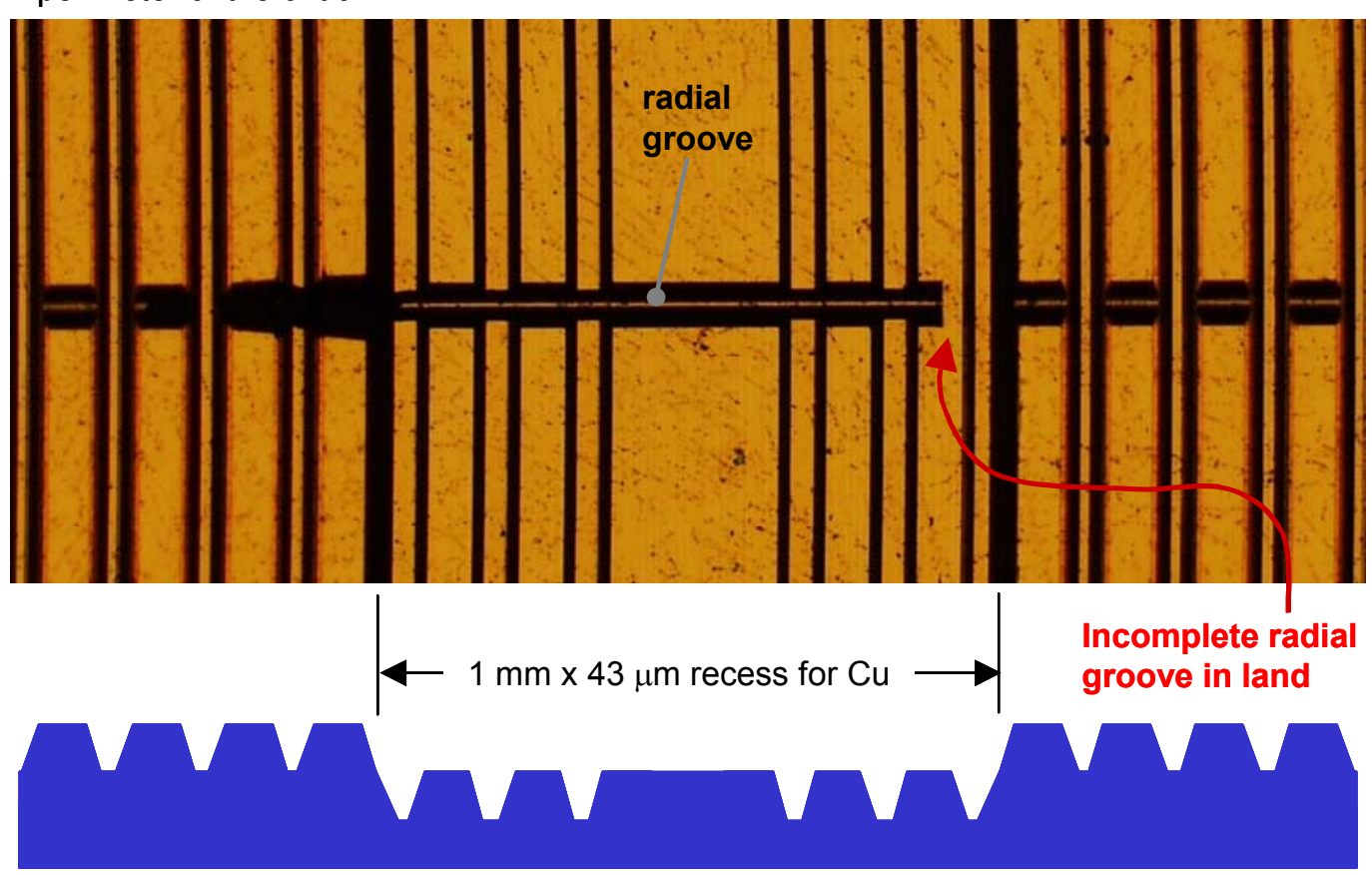

Figure 48. Error on the vacuum chuck used to machine disk D2

This problem with the vacuum chuck was corrected before machining disk D3. When disk D3 was placed against this vacuum chuck, its axial runout was $150 \mathrm{~nm}$. This disk was successfully machined to a thickness of $63 \mu \mathrm{m}$, as shown in Figure 49 . Note that the thickness of $63 \mu \mathrm{m}$ was within the specification of $62 \pm 2 \mu \mathrm{m}$.
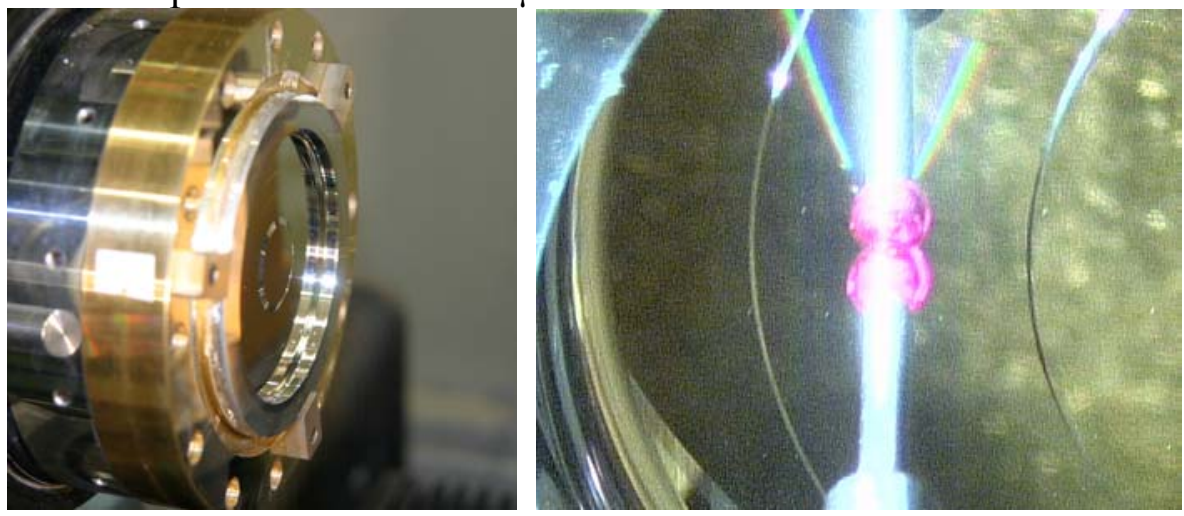

Figure 49. Disk D3 after being machined to a thickness of $63 \mu \mathrm{m}$ (left) and measured with the LVDT (right)

The cut schedule used when machining the Al to a thin foil is listed in Figure 50. 


\begin{tabular}{|l|c|c|c|c|}
\hline Tool & $\begin{array}{c}\text { Tool Nose Radius } \\
{[\mu \mathrm{m}]}\end{array}$ & Depth of Cut $[\mu \mathrm{m}]$ & $\begin{array}{c}\text { Starting Al } \\
\text { thickness }[\mu \mathrm{m}]\end{array}$ & $\begin{array}{c}\text { Ending Al thickness } \\
{[\mu \mathrm{m}]}\end{array}$ \\
\hline HSS & 250 & 25 & 6,000 & 2,000 \\
\hline Diamond & 125 & 20 & 2,000 & 500 \\
\hline Diamond & 25 & 10 & 500 & 200 \\
\hline Diamond & 25 & 1.5 & 200 & 63 \\
\hline
\end{tabular}

Figure 50. Cut schedule used when machining the Al to a thin foil

\section{BONDING THE ICH AND CH PADS TO THE 100 mm AI DISK}

\section{Development of a bonding process}

Prior to machining the $100 \mathrm{~mm} \mathrm{Al} \mathrm{disks} \mathrm{to} \mathrm{a} \mathrm{thickness} \mathrm{of} 62 \mu \mathrm{m}$, testing was performed to develop a method of bonding the ICH pads for the pre-heat shields and the $\mathrm{CH}$ pads for the ablators with an adhesive thickness of less then $3 \mu \mathrm{m}$. Several $\mathrm{ICH}$ and $\mathrm{CH}$ pads with a thickness of $500 \mu \mathrm{m}$ had been fabricated with the forms shown in Figure 51. Originally, ICH and $\mathrm{CH}$ pads with the form shown on the left side of Figure 51 were fabricated. Both surfaces of these pads were diamond turned. However, additional pads had to be fabricated, and the new pads had the form shown on the right side of Figure 51. These pads were fabricated using a slightly different process that was significantly faster and less expensive.

To fabricate the pads shown on the right side of Figure 51, a single point diamond tool, a diamond parting tool, and a HSS parting tool were setup on a two-axis diamond turning machine. The pads were machined from a rod of $\mathrm{ICH}$ or $\mathrm{CH}$ mounted in the spindle. The single point diamond tool machined the face of each pad, including the $3^{\circ}$ chamfer. The diamond parting tool then parted most of the way through the rod, machining the outer portion of the back face of the pad in the process. Note that the diamond parting tool created a diamond turned surface that was parallel to the front face of the pad to better than $0.1 \mu \mathrm{m}$. However, the diamond parting tool was too short to reach the center of the pad, so the remainder of the parting operation was performed with a HSS parting tool, which resulted in a poor surface finish on the center section of the back face.

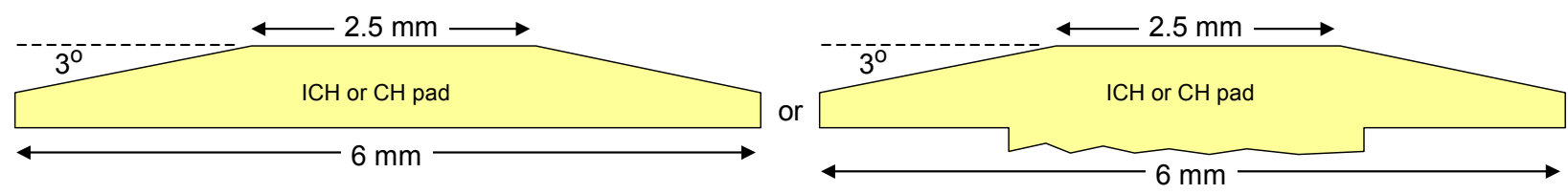

Figure 51. Two different types of ICH and CH pads used for the EOS targets

Several of the machined pads were measured on the Wyko using PSI mode at $20 \times$. The Rexolite pads had a surface finish of approximately $\mathrm{Rt}=70-80 \mathrm{~nm}, \mathrm{Ra}=5-6 \mathrm{~nm}, \mathrm{Rq}=7 \mathrm{~nm}$. The $\mathrm{ICH}$ pads had a surface finish of approximately $\mathrm{Rt}=70-80 \mathrm{~nm}, \mathrm{Ra}=4 \mathrm{~nm}, \mathrm{Rq}=5 \mathrm{~nm}$. Therefore, the surfaces of the pads were well within the specification of Rt $<600 \mathrm{~nm}$.

The thickness and thickness uniformity of the $\mathrm{ICH}$ and $\mathrm{CH}$ pads were measured by placing them on a vacuum chuck on the diamond turning machine and measuring them with an LVDT. Figure 52 depicts the measurement of one of the $\mathrm{CH}$ pads illustrated on the left side of Figure 51. 


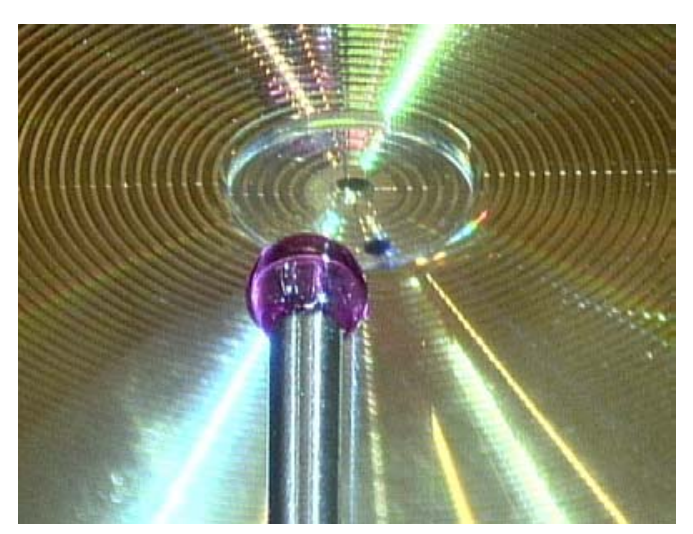

Figure 52. Measurement of thickness and thickness uniformity of a CH pad

The accuracy of this method of measuring the pads was determined by measuring a gauge block with a thickness that was certified to be within $50 \mathrm{~nm}$ of $3 \mathrm{~mm}$. This block was wrung onto the flat section of the vacuum chuck and was measured to be within $10 \mathrm{~nm}$ of $3 \mathrm{~mm}$. The gauge block was also placed in the center of the vacuum chuck (so that it was being held by vacuum) and measured again in six places. All six measurements were within $50 \mathrm{~nm}$ of $3 \mathrm{~mm}$. Therefore, when measuring the thickness of a rigid part, this method is probably accurate to approximately $\pm 50-100 \mathrm{~nm}$.

The pads depicted on the right side of Figure 51 had to be measured using a special vacuum chuck that provided clearance for the rough material near the center of the back face. It was later discovered that these ICH and $\mathrm{CH}$ pads flexed from the vacuum pressure while they were being measured with the LVDT. Each of the pads may have been measured with an error of 0.6 to $1.0 \mu \mathrm{m}$. While measuring each of the $\mathrm{ICH}$ and $\mathrm{CH}$ pads, a $4.375 \mathrm{~mm}$ diameter section of the pad was unsupported by the vacuum chuck, as shown in Figure 53.

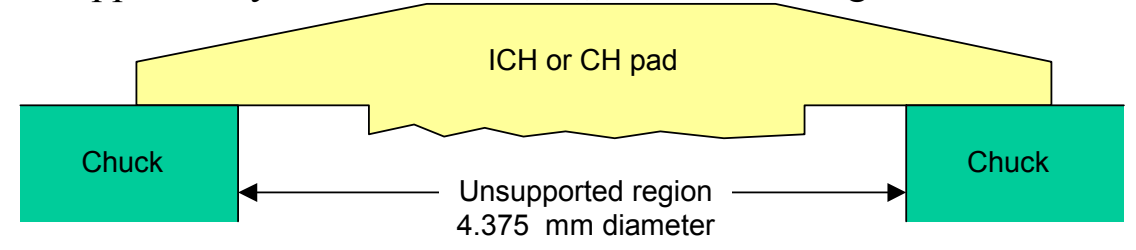

Figure 53. Support of an ICH or CH pad with a vacuum chuck while its thickness is being measured

An finite element analysis indicates that the vacuum pressure of 50,796 $\mathrm{Pa}(15 \mathrm{in} \mathrm{Hg}$ ) would have caused the center section of the pad to deflect 0.6 to $1 \mu \mathrm{m}$ (assuming the modulus of the plastic is 1.8 GPA to 3 GPA, respectively), as shown in Figure 54. Therefore, the recorded values of the pad thickness may have been 0.6 to $1 \mu \mathrm{m}$ less than the actual pad thickness.

After bonding the pads to the $100 \mathrm{~mm}$ diameter Al disk, this deflection will not occur. Therefore, the if the raw measured values of the pad thickness are used to calculate the adhesive layer thickness, then the adhesive layer thickness will appear to be 0.6 to $1 \mu \mathrm{m}$ larger than it actually is. 


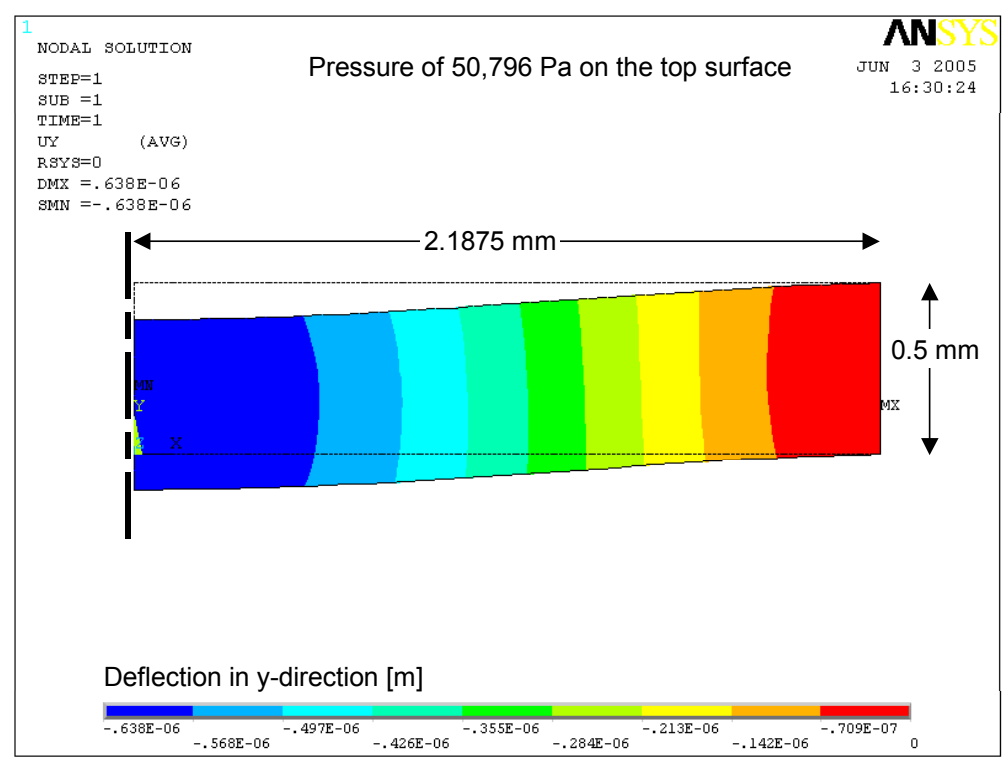

Figure 54. Finite element analysis of the deflection of an ICH or CH pad while its thickness is being measured

To avoid this problem, the back surface of the pad should be machined using a diamond parting tool that is long enough to reach the center of the pad. If the entire back surface of the pad is diamond turned, then the entire back surface of the pad could be supported by a vacuum chuck while its thickness is being measured. Alternatively, a low vacuum pressure could be used when measuring the thickness of the ICH and $\mathrm{CH}$ pads with the LVDT.

\section{$\underline{\text { UV curing adhesives }}$}

To practice bonding the ICH and $\mathrm{CH}$ pads onto the $63 \mu \mathrm{m}$ thick $\mathrm{Al}$, several pads were bonded to a diamond turned aluminum flat using various adhesives. The first adhesives tested were UV adhesives, which cured upon exposure to ultraviolet (UV) light. These adhesives are available in a range of viscosities, and they do not cure until they are exposed to UV light for several seconds. Tests were performed with LocTite 3104, 3494, and 3525.

The bonding tests were performed directly on the diamond turning machine. A $100 \mathrm{~mm}$ diameter Al workpiece was diamond turned and left on the machine tool, and the air bearing assembly station shown in Figure 55 was mounted on the B-axis of the machine tool. This assembly station incorporates an air bearing in series with a spring and a force transducer and allows the operator to control the assembly force to within approximately $0.01 \mathrm{~N}$. 


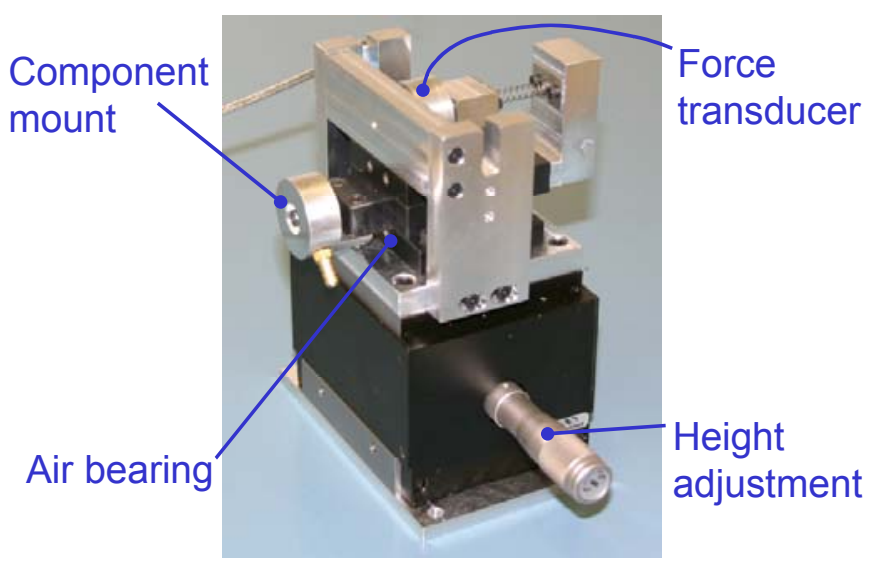

Figure 55. Air bearing assembly station used to bond the ICH and $\mathrm{CH}$ pads

One of the pads was bonded onto the tip of a polystyrene assembly cone attached to one of the aluminum holders shown in Figure 3. The pad was bonded to the cone using a small droplet of LocTite 3103 UV curing adhesive, as shown in the top left picture of Figure 56. The assembly of the pad onto the cone was performed with a benchtop assembly station. The aluminum holder containing the cone and the pad was then placed on the assembly station on the diamond turning machine. Using a small brush (for the LocTite 3104) or a single hair (for the LocTite 3494 and 3525), a drop of UV curing adhesive was placed onto the pad using a hair, as shown in the top center picture of Figure 56. The pad was then pressed against the Al flat with a force of 5 grams-force. The C-axis of the DTM then moved the pad through an arclength of 0.75 $\mathrm{mm}$ in either direction and then back to the original position, as shown in the top right picture of Figure 56. Note that the $\mathrm{C}$-axis of the Moore 350 diamond turning machine does not obey feedrate commands. In order to control the rate of motion of the pad with respect to the Al, a 5 $\mu \mathrm{m}$ move in the $\mathrm{x}$-direction accompanied the rotation of the $\mathrm{C}$-axis. The pad was then pressed further into the $\mathrm{Al}$ until the force reached 10 grams-force, and the $\mathrm{C}$-axis moves were repeated. The adhesive was then cured using the handheld Norland UV light, as shown in the bottom right picture of Figure 56. The UV light was held approximately $13 \mathrm{~mm}$ from the part for 2 minutes.
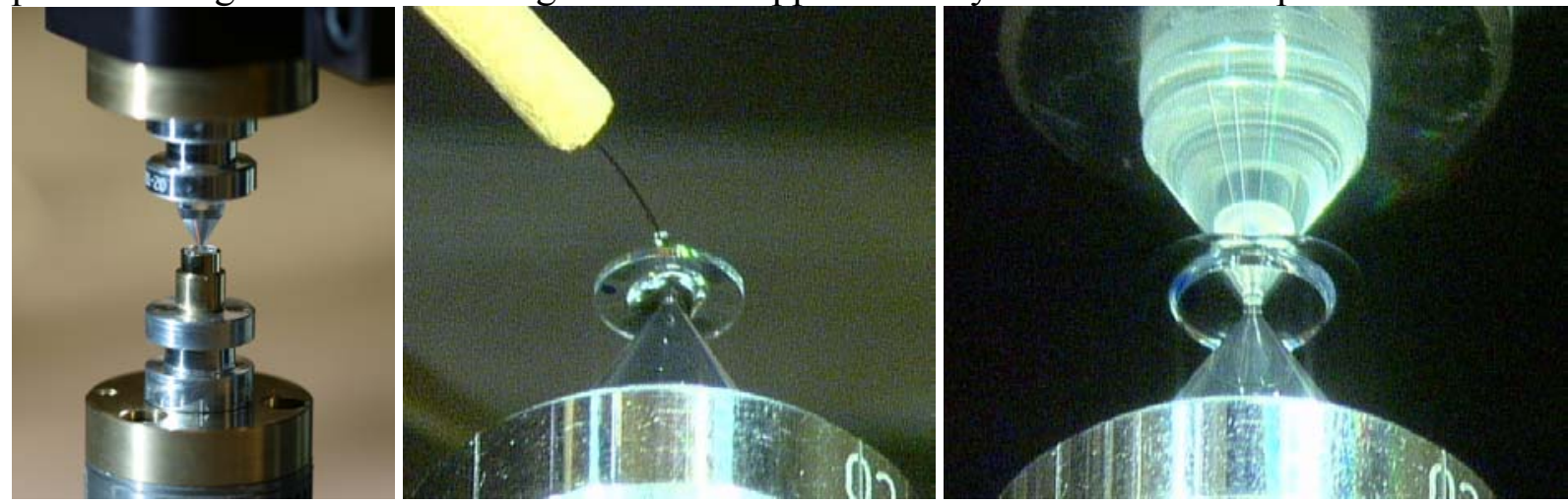

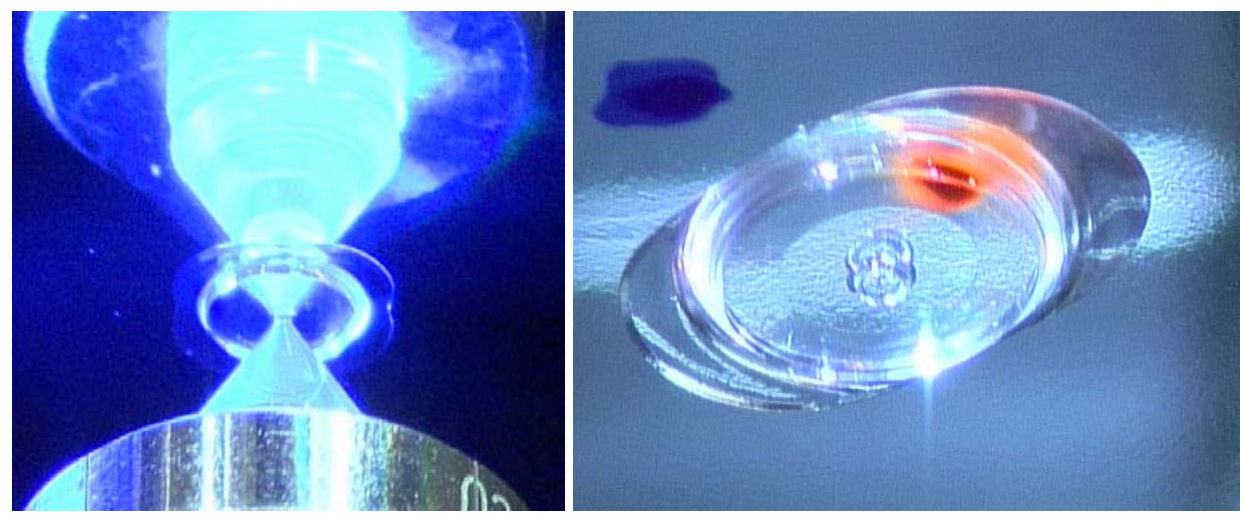

Figure 56. Bonding of an ICH pad to an assembly cone, application of UV curing adhesive, application of the pad to an Al flat, and curing of the adhesive with a UV light source

The assembly cone was freed from the pad by rotating the C-axis. An image of the bonded pad appears in the bottom right picture of Figure 56. The LVDT mounted to the B-axis platform was then used to measure the distance from the surface of the bonded pad to the surface of the Al flat in four spots. The thicknesses of the adhesives in the four measured locations are given below. The pads that were used to perform these initial bonding tests were not subject to the measurement uncertainty illustrated in Figure 53, so these numbers reflect the actual thickness of the adhesive in the measured location with an uncertainty of approximately $100 \mathrm{~nm}$.

$\begin{array}{lllllll}\text { LocTite } 3525 & (10,000 \mathrm{cP}) & \text { Force }=15 \mathrm{~g} & 0.13 & 2.10 & 1.20 & 1.86 \mu \mathrm{m} \\ \text { LocTite } 3104(100 \mathrm{cP}) & \text { Force }=10 \mathrm{~g} & 0.14 & 0.69 & 0.51 & 0.23 \mu \mathrm{m} \\ \text { LocTite } 3494(6,000 \mathrm{cP}) & \text { Force }=10 \mathrm{~g} & 2.27 & 1.56 & 1.50 & 1.75 \mu \mathrm{m}\end{array}$

These pads were then diamond turned to a thickness of approximately $100 \mu \mathrm{m}$ using a diamond tool with a nose radius of $125 \mu \mathrm{m}$. This operation revealed that the surfaces of the UV adhesives remained tacky after being cured by the UV light. The tackiness probably resulted from oxygen in the air inhibiting the curing process near the surface of the adhesive. Therefore, chips generated in the diamond turning process were also tacky and adhered to the freshly diamond turned plastic and the adjacent adhesive, as shown in Figure 57. It is important to note that the lighting conditions can significantly affect the visibility of debris on the surface of the pad. The pad might appear clean with certain lighting conditions, but debris can become apparent with a small change in the angle of incidence of the lamp, as shown in the picture on the right side of Figure 57. 

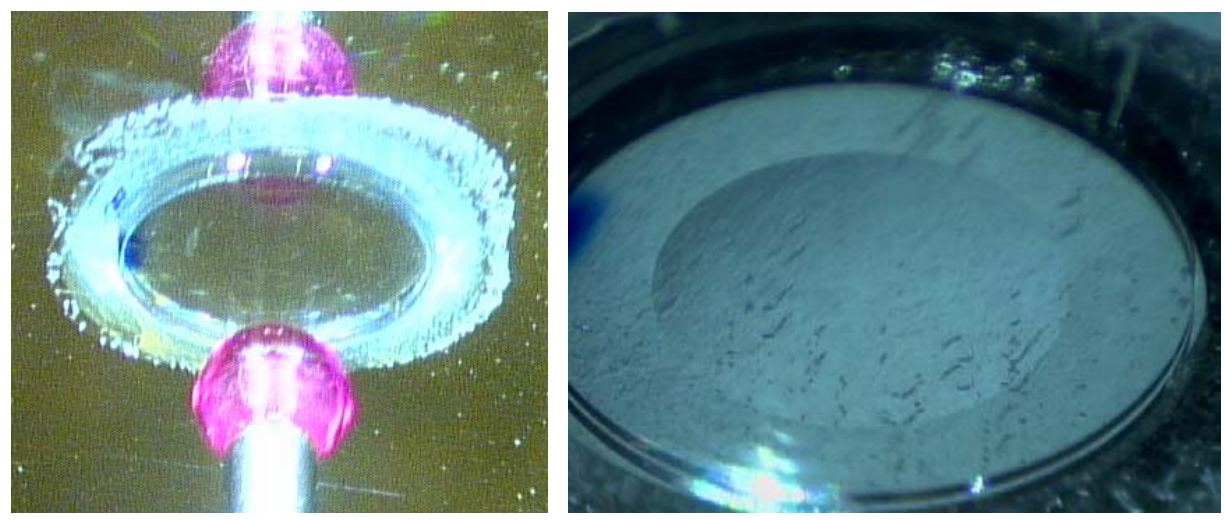

Figure 57. Chips sticking to the diamond turned UV curing adhesive and the ICH pad

This debris could not be removed using a dry cotton swab. In an effort to free the debris, a swab containing alcohol was brushed over the surface of the pad. The alcohol appeared to partially dissolve the UV adhesive, which attracted additional debris onto the surface of pad. Therefore, the alcohol actually made the situation worse. Because of the difficulty in removing this debris from the surface, UV curing adhesives were abandoned in favor of other adhesives that were known to have more favorable curing properties.

\section{Cyanoacrylate}

A pad was bonded to the Al flat using LocTite 495 cyanoacrylate. This adhesive is commonly used by the Target Fabrication Group and was known to be fairly hard upon curing, and cured cyanoacrylate had often been machined with a diamond tool. Unfortunately, the geometry of this assembly operation prevented the cyanoacrylate from curing as expected. After applying a droplet of cyanoacrylate to an $\mathrm{ICH}$ pad and assembling the pad onto the Al flat, the pad was moved in an X pattern. After about 60 seconds, the cyanoacrylate had not cured, and the pad pulled off of the Al when the assembly cone was retracted. Another pad was then assembled using LocTite 495. After several minutes, the pad was firmly secured to the Al flat, but the cyanoacrylate in the chamfered section of the pad remained liquid and did not cure. Apparently, the cyanoacrylate did not cure completely, because it was not exposed to the atmosphere, where the humidity could cause it to cure. The cyanoacrylate in contact with the surfaces of the pads probably cured quickly because of the moisture resident on the surfaces. However, the thickness of the adhesive layer was apparently too large to achieve a completely cured layer.

\section{Two-part epoxies}

Two-part epoxies, such as Hardman Green and StyCast, do not experience problems with oxygen inhibition, and they do not require moisture to cure. Furthermore, they had been used in the past by the Target Fabrication Group and were known to have reasonably good diamond turning properties. Therefore, an additional test was performed to bond an ICH pad to the Al flat using Hardman Green epoxy. The epoxy was mixed in a small plastic vial with a plastic rod. It was then centrifuged for a few minutes, which removed all of the visible bubbles created during the mixing process. A droplet of this epoxy was then placed on an $\mathrm{ICH}$ pad, and the pad was assembled with a force of 10 grams-force and moved back and forth a distance of $0.75 \mathrm{~mm}$ across the surface of the Al, as shown in Figure 58. 

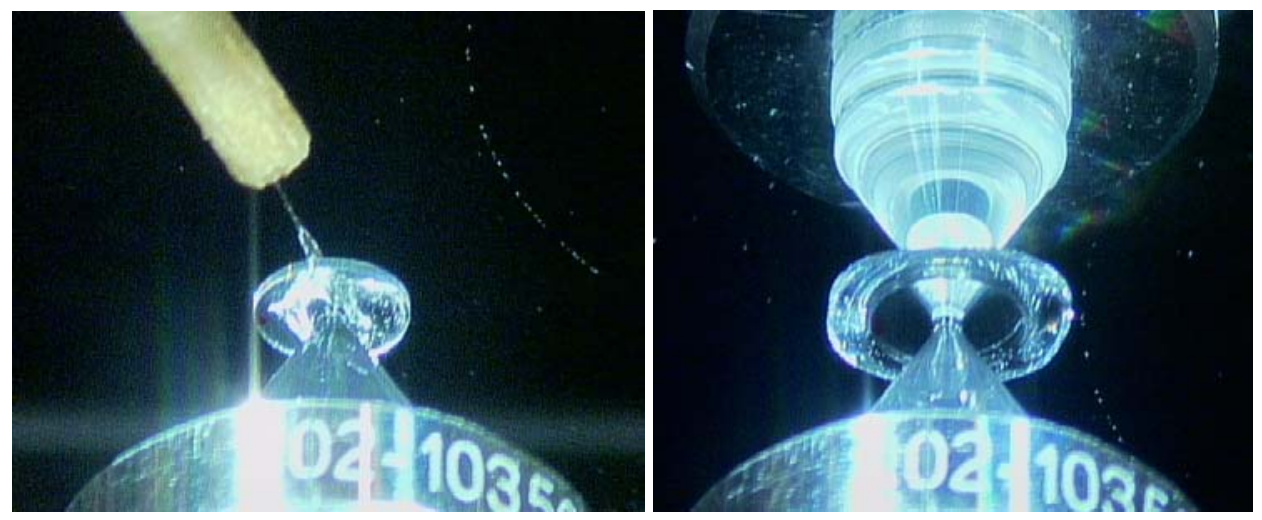

Figure 58. Application of Hardman Green epoxy to an ICH pad using a hair (left) and bonding of the pad to an Al flat (right)

The LVDT then measured the thickness of the adhesive in four locations. The measured values were $1.27,2.18,1.04$, and $2.46 \mu \mathrm{m}$. Therefore, the epoxy successfully created a bond layer with a thickness of less than $3 \mu \mathrm{m}$.

The bonded ICH pad was then diamond turned to a thickness of approximately $100 \mu \mathrm{m}$ using a diamond tool with a nose radius of $125 \mu \mathrm{m}$. Images of the diamond turned pad appear in Figure 59. There were only a few pieces of debris visible on the surface, which could be removed using a cotton swab.
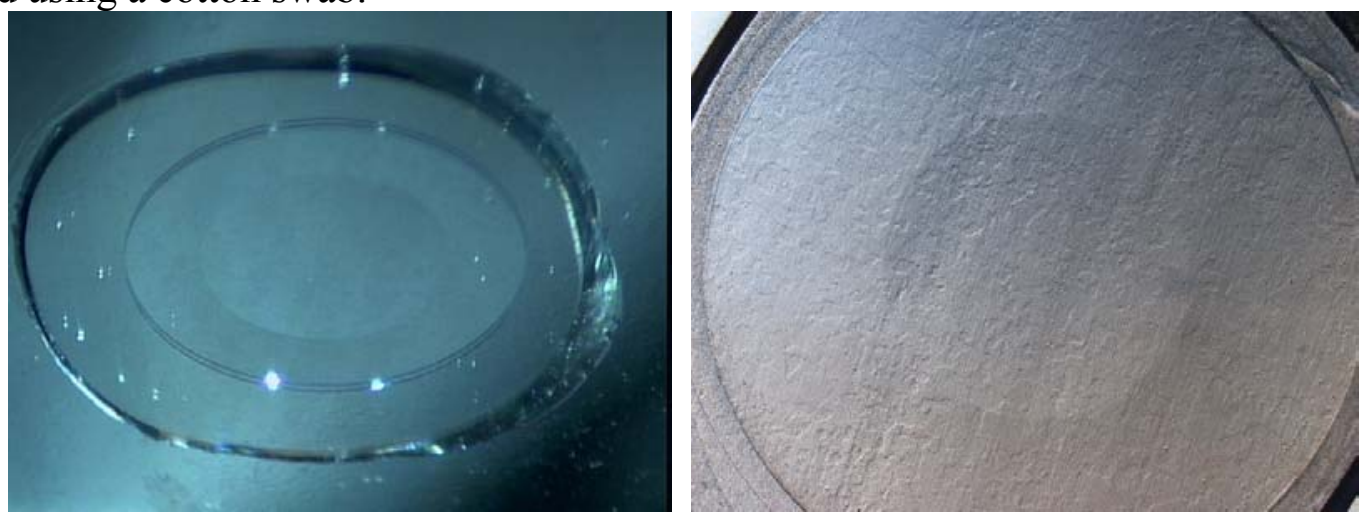

Figure 59. Machined ICH pad bonded to Al with Hardman Green epoxy (left). Microscope image of a typical diamond turned pad taken with Interference Contrast mode (right).

A CH pad was then bonded on top of this ICH pad using StyCast epoxy. StyCast has a relatively low viscosity and is often used to obtain thin bondlines. StyCast comes in pint-sized containers, and the two parts must be measured using a balance to obtain the proper mixing ratio. A $2 \mathrm{~mL}$ batch of this epoxy was mixed in a plastic vial and then centrifuged for several minutes. A few droplets of the epoxy were then applied to a $\mathrm{CH}$ pad using a hair. This epoxy has a low viscosity, so one must be careful not to apply too much of it to the pad. The pad was then assembled on top of the ICH pad on the Al flat. StyCast epoxy has a pot life of several hours, and it must cure for 7 to 8 hours before the assembly cone can be removed. Figure 60 illustrates the application of the StyCast to the $\mathrm{CH}$ pad, the bonding of the $\mathrm{CH}$ pad to $\mathrm{ICH}$ pad on the $\mathrm{Al}$ flat, and the bonded $\mathrm{CH}$ pad after removing the assembly cone. 

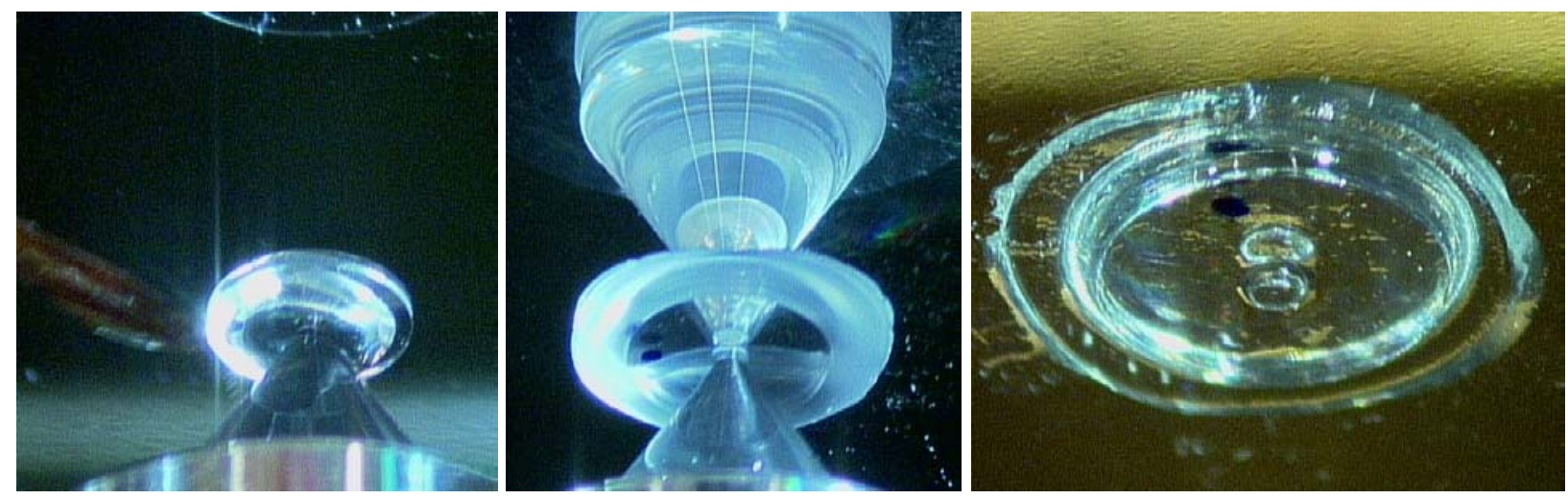

Figure 60. Bonding a CH pad on top of an ICH pad using Stycast epoxy

The LVDT then measured the thickness of the adhesive in four locations. The measured values were $1.07,0.31,0.66$, and $0.69 \mu \mathrm{m}$. Therefore, the adhesive successfully created an adhesive layer well within the limit of $3 \mu \mathrm{m}$.

The $\mathrm{CH}$ pad was then diamond turned to a thickness of approximately $32.5 \mu \mathrm{m}$. The StyCast epoxy did not machine as cleanly as the Hardman Green epoxy. The chips formed by the diamond tool had a tendancy to stick to the $\mathrm{CH}$, but they could be removed using a cotton swab with some effort.

This study of bonding processes for the ICH and $\mathrm{CH}$ pads concluded that Hardman Green epoxy should be used to bond the ICH pad to the Al. A sub- $\mu$ m bond can be created with StyCast epoxy, so StyCast could be used to bond the $\mathrm{CH}$ pads to the ICH pads. Note that Hardman Green could also be used to bond $\mathrm{CH}$ pads to the ICH pads. Hardman Green cures more quickly than the StyCast, but it has a larger viscosity and forms slightly thicker adhesive layers. A summary of the procedure for bonding the $\mathrm{ICH}$ and $\mathrm{CH}$ pads appears in Appendix C.

\section{Bonding ICH and CH pads to disk D3}

After machining disk D3 to a thickness of $63 \mu \mathrm{m}$, it was kept on the vacuum chuck on the diamond turning machine, and six ICH pads were bonded to it. The center of each pad was placed at a radius of $31 \mathrm{~mm}$, so it would lie directly over the inside edge of the $1 \mathrm{~mm} \times 43 \mu \mathrm{m}$ $\mathrm{Cu}$ band on the opposite face of the disk. Each ICH pad was bonded with Hardman Green epoxy using the process described in Appendix C. After bonding each of the pads, the step height from the surface of the pad to the Al baseplate was measured with the LVDT mounted to the diamond turning machine, as shown in Figure 61.

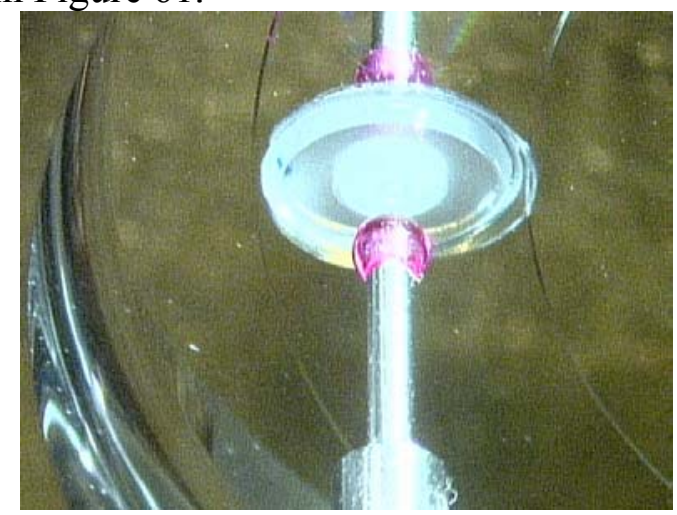

Figure 61. Measurement of adhesive layer thickness for an ICH pad 
The LVDT measurements indicated that several of the adhesive bonds met the specification, but others were thicker than the limit of $3 \mu \mathrm{m}$. Many of the ICH pads contained debris that had to be removed prior to bonding. This debris was very difficult to see and was often only visible in certain lighting conditions. The thicker adhesive bonds probably resulted from debris that prevented the pad from seating correctly onto the Al baseplate. Prior to bonding the pads in place, it is very important that they be adequately cleaned. All debris should be removed from the surface.

A summary of the adhesive bonds for the ICH pads appears in Figure 62. The values listed in the second, third, fourth, and fifth columns of this table were obtained by measuring the step height from the surface of the bonded pad to the Al baseplate and subtracting the measured thickness of the ICH pad. This step height was measured in four different spots around the perimeter of the $6 \mathrm{~mm}$ diameter ICH pad. The pad thicknesses used to make the calculations were the raw measurements made by the LVDT; the deflection of the pad while its thickness was being measured was not considered. The sixth column of the table interpolates these four calculated values to determine the thickness of the adhesive layer in the area of interest on the target. Once again, the deflection of the ICH pad while its thickness was being measured is not considered in this calculation. The final column of the table lists the likely actual thickness of the adhesive layer in the area of interest after the issue related to the measurement of the thickness of the ICH pad described in Figure 53 and Figure 54 has been considered.

\begin{tabular}{|c|c|c|c|c|c|c|}
\hline & \multicolumn{5}{|c|}{$\begin{array}{c}\text { Do not account for the deflection of the pad while its } \\
\text { thickness was measured }\end{array}$} & $\begin{array}{c}\text { Account for the deflection of } \\
\text { the pad while its thickness } \\
\text { was measured }\end{array}$ \\
\hline Pad & $\begin{array}{l}\text { Step1- } \\
\text { meas } \\
\text { pad t }\end{array}$ & $\begin{array}{c}\text { Step2- } \\
\text { meas } \\
\text { pad t }\end{array}$ & $\begin{array}{c}\text { Step3- } \\
\text { meas } \\
\text { pad t }\end{array}$ & $\begin{array}{l}\text { Step4- } \\
\text { meas } \\
\text { pad t }\end{array}$ & $\begin{array}{l}\text { Calculated adhesive thickness } \\
\text { in area of interest }\end{array}$ & $\begin{array}{l}\text { Likely actual adhesive } \\
\text { thickness in area of interest }\end{array}$ \\
\hline$\overline{\mathrm{ICH} 1}$ & 4.4 & 2.9 & 6.6 & 0.3 & 3.5 & 2.5 to 2.9 \\
\hline$\overline{\mathrm{ICH} 2}$ & 4.1 & 1.4 & 3.6 & 1.9 & 2.8 & 1.8 \\
\hline$\overline{\mathrm{ICH} 3}$ & 2.1 & 4.6 & 2.8 & 3.9 & 3.4 & 2.4 \\
\hline$\overline{\mathrm{ICH} 4}$ & 3.3 & 2.9 & 2.9 & 3.6 & 3.2 & 2.2 \\
\hline $\mathrm{ICH} 5$ & 3.5 & 4.0 & 3.6 & 4.2 & 3.8 & 2.8 \\
\hline$\overline{\mathrm{ICH} 6}$ & 3.4 & 2.0 & 3.1 & 2.7 & 2.8 & 1.8 \\
\hline
\end{tabular}

Figure 62. Summary of adhesive bonds for the ICH pads. All numbers have units of $\mu \mathrm{m}$.

After bonding the last ICH pad in place, the six pads were diamond turned to the proper thickness using a diamond tool with a nose radius of $25 \mu \mathrm{m}$. A depth of cut of $1 \mu \mathrm{m}$, a spindle speed of $1600 \mathrm{rpm}$, and a feedrate of $5 \mathrm{~mm} / \mathrm{min}$ were used for the finishing passes. The LVDT verified that the thickness of each of the preheat shields, which consists of the ICH material and the Hardman Green epoxy, was $103.6 \mu \mathrm{m}$.

A CH pad was then bonded directly over each ICH pad with StyCast epoxy using the procedure described in Appendix C. Figure 63 depicts the application of the StyCast to the $\mathrm{CH}$ pad, the centering of the $\mathrm{CH}$ pad over the $\mathrm{ICH}$ pad, and the application of the $\mathrm{CH}$ to the ICH. Each $\mathrm{CH}$ pad was allowed to cure overnight before removing the assembly cone. 

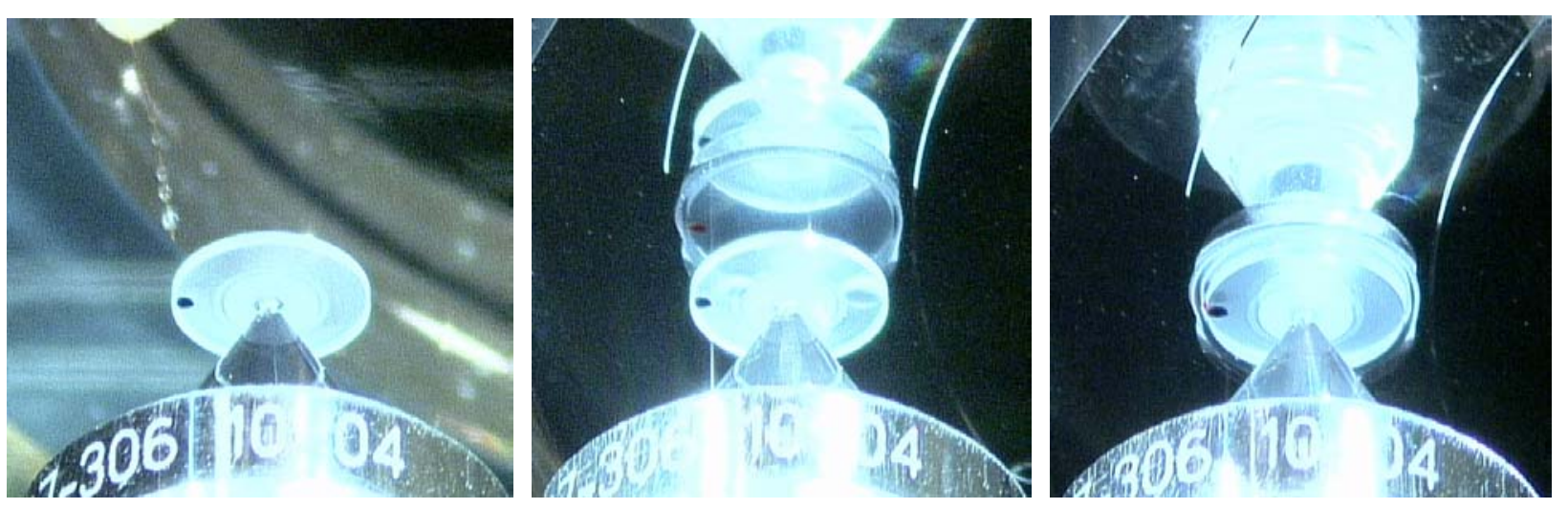

Figure 63. Bonding and assembly of a CH pad on an ICH pad on disk D3

The step height from the surface of each $\mathrm{CH}$ pad to the $\mathrm{Al}$ baseplate was measured with the LVDT mounted to the diamond turning machine. Once again, several of the adhesive bonds met the specification, but others were thicker than the limit of $3 \mu \mathrm{m}$. The cleanliness of the $\mathrm{CH}$ pads and the surface of the ICH were critical to achieving acceptable adhesive layers, and debris on these surface probably prevented some of the pads from being bonded correctly. A summary of the adhesive bonds for the $\mathrm{CH}$ pads appears in Figure 64.

Figure 64 has the same form as Figure 62. The values listed in the second, third, fourth, and fifth columns of this table were obtained by measuring the step height from the surface of the bonded $\mathrm{CH}$ pad to the Al baseplate and subtracting the $103.6 \mu \mathrm{m}$ thickness of the preheat shield and the measured thickness of the $\mathrm{CH}$ pad. The pad thicknesses used to make the calculations do not consider the deflection of the $\mathrm{CH}$ pad while its thickness was being measured. The sixth column of the table interpolates these four calculated values to determine the thickness of the adhesive layer in the area of interest on the target. Once again, the deflection of the $\mathrm{CH}$ pad while its thickness was being measured is not considered in this calculation. The final column of the table lists the likely actual thickness of the adhesive layer in the area of interest after the issue related to the measurement of the thickness of the $\mathrm{CH}$ pad described in Figure 53 and Figure 54 has been considered.

\begin{tabular}{|c|c|c|c|c|c|c|}
\hline & Do not & accoun & $t$ for the & $\begin{array}{l}\text { deflectic } \\
\text { was me }\end{array}$ & $\begin{array}{l}\text { on of the pad while its thickness } \\
\text { easured }\end{array}$ & $\begin{array}{c}\text { Account for the deflection of } \\
\text { the pad while its thickness } \\
\text { was measured }\end{array}$ \\
\hline Pad & $\begin{array}{c}\text { Step1- } \\
103.6- \\
\text { meas } \\
\text { pad t }\end{array}$ & \begin{tabular}{|l|} 
Step2- \\
$103.6-$ \\
meas \\
pad $t$
\end{tabular} & \begin{tabular}{|c|} 
Step3- \\
$103.6-$ \\
meas \\
pad t
\end{tabular} & $\begin{array}{l}\text { Step4- } \\
103.6 \text { - } \\
\text { meas } \\
\text { pad t }\end{array}$ & $\begin{array}{c}\text { Calculated adhesive thickness } \\
\text { in area of interest }\end{array}$ & $\begin{array}{l}\text { Likely actual adhesive } \\
\text { thickness in area of interest }\end{array}$ \\
\hline REX1 & 2.0 & 2.8 & 3.3 & 1.3 & 2.4 & 1.4 to 1.8 \\
\hline REX2 & 2.7 & 3.1 & 4.1 & 1.6 & 2.9 & 1.9 to 2.3 \\
\hline REX3 & -1.3 & 32.5 & 26.7 & 3.3 & 15.3 & 14.3 \\
\hline REX4 & 8.1 & 0.9 & 9.1 & -0.5 & 4.4 & 3.4 \\
\hline REX5 & 2.8 & 2.3 & 4.0 & 1.3 & 2.6 & 1.6 \\
\hline REX6 & 3.5 & 2.8 & 3.6 & 2.8 & 3.2 & 2.2 to 2.6 \\
\hline
\end{tabular}

Figure 64. Summary of adhesive bonds for the CH pads. All numbers have units of $\mu \mathrm{m}$.

After bonding the last $\mathrm{CH}$ pad in place and allowing the adhesive to cure for 24 hours, the six pads were diamond turned to the proper thickness. A depth of cut of $1 \mu \mathrm{m}$, a spindle speed of $1600 \mathrm{rpm}$, and a feedrate of $5 \mathrm{~mm} / \mathrm{min}$ were used for the finishing passes. The LVDT verified 
that the thickness of each of the ablators components, which consists of the $\mathrm{CH}$ material and the Stycast epoxy, was $32.8 \mu \mathrm{m}$.

After machining the $\mathrm{CH}$ pads to thickness, the $100 \mathrm{~mm}$ Al disk was removed from the vacuum chuck. The face of the disk that had been against the vacuum chuck wad covered with a viscous substance. This substance could be removed with mineral spirits and a cotton swab.

The surface finish on the $\mathrm{Cu}$ appeared to have been altered by the vacuum chuck. Before placing the part into the vacuum chuck, the $\mathrm{Cu}$ had a lustrous finish, as shown in the picture on the left side of Figure 65. The small spots on the $\mathrm{Cu}$ in this image are residue from alcohol. After removing the part from the vacuum chuck, several features were visible on the $1 \mathrm{~mm}$ wide band of $\mathrm{Cu}$ in the locations of the radial grooves on the vacuum chuck. The center photograph in Figure 65 depicts the region on the $\mathrm{Cu}$ that had the most prominent features. The grooves of the vacuum chuck may have been mechanically or chemically imprinted into the $\mathrm{Cu}$. In some isolated spots, the $\mathrm{Cu}$ contained pits with a depth of approximately $1 \mu \mathrm{m}$. As shown in the picture on the right side of Figure 65, these features did not appear on the $\mathrm{Cu}$ regions between the radial grooves in the vacuum chuck.

The ICH and $\mathrm{CH}$ pads on disk D3 had been placed directly over the radial grooves in the vacuum chuck, so the $\mathrm{Cu}$ contained these features on the targets. However, the $\mathrm{Cu}$ on the targets still met the surface finish specification. In the future, the ICH and CH pads should NOT be bonded directly over the radial grooves of the vacuum chuck. In addition, the portion of the vacuum chuck that supports the $\mathrm{Cu}$ should be reconsidered. It may be preferable to eliminate the circumferential vacuum grooves and use a simple flat surface to prevent the $\mathrm{Cu}$ from deflecting. It might also be preferable to use a material in these vacuum grooves that will not cause chemical or mechanical damage to the $\mathrm{Cu}$.
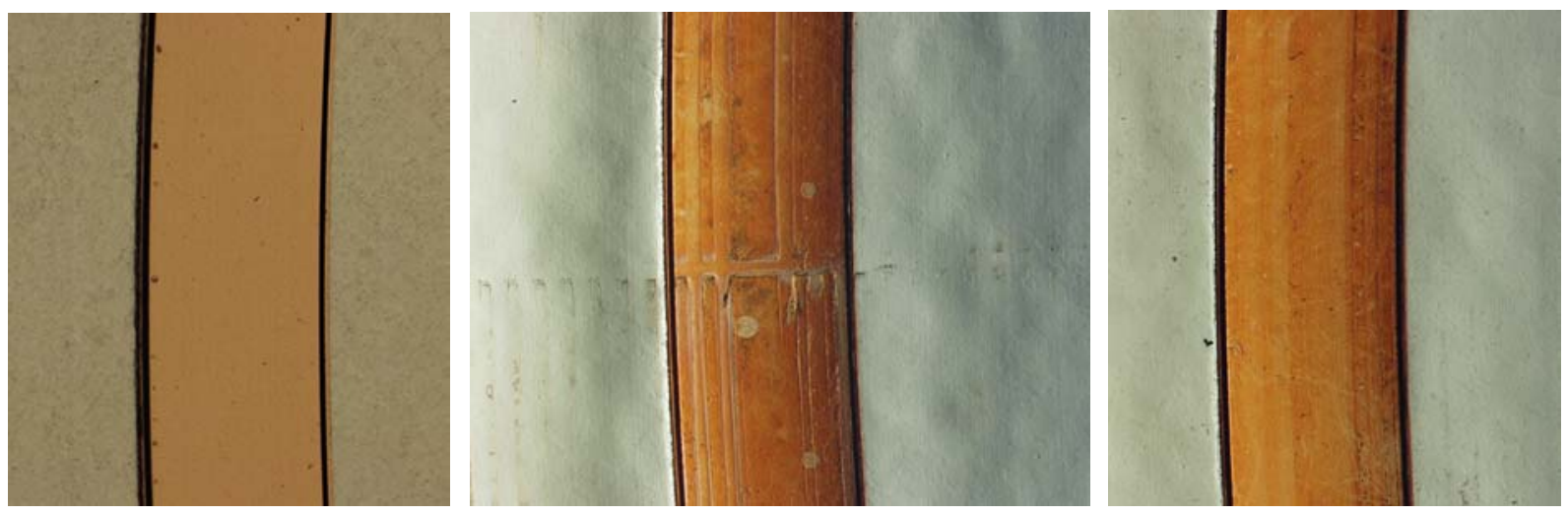

Figure 65. Freshly diamond turned $1 \mathrm{~mm} \times 43 \mu \mathrm{m}$ band of $\mathrm{Cu}$ (left). Cu that was adjacent to the radial grooves in the vacuum chuck (center). Cu that was not adjacent to the radial grooves in the vacuum chuck (right).

The center photograph in Figure 65 depicts the region of the $\mathrm{Cu}$ with the most prominent features. Most of the regions on the $\mathrm{Cu}$ that were in the vicinity of the radial grooves on the vacuum chuck contained features that were less prominent, as shown in Figure 66. 


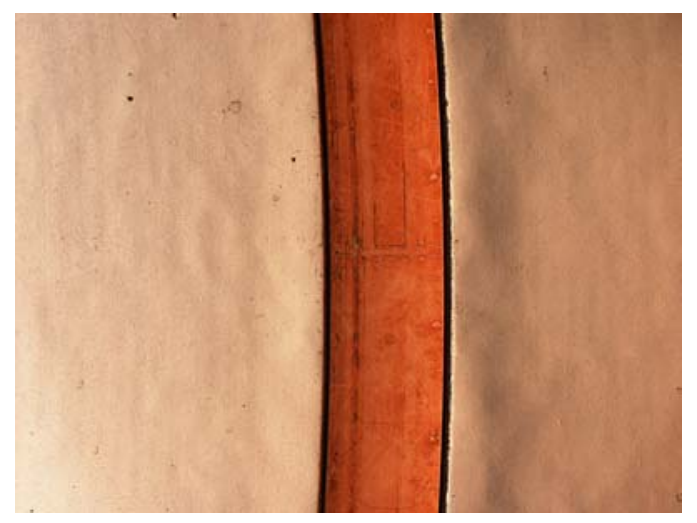

Figure 66. Features on the $\mathrm{Cu}$ in the vicinity of a radial groove on the vacuum chuck. The photograph is representative of most of the features on the $\mathrm{Cu}$.

\section{LASER MACHINING}

The excimer laser in B131 was used to cut $4 \mathrm{~mm}$ diameter subassemblies from the 100 $\mathrm{mm}$ disk. The $4 \mathrm{~mm}$ pieces were cut out of the $6 \mathrm{~mm}$ diameter $\mathrm{ICH}$ and $\mathrm{CH}$ pads. To perform the laser machining, the $100 \mathrm{~mm}$ disk was placed on a brass surface. The side of the disk containing the $\mathrm{Cu}$ was placed against the brass, and the laser spot was incident from the top onto the $\mathrm{CH}$ pads. The initial cuts were made in part ICH1-REX4, which had a cracked $\mathrm{CH}$ pad. Images of this part appear in Figure 67.
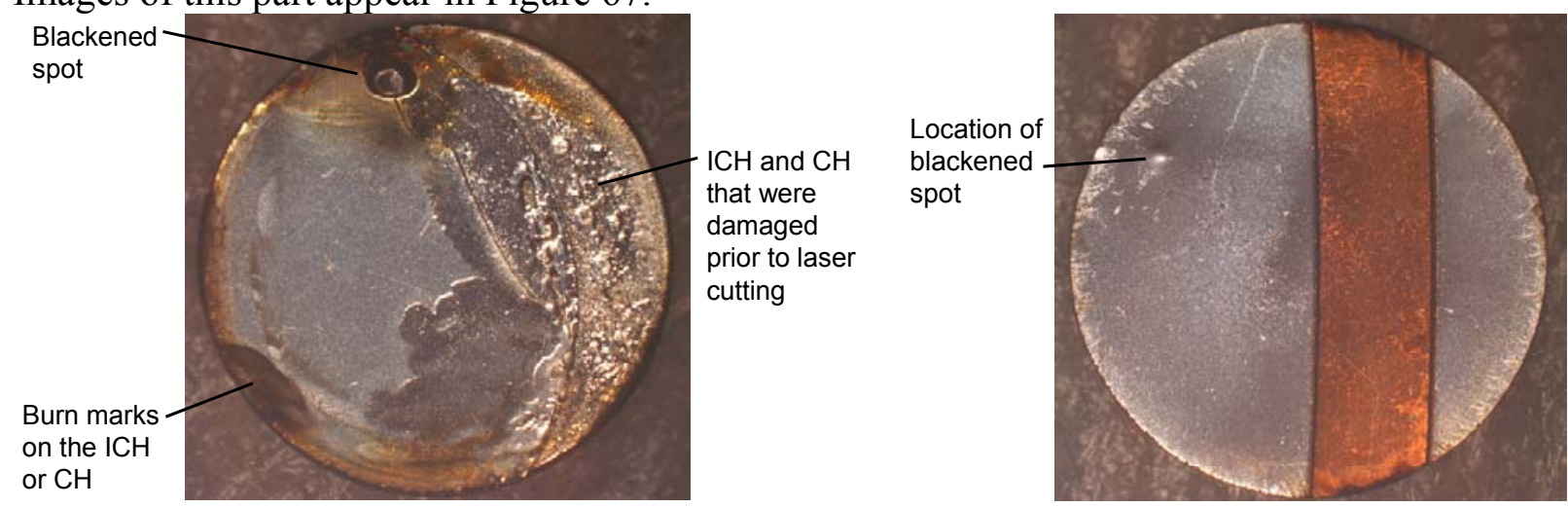

Figure 67. Part ICH1-REX4. CH side of the disk (left) and Al-Cu side of the disk (right).

Several observations were made from this trial. The $\mathrm{CH}$ and/or the $\mathrm{ICH}$ adjacent to the edge of the $4 \mathrm{~mm}$ part appears to have been burned. When machining parts with the excimer laser, a sheet of paper is typically placed between the part and the surface supporting the part. However, in this case, paper was not used between the brass chuck and the workpiece. Without any paper beneath the part, the laser may have reflected off of the brass and could have created the white features near the edge of the aluminum, which are apparent in the right side of Figure 67. The zinc in the brass chuck has a low vapor pressure and may have been ablated by the laser. Because of the profile of the workpiece and the shape of the brass chuck, after the laser had finished machining, the $4 \mathrm{~mm}$ part fell through the newly created hole. As it fell, the laser may have hit it and created the blackened spot that is apparent in the left side of Figure 67. Note that on the opposite face of the part, there is a raised feature at the location of the blackened spot.

Several trials were performed to develop a laser machining process that eliminated each of these problems. Testing revealed that an Ar gas shield actually caused the plastic layers to blacken even further. Therefore, an Ar gas shield should not be used when laser machining these 
parts. To reduce the burn marks on the part, the laser machining parameters were adjusted. The parameters that were used on subsequent parts are listed in Figure 68.

\begin{tabular}{|l|c|l|c|}
\hline Parameters & Value & Parameters & Value \\
\hline System Operator: & Brian Kelly & Travel Speed/VV & 0.04 \\
\hline Data File Name: (example) & EOS2nd & Vector Acceleration & N/A \\
\hline Wavelength: & 248 & Kerf Width & $\sim 0.050 \mathrm{~mm}$ \\
\hline FF Lens & LMU-5X-248 & \# of Passes Through & one \\
\hline Focus Distance & $1.424 "$ & Shutter Dwell (seconds) & 0.2 \\
\hline Entrance Aperture (pin hole) & .28 l $^{\prime \prime} \mathrm{Cu}$ & Displayed Values: & \\
\hline Image Aperture Size (mask) & $0.100 "$ & HV (KV) & 14 \\
\hline Demag & $24.4: 1$ & Power (W) & 65 \\
\hline Energy, $\mathrm{mJ}$ & 360 & Energy, $(\mathrm{mJ})$ & 300 \\
\hline Rep Rate, $\mathrm{Hz}$ & 180 & & \\
\hline
\end{tabular}

Figure 68. Parameters used for the excimer laser

To eliminate any burn marks at the location where the laser initially enters the workpiece, the laser should enter the workpiece several $\mathrm{mm}$ from the location of the part and should tangentially move onto the diameter of the part. To reduce the back reflection from the brass chuck, one or more pieces of paper should be placed between the workpiece and the chuck. A technique was also developed to prevent the part from falling through the newly machined hole at the conclusion of the cut. Rather than cutting the full $360^{\circ}$ of the $4 \mathrm{~mm}$ circle, only $356^{\circ}$ was cut, leaving a $4^{\circ}$ span of material. This tab of material held the $4 \mathrm{~mm}$ disk in place until the laser was turned off. The part could then be held with a vacuum pencil and gently rocked back and forth to break the tab. This process left only a small burr on the edge of the $4 \mathrm{~mm}$ part.

The laser cutting process left a white residue on the surface of the Al. Most of this residue could be removed using a dry cotton swab. After removing most of the residue, the parts could be cleaned further using a cotton swab containing alcohol. However, it is best to not use any alcohol on the parts until most of the debris has been removed, because the alcohol can actually causes debris to bond to the surface of the aluminum.

\section{MEASUREMENT OF SURFACE FINISH}

Each part was cleaned by removing as much debris as possible with a dry cotton swab and then wiping it with a cotton swab containing alcohol. The surface finish of the $\mathrm{Cu}$ and $\mathrm{Al}$ in the area of interest on the target were measured on the Wyko NT 8000 optical profiling system using PSI mode at 20×. The measurements for target ICH6-REX1 are shown below. After removing the tilt and cylindrical form from the dataset for the $\mathrm{Cu}$ surface, $\mathrm{Sa}=10 \mathrm{~nm}$ and $\mathrm{St}=192$ $\mathrm{nm}$, as shown in Figure 69. A profile trace through the dataset for the $\mathrm{Cu}$ had $\mathrm{Ra}=12 \mathrm{~nm}$ and $\mathrm{Rt}=108 \mathrm{~nm}$, as shown in Figure 70. Therefore, the $\mathrm{Cu}$ met the specification of $\mathrm{Ra}<25 \mathrm{~nm}$. 


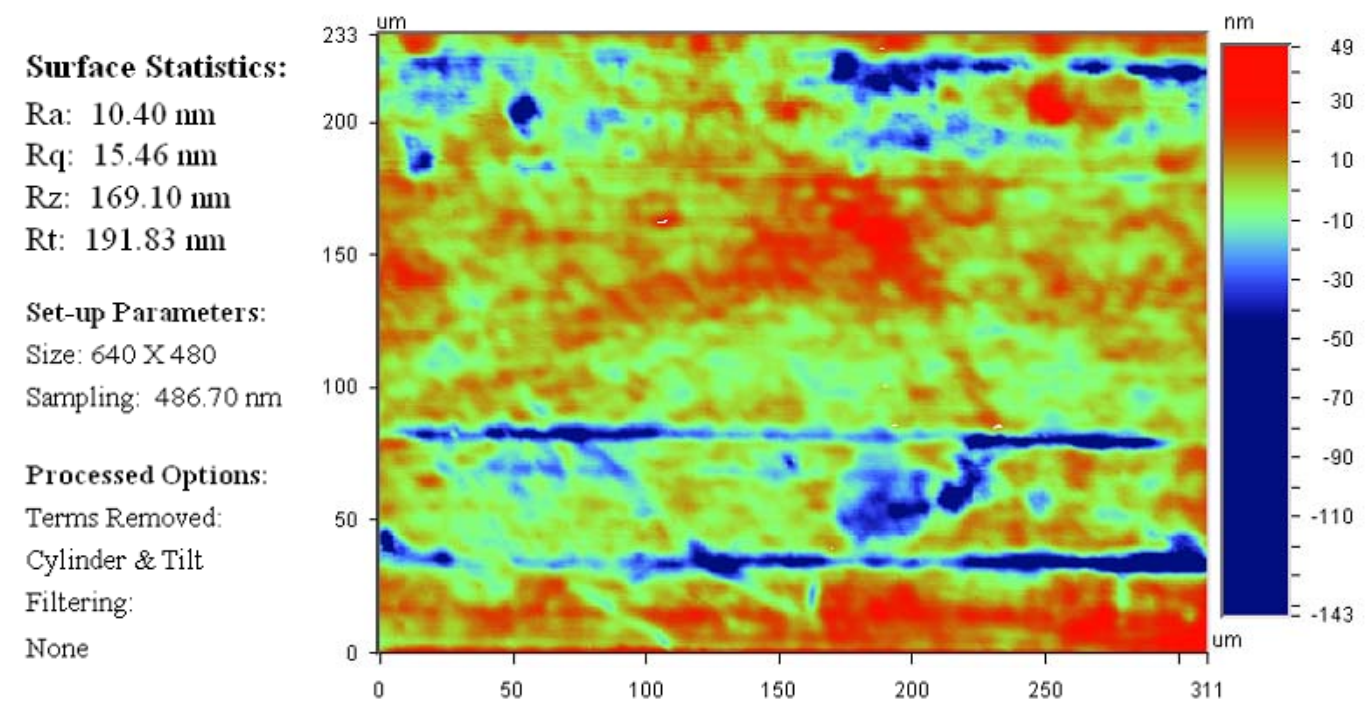

Figure 69. Wyko PSI 20× measurement of the $\mathrm{Cu}$ in the area of interest of ICH6-REX1. Tilt and cylindrical form have been removed from the dataset.
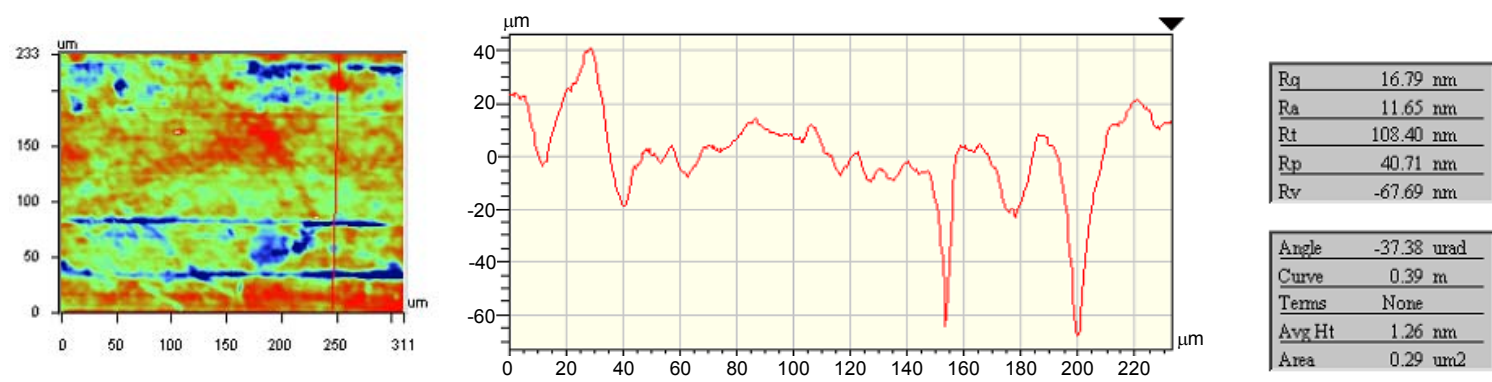

Figure 70. Profile trace through the Wyko dataset for the Cu of ICH6-REX1.

After removing the tilt and cylindrical form from the dataset for the Al surface, $\mathrm{Sa}=15 \mathrm{~nm}$ and $\mathrm{St}=167 \mathrm{~nm}$, as shown in Figure 71. A profile trace through the dataset for the $\mathrm{Al}$ had $\mathrm{Ra}=13$ $\mathrm{nm}$ and $\mathrm{Rt}=63 \mathrm{~nm}$, as shown in Figure 72. Therefore, the Al met the specification of $\mathrm{Ra}<25 \mathrm{~nm}$. 

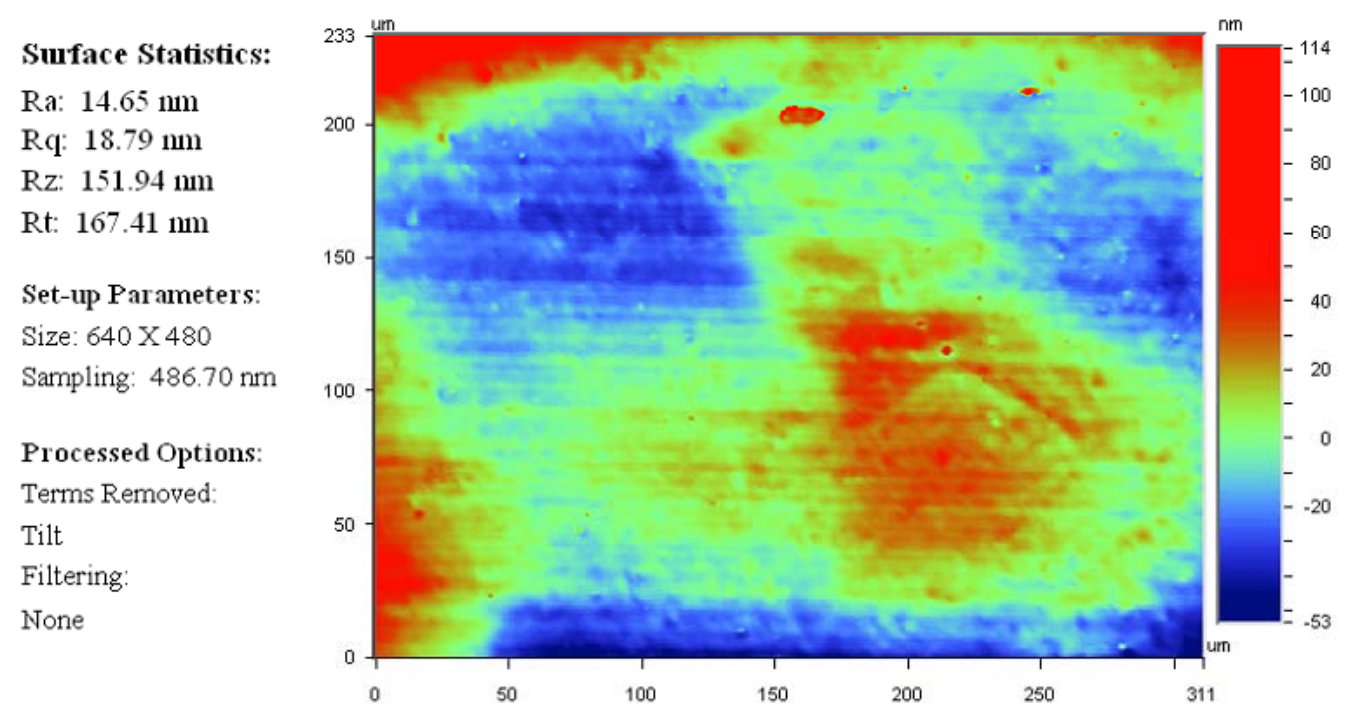

Figure 71. Wyko PSI 20× measurement of the Al in the area of interest of ICH6-REX1. Tilt and cylindrical form have been removed from the dataset.
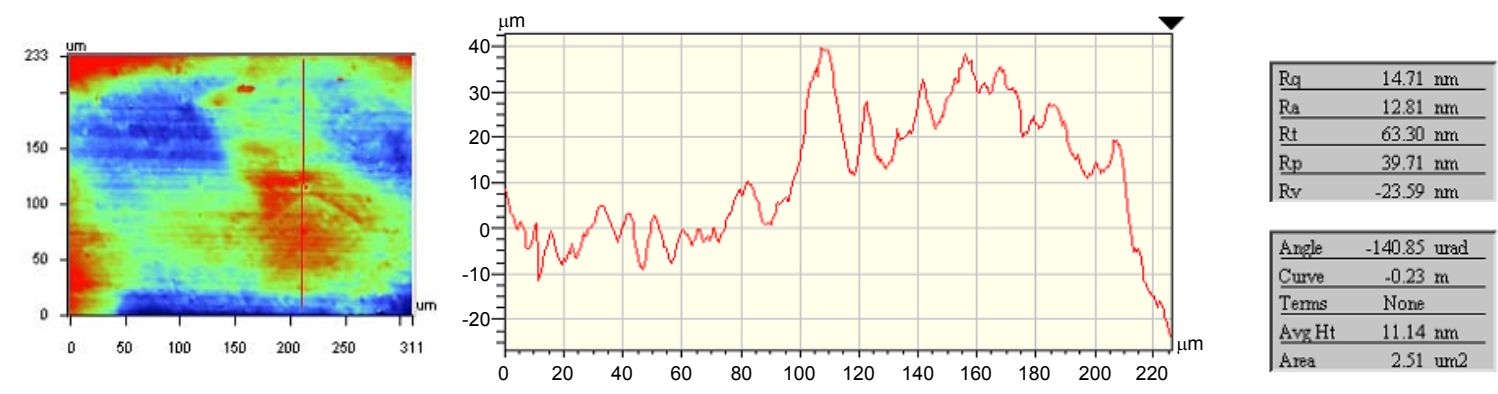

Figure 72. Profile trace through the Wyko dataset for the Al of ICH6-REX1.

\section{BONDING WINDOWS TO THE CU SAMPLE AND AI BASEPLATE}

The thickness of several $1 \mathrm{~mm} \times 1.4 \mathrm{~mm}$ quartz windows was measured by placing each window on a vacuum chuck and measuring the step height from the surface of the window to the surface of the chuck using the Wyko NT 8000 optical profiling system in VSI mode at $2.5 \times$. Each of the windows used on the targets had a measured thickness of $102 \mu \mathrm{m}$. The uncertainty of this measurement was approximately $1 \mu \mathrm{m}$. Windows were bonded onto the $\mathrm{Cu}$ sample and the Al baseplate of the target using the benchtop air-bearing assembly station. The $4 \mathrm{~mm}$ subassembly consisting of the $\mathrm{Cu}, \mathrm{Al}, \mathrm{ICH}$, and $\mathrm{CH}$ was placed onto a vacuum chuck in the lower actuator of the assembly station. Using a plastic vacuum pipette located in the upper actuator of the assembly station, each window was carefully aligned into position, as shown in Figure 73. A droplet of LocTite 3104 UV curing adhesive was used to bond the window in place. After pressing the window into the target with a force of $0.01 \mathrm{~N}$, the UV adhesive was cured with the handheld Norland UV light. 


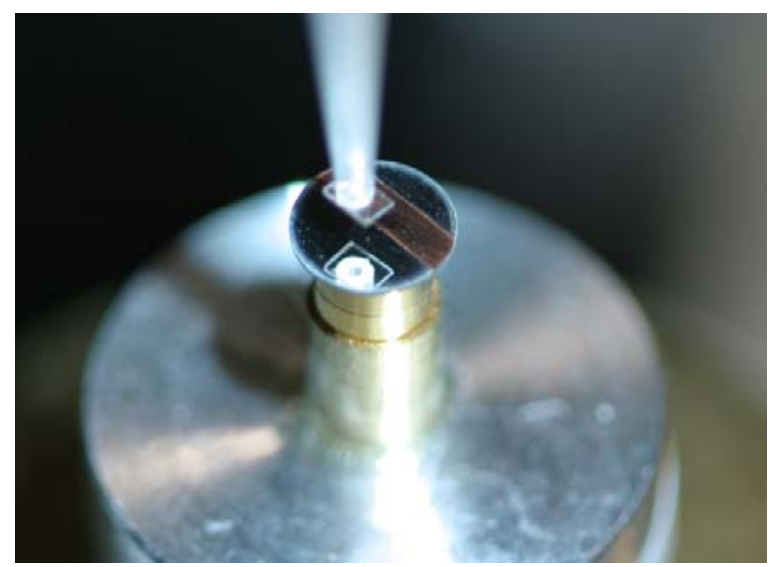

Figure 73. Alignment of a quartz window on an EOS target

Windows were bonded to several test pieces and to several targets. Figure 74 contains microscope images of windows bonded to three different targets.
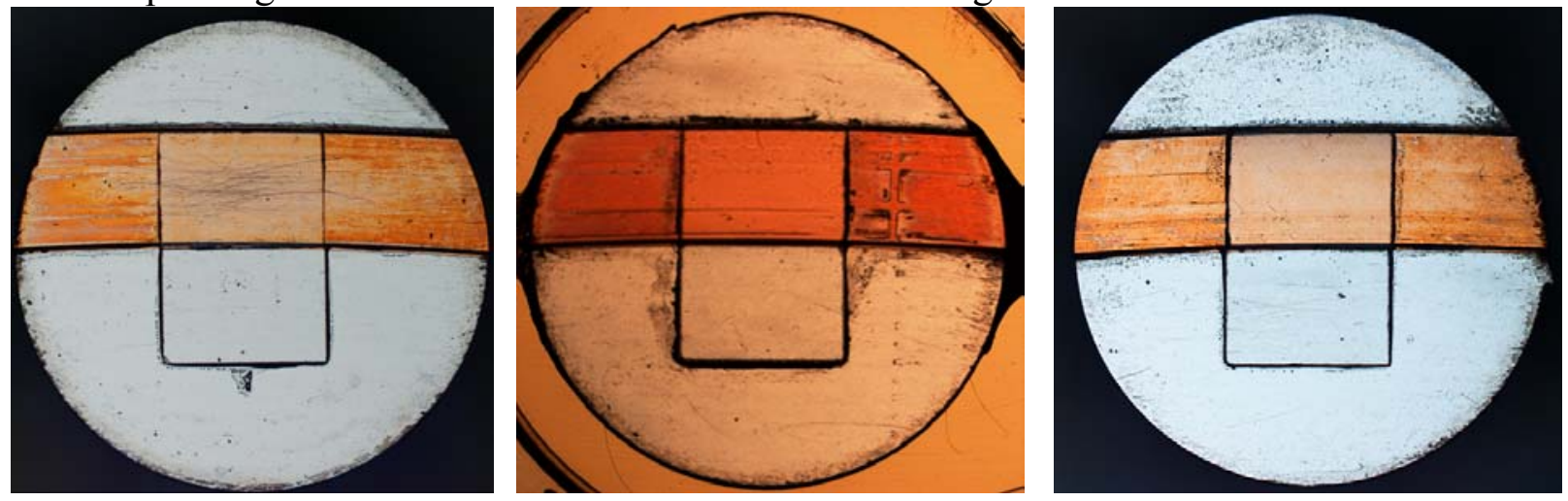

Figure 74. Windows bonded to three EOS targets

After bonding each window in place, the thickness of the adhesive bond was determined by measuring the step height from the surface of the window to the substrate using the Wyko NT 8000 optical profiling system in VSI mode with a Modulation Threshold of $2 \%$. Of the ten windows bonded in this effort, eight of them met the specification of an adhesive bond of less than $5 \mu \mathrm{m}$. The adhesive bonds that did not meet the specification probably resulted from debris on the windows that prevented them from seating correctly on the substrates. It is very important that the windows be cleaned as well as possible before being bonded, and the assembly area should be as clean as possible to prevent debris from interfering with assembly.

Figure 75 contains a plot of the Wyko measurement of the quartz window on the Al baseplate of target ICH6-REX1. This measurement was made after bonding the window to the $\mathrm{Al}$, but before a window was bonded to the $\mathrm{Cu}$. The numbers in the yellow boxes in the figure represent the measured step heights from the surface of the window to the Al baseplate at various locations around the window. The window had a thickness of $102 \pm 1 \mu \mathrm{m}$, so the thickness of the adhesive bond in the area of interest of the target is approximately $1 \pm 1 \mu \mathrm{m}$. 


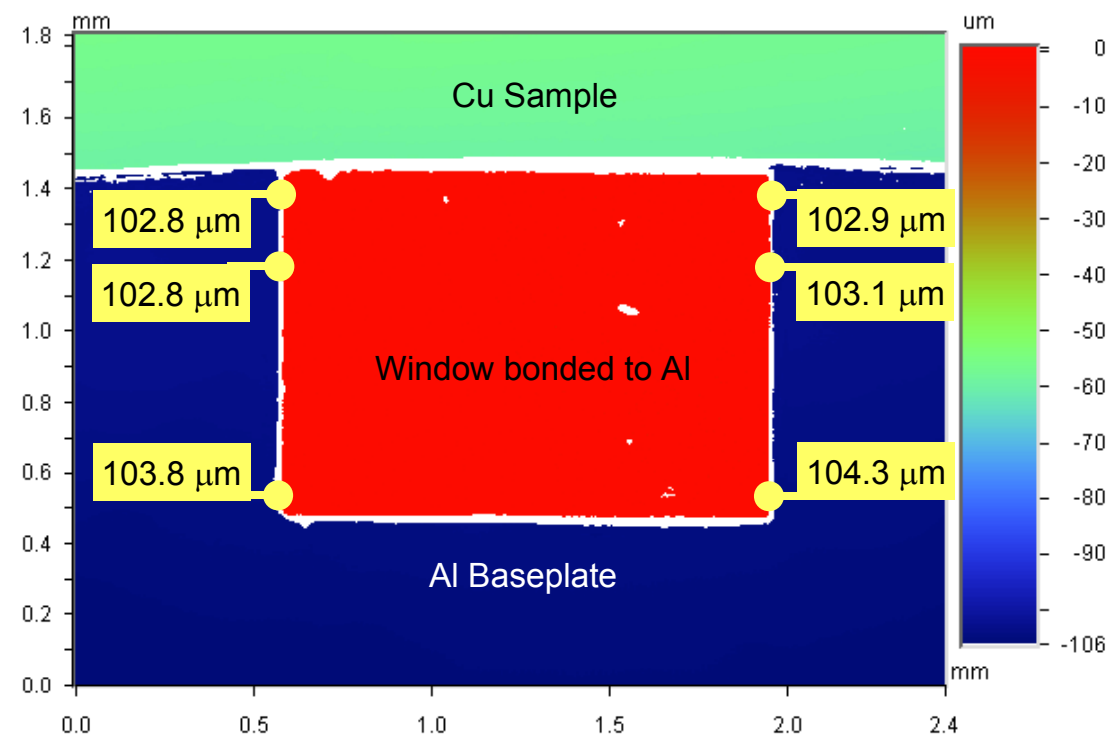

Figure 75. Wyko measurement of the window on the Al baseplate on target ICH6-REX1

Figure 76 contains a plot of the Wyko measurement of the quartz window on the $\mathrm{Cu}$ sample of target ICH6-REX1. This measurement was made after bonding the window to the $\mathrm{Cu}$. The numbers in the yellow boxes in the figure represent the measured step heights from the surface of the window to the $\mathrm{Cu}$ substrate at various locations around the window. The window had a thickness of $102 \pm 1 \mu \mathrm{m}$, so the thickness of the adhesive bond in the area of interest of the target is approximately $2 \pm 1 \mu \mathrm{m}$. Note that outside the area of interest, the adhesive reached a thickness of approximately $5 \pm 1 \mu \mathrm{m}$.

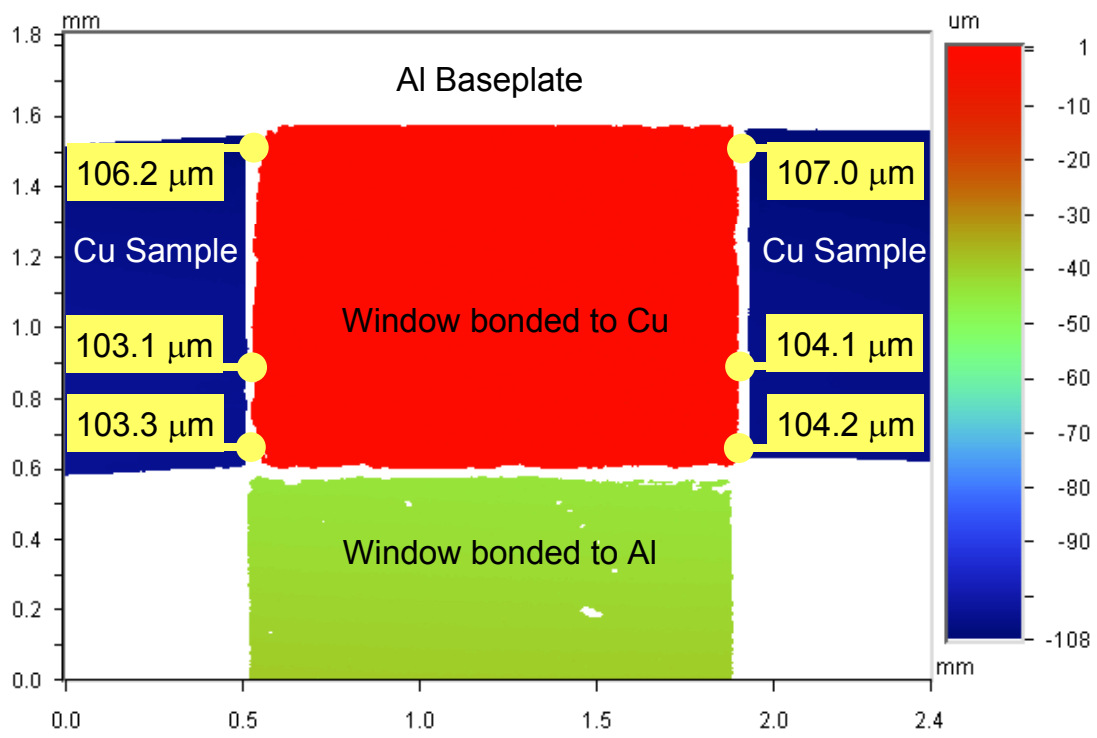

Figure 76. Wyko measurement of the window on the Cu sample on target ICH6-REX1

\section{COMPLETION OF A Cu EOS TARGET}

Target ICH6-REX1 was completed by bonding the target to a gold support ring. Figure 77 depicts the target just before it was bonded to the support ring. 


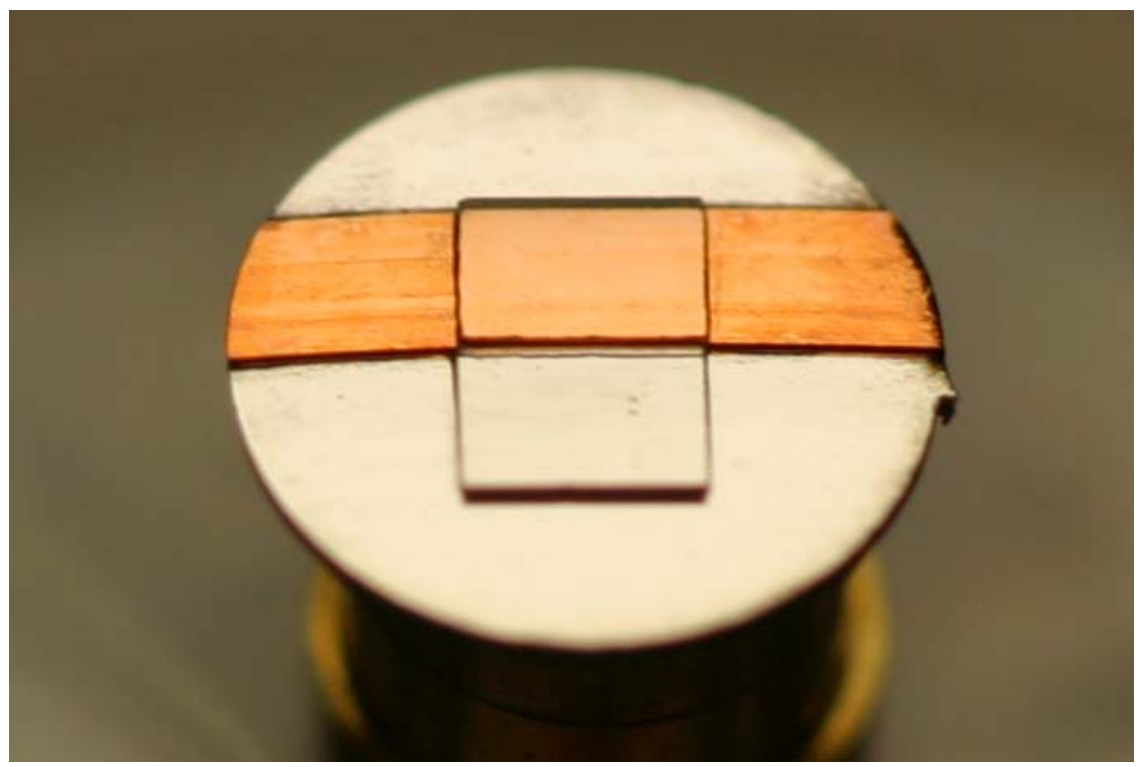

Figure 77. Target ICH6-REX1 after bonding the windows but before bonding the support ring

Figure 78 depicts the completed $\mathrm{Cu}$ EOS target after bonding it to a gold support ring. This target met all of the fabrication and metrology specifications.

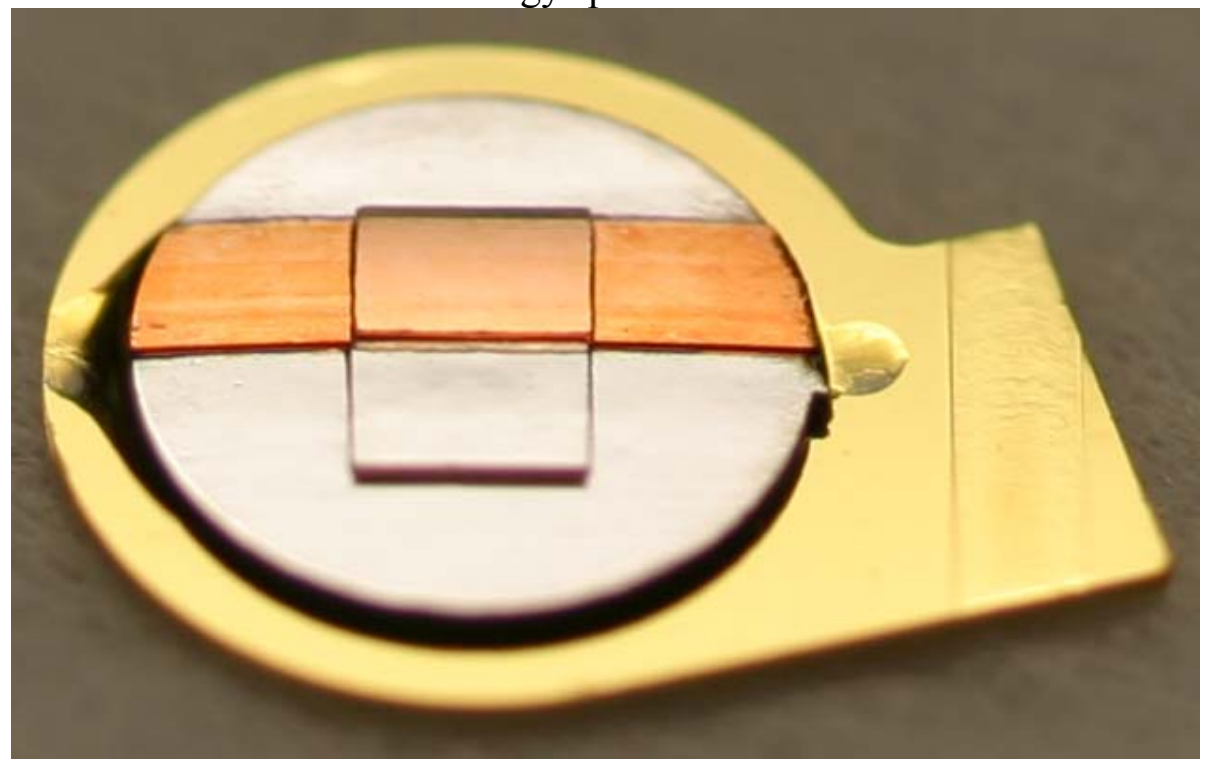

Figure 78. Complete Cu EOS target

\section{CONCLUSION}

The $\mathrm{Cu}$ Equation of State laser target was successfully fabricated and met all of the manufacturing and metrology specifications. The target consisted of planar layers of copper, aluminum, iodine-doped polystyrene, and pure polystyrene. The required thickness uniformities of the various layers of the target ranged from $\pm 0.1 \mu \mathrm{m}$ to $\pm 0.3 \mu \mathrm{m}$, and they had to be measured with this same level of accuracy. To meet the requirements for the interface between the aluminum and the copper, a sputter-seeded electroplating process was developed to deposit copper onto the aluminum. The thickness uniformity requirements for the various layers were obtained by fabricating the targets on a $100 \mathrm{~mm}$ diameter aluminum disk that was held on the 
diamond turning machine using carefully designed vacuum chucks. By performing assembly and metrology directly on the diamond turning machine, the workpiece could remain in the vacuum chuck throughout the manufacturing process. Therefore, the reference surfaces required for the fabrication and metrology of the targets could be maintained, and the targets could be manufactured to meet all of the specifications.

\section{RECOMMENDATIONS}

There are a number of ways in which the process developed in this effort could be improved. The chuck that held the $100 \mathrm{~mm} \mathrm{Al}$ disk on the diamond turning machine while it was being machined to a thickness of $62 \mu \mathrm{m}$ created features on the $\mathrm{Cu}$ sample. The chuck contained a recess of width $1 \mathrm{~mm}$ and depth $43 \mu \mathrm{m}$ to accommodate the band of $\mathrm{Cu}$ on the 100 $\mathrm{mm} \mathrm{Al}$ disk. The bottom surface of this recess contained several circumferential vacuum grooves that were connected to the other grooves on the chuck by eight radial grooves. In the vicinity of these radial grooves, the form of the vacuum grooves became imprinted into the $\mathrm{Cu}$. Fortunately, even with these features imprinted in the $\mathrm{Cu}$, the targets met the surface finish specification. However, in the future, steps should be taken to prevent any damage occurring to the $\mathrm{Cu}$. It may be possible to eliminate the circumferential vacuum grooves and use a simple flat surface on the bottom of the $1 \mathrm{~mm} \times 43 \mu \mathrm{m}$ recess in the chuck. It might also be preferable to use a material in these vacuum grooves that will not cause chemical or mechanical damage to the $\mathrm{Cu}$. Furthermore, the ICH and $\mathrm{CH}$ pads should not be bonded directly over the radial grooves of the vacuum chuck.

After the $100 \mathrm{~mm} \mathrm{Al} \mathrm{disk} \mathrm{was} \mathrm{machined} \mathrm{to} \mathrm{a} \mathrm{thickness} \mathrm{of} 62 \mu \mathrm{m}$ and was removed from the vacuum chuck, the surface was covered with a viscous substance. This substance may have been cutting fluid that had been pulled beneath the workpiece by the vacuum. To prevent any fluid from penetrating beneath the workpiece, its perimeter could be bonded to the chuck using urethane or viscous vacuum grease.

One of the biggest obstacles to achieving thin, uniform layers of adhesive between the components of the target was debris on the surfaces. Chips generated in the machining processes, dust, and debris from containers used to store components had a tendency to stick to the ICH pads, $\mathrm{CH}$ pads, and quartz windows. It was extremely important to clean all parts carefully before assembling them. All parts must be stored in clean containers that do not generate particles. For example, glass containers that have been carefully cleaned work well. Plastic bags should never be used to store components. To eliminate the possibility of dust settling onto components, assembly must be performed in a clean room. All parts must be carefully examined with a microscope to ensure their cleanliness.

Great care must be exercised when using alcohol to clean parts. In many cases, alcohol can be used to clean parts thoroughly. However, alcohol can dissolve certain materials and weld particles to the surface, making it even more difficult to remove them. Therefore, before using alcohol to remove particles from a surface, it must first be tested to determine its effectiveness.

When fabricating the ICH and $\mathrm{CH}$ pads that formed the pre-heat shield and ablator, the diamond parting tool used to machine the back surface was not long enough to reach the center of the $6 \mathrm{~mm}$ diameter pads. Therefore, a HSS parting tool was used to machine the center section of the back surface, which created a $4 \mathrm{~mm}$ rough area on each pad. When measuring the thickness of the pads using the LVDT, the rough area had to be cantilevered over a hole in the chuck, which caused the pads to deflect and led to an error of up to $1 \mu \mathrm{m}$ in the measured thickness. To avoid this problem, the back surface of each pad must be machined using a 
diamond parting tool that is long enough to reach the center of the pad. If the entire back surface of the pad is diamond turned, then the entire back surface of the pad could be supported by a vacuum chuck while its thickness is being measured.

StyCast epoxy was used to bond the $\mathrm{CH}$ pads on top of the ICH pre-heat shields. This epoxy must cure for approximately 8 hours before the assembly cone can be removed from the $\mathrm{CH}$ pad. Therefore, only a single $\mathrm{CH}$ pad could be bonded each day. Hardman Green epoxy could be used in place of the StyCast to bond the $\mathrm{CH}$ pads. Hardman Green epoxy requires only about 2 hours before the assembly cone can be removed from the $\mathrm{CH}$ pad, but it is slightly more viscous and produces bonds that are slightly thicker. The time required to apply the pre-heat shields and ablators could be reduced considerably if doped-epoxies were developed that met the material requirements for these components. The components could then be created by applying the epoxy, letting it cure, and then diamond turning it to the required thickness.

Future Equation of State targets may require a sample material than cannot be electroplated. For these targets, it may be necessary to sputter the sample material to the required thickness. Sputtering techniques must be developed to ensure that acceptable stresses are created in the sputtered material. Recall that in this study, the stresses created by sputtering $30 \mu \mathrm{m}$ of $\mathrm{Cu}$ onto an $\mathrm{Al}$ substrate were not adequately studied. Therefore, it is not known if this process could have been used to fabricate targets.

\section{ACKNOWLEDGEMENTS}

This work would not have been possible without the skill and expertise of Carlos Castro, who performed the vast majority of the work in this effort. Many of the manufacturing and metrology details that made this effort a success originated with Carlos. His machining skills, knowledge of vacuum chuck design, and experience with precision metrology equipment made this work possible. The success of this effort is due largely to his hard work.

A number of other people also made contributions. Ron Foreman and Johann Lotscher contributed greatly to this project. They designed and executed the processes for sputtering the seed layer of $\mathrm{Cu}$ onto the Al. Thanks to their expertise, an acceptable interface between the $\mathrm{Cu}$ and the Al was achieved. Rudy Robles performed the electroplating, assisted with the identification of proper plating parameters, and helped design the hardmask used for electroplating. His efforts are also greatly appreciated. Steve Strodtbeck helped with some of the machining and assembly. Brian Kelly designed the laser machining process and performed all of the cutting with the excimer laser. Joe Satcher, Stuart Gammon, and Bob Reibold provided materials, identified proper solvents for removing cutting fluids from the parts, and provided general knowledge that was useful when designing the manufacturing process for the targets. Robin Miles applied the lithographic masks. Alan Jankowski performed some of the $\mathrm{Cu}$ deposition processes during the preliminary tests. Kuang Jen $\mathrm{Wu}$ performed SIMS analyses during the development of a cleaning process. Alex Hamza assisted with issues related to materials science. Marcia Kellam assisted with the quartz windows and measured the window thickness. Lee Griffith and Jeff Kass provided guidance and managerial support for this effort.

This work was performed under the U.S. Department of Energy by the University of California, Lawrence Livermore National Laboratory under Contract No. W-7405-Eng-48. 


\section{Appendix A - Target Specifications}

*thickness uniformity spec is written so that $+/$ - means TOTAL wedge (from one side of piece to other) can be twice number quoted ${ }^{* *}$ Will measure 6 locations on the $100 \mathrm{~mm}$ disk and interpolate to obtain values for the targets locations

[Numbers in brackets are for reference only; they are not acceptance criteria. The metrology of the feature is not critical to Physics.] It is understood btwn Physics \& Target Fab that if the uncertainty in measuring the feature is comparable to the requested dimension of the feature, then the metrology will not prove if the desired $\mathrm{mfg}$ spec has been met.

\section{Physics requirements for EOS targets}

\begin{tabular}{|c|c|c|}
\hline Feature & $\begin{array}{l}\text { Specification } \\
\text { [microns] }\end{array}$ & $\begin{array}{c}\text { Actual value } \\
\text { [microns] }\end{array}$ \\
\hline \multicolumn{3}{|l|}{ Components } \\
\hline \multicolumn{3}{|l|}{ Baseplate (AI 1100) } \\
\hline Nominal thickness of bare baseplate & $62+/-2.0$ & 63.0 \\
\hline Measurement uncertainty & 1.0 & $<0.2$ \\
\hline Al step btwn sample \& bare baseplate & $<1.0$ & 0.02 \\
\hline Measurement uncertainty & 0.2 & 0.05 \\
\hline Thickness uniformity of bare baseplate ${ }^{*}$ & $+/-0.25$ & Satisfied \\
\hline Acceptance Criterion & see note & 0.15 \\
\hline Thickness uniformity of Al under sample* & $+/-0.25$ & Satisfied \\
\hline Acceptance Criterion & see note & 0.15 \\
\hline \multirow{2}{*}{ Surface roughness $(\mathrm{Ra}=$ average $)$} & $\begin{array}{c}\mathrm{Ra}<25 \mathrm{~nm} \text { on } \\
\text { VISAR side }\end{array}$ & $\mathrm{Ra}=13 \mathrm{~nm}$ \\
\hline & $\begin{array}{c}\mathrm{Ra}<100 \mathrm{~nm} \text { on } \\
\mathrm{ICH} \text { side }\end{array}$ & $\mathrm{Ra}=15 \mathrm{~nm}$ \\
\hline \multicolumn{3}{|l|}{ Sample (Cu OFHC) for Cu targets only } \\
\hline Nominal thickness & $43+1-2.0$ & 43.0 \\
\hline Measurement uncertainty & 0.3 & 0.07 \\
\hline Thickness uniformity* & $+/-0.1$ & Satisfied \\
\hline Acceptance Criterion & see note & 0.20 \\
\hline Surface roughness ( $\mathrm{Ra}=$ average) & $\mathrm{Ra}<25 \mathrm{~nm}$ & $\mathrm{Ra}=12 \mathrm{~nm}$ \\
\hline Bulk density, \% TMD & $\begin{array}{c}>96 \%, \text { if } \\
\text { homogeneous }\end{array}$ & Satisfied \\
\hline Measurement uncertainty, $\%$ & 0.5 & Satisfied \\
\hline \multicolumn{3}{|l|}{ Preheat Shield (6.25 at\% I-CH)+adhesive } \\
\hline Nominal thickness (ICH+adhesive) & $102+/-3$ & 103.6 \\
\hline Measurement uncertainty & 2.5 & 0.05 \\
\hline Thickness uniformity (ICH+adhesive) $)^{*}$ & {$[+/-0.25]$} & $<0.05$ \\
\hline Measurement uncertainty & {$[0.25]$} & 0.05 \\
\hline Surface roughness (peak-valley) & $\mathrm{Rt}<600 \mathrm{~nm}$ & $\mathrm{Rt}=80 \mathrm{~nm}$ \\
\hline \multicolumn{3}{|l|}{ Ablator $(\mathrm{CH})+$ adhesive } \\
\hline Nominal thickness (CH+adhesive) & $32.5+/-2.5$ & 32.8 \\
\hline Measurement uncertainty & [2.5] & 0.07 \\
\hline $\begin{array}{l}\text { Thickness uniformity of } \\
\text { (glue }+\mathrm{ICH}+\text { glue }+\mathrm{CH}) \text { subassembly * }\end{array}$ & {$[+/-0.3]$} & $<0.07$ \\
\hline Measurement uncertainty & {$[0.3]$} & 0.07 \\
\hline Surface roughness (peak-valley) & $\mathrm{Rt}<600 \mathrm{~nm}$ & $\mathrm{Rt}=80 \mathrm{~nm}$ \\
\hline \multicolumn{3}{|l|}{ Window (alpha quartz) } \\
\hline Nominal thickness & $100+/-25$ & 102 \\
\hline Measurement uncertainty & 1.0 & 1 \\
\hline Thickness uniformity* & {$[+/-0.25]$} & $<1$ \\
\hline Acceptance Criterion & see note & -- \\
\hline Flatness & $+/-0.25$ & $<0.12$ \\
\hline A.R. coating for reflective $0.5-1.5 \%$ at & $659 \mathrm{~nm}$ & \\
\hline Al coating thickness, angstroms & 0 & \\
\hline
\end{tabular}

Final Specs Set on 12/16/04

Method for verifying part is acceptable. Notes on acceptance criteria are indicated in blue

Cap probe on DTM will measure from chuck face to baseplate face **

LVDT on DTM will measure step **

Cap probe on DTM will measure seating of $100 \mathrm{~mm}$ disk on vacuum chuck **

The runout of the $100 \mathrm{~mm}$ diameter disk must be $<200$ nm

Cap probe on DTM will measure seating of $100 \mathrm{~mm}$ disk on vacuum chuck **

Predicted max $\Delta$ of $1 \mathrm{~mm}$ wide band of sample matl with 1 atm on vac chuck is $94 \mathrm{~nm}$. Acceptance criterion is: the runout of the $100 \mathrm{~mm}$ diameter disk must be $<200 \mathrm{~nm}$ with the sample side of the disk against the vacuum chuck.

Wyko, PSI mode - Measure directly on VISAR side ** Measure a witness area on the $\mathrm{ICH}$ side.

\section{Wyko VSI mode **}

Cap probe on DTM will measure seating of $100 \mathrm{~mm}$ disk on vacuum chuck **

The runout of the $100 \mathrm{~mm}$ diameter disk must be $<200$ nm when machining $\mathrm{Cu}$

Wyko, PSI mode. Can only measure window side **

Rutherford Back Scattering (RBS)

LVDT on DTM will measure 4 points on machined ICH, 4 pts on baseplate

LVDT on DTM will measure 4 points on machined ICH, 4 pts on baseplate

Measure one witness sample with Wyko PSI mode

LVDT on DTM will measure 4 points on surface of final machined $\mathrm{CH}, 4$ pts on baseplate

LVDT on DTM will measure 4 points on surface of final machined $\mathrm{CH}, 4$ pts on baseplate

Wyko, PSI mode. Will measure one part only.

ATMM, SEM, measuring mic, Wyko, or laser micrometer (Target Fab will choose method)

ATMM, SEM, measuring mic, Wyko, or laser micrometer (Target Fab will choose method)

Target Fab will choose the method and will provide an estimate of the uncertainty of the measurement. No method has yet been proven to have an uncertainty of $0.25 \mu \mathrm{m}$ or better.

Wyko, PSI mode 


\section{Appendix A - Target Specifications}

\begin{tabular}{|c|c|c|}
\hline Feature & $\begin{array}{c}\text { Specification } \\
\text { [microns] }\end{array}$ & $\begin{array}{c}\text { Actual value } \\
\text { [microns] }\end{array}$ \\
\hline \multicolumn{3}{|l|}{ Assembly } \\
\hline \multicolumn{3}{|l|}{ Baseplate-Sample joint } \\
\hline Thickness & $<0.5$ & $<0.1$ \\
\hline Thickness uniformity* & $+/-0.1$ & $<0.1$ \\
\hline Measurement uncertainty & 0.1 & $<0.1$ \\
\hline
\end{tabular}

Method for verifying part is acceptable. Notes on acceptance criteria are indicated in blue

\begin{tabular}{|l|c|c|}
\hline Baseplate-Preheat Shield joint & {$[<3.0]$} & $\leq 2.80$ \\
\hline Thickness & {$[+/-1.5]$} & $\leq 1.40$ \\
\hline Thickness uniformity* & {$[3.0]$ see note } & $+0.05-1.0$ \\
\hline Measurement uncertainty & &
\end{tabular}

Cu will be deposited onto the Al baseplate with a 20 $\mathrm{nm}$ adhesion layer of Ti. There is no need to metrologize the interface.

\begin{tabular}{|l|c|c|}
\hline Preheat Shield-Ablator joint & {$[<3.0]$} & $\leq 2.36$ \\
\hline Thickness & {$[+/-1.5]$} & $\leq 1.18$ \\
\hline Thickness uniformity* & {$[3.0]$ see note } & $+0.05-1.0$ \\
\hline Measurement uncertainty & & \\
\hline
\end{tabular}

Measure ICH pad before bonding, measure "ICH+adhesive" with LVDT after bonding. Metrology data will consist of ICH thickness at 4 pts with uncertainty of $\pm 1-2 \mu \mathrm{m}$, and "ICH+adhesive" thickness at 4 pts with uncertainty of $\pm 0.1 \mu \mathrm{m}$. Acceptance criterion is: (nominal measured "ICH+adhesive" thickness) - (nominal measured ICH thickness) $<5 \mu \mathrm{m}$

Subassembly (w/o windows)

\begin{tabular}{|l|c|c|}
\hline Thickness uniformity* & $+/-0.3$ & Satisfied \\
\hline Acceptance Criterion & see note & 0.15 \\
\hline Flatness & 20 & $<3$ \\
\hline
\end{tabular}

Measure $\mathrm{CH}$ pad before bonding, measure "CH+adhesive" with LVDT after bonding. Metrology data will consist of $\mathrm{CH}$ thickness at 4 pts with uncertainty of $\pm 1-2 \mu \mathrm{m}$, and " $\mathrm{CH}+a d h e s i v e "$ thickness at 4 pts with uncertainty of $\pm 0.1 \mu \mathrm{m}$. Acceptance criterion is: (nominal measured " $\mathrm{CH}+a d h e s i v e "$ thickness) - (nominal measured CH thickness) $<5 \mu \mathrm{m}$

Baseplate-Wndw \& Sample-Wndw joint

\begin{tabular}{|l|c|c|}
\hline Thickness & {$[<5.0]$} & 2 \\
\hline Thickness uniformity* & {$[+/-1.5]$} & 1 \\
\hline Measurement uncertainty & {$[1.5]$} & $<1.5$ \\
\hline
\end{tabular}

LVDT on DTM will measure 4 points on surface of final machined $\mathrm{CH}, 4$ pts on baseplate

The runout of the $100 \mathrm{~mm}$ diameter disk must be $<200$ $\mathrm{nm}$

Wyko, VSI mode

Measure "window+adhesive" with Wyko VSI after bonding. Metrology data will consist of aforementioned window metrology, and "window+adhesive" thickness at 4 pts with uncertainty of $\pm 0.2 \mu \mathrm{m}$. Acceptance criterion is: (nominal measured "window+adhesive" thickness) - (nominal measured window thickness) $<6 \mu \mathrm{m}$ 


\section{Appendix B - Data from cleaning tests}

\section{Process Sheet for Diamond Turned 1" Al Disk - Sample \#3}

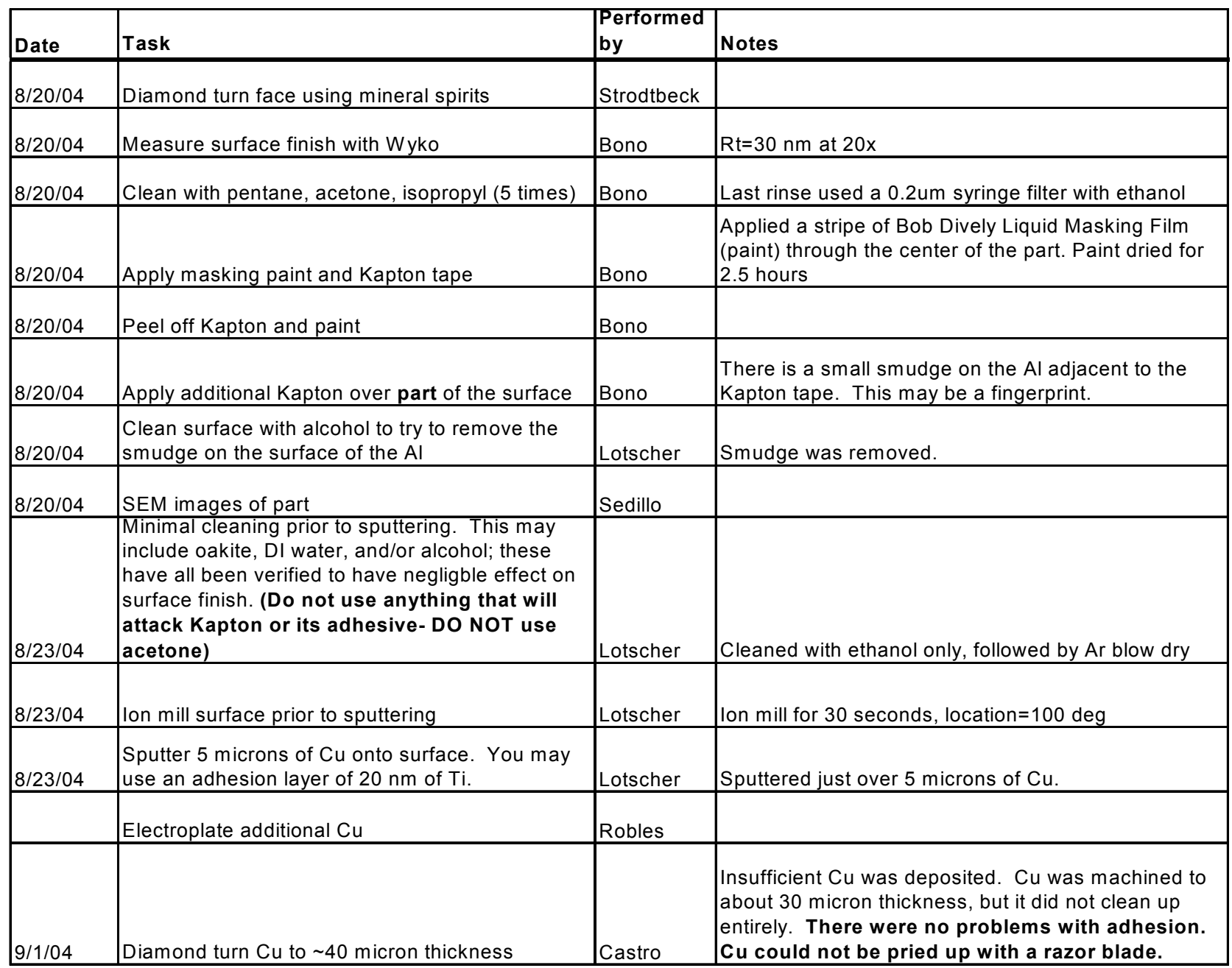

FINISHED

We later discovered on 9/14/04 that ethanol created a white debris when applied to a masked 4" disk with $1 \mathrm{~mm}$ of exposed Al. 
The following process was used to examine Sample \#3.

\section{Examining residue left by paint, and adhesion of sputtered $\mathrm{Cu}$ to masked diamond turned Al 1100}

Please contact Matt Bono 2-5883 with any questions.

The objectives are 1) to determine how much residue is left after peeling off masking paint 2) to determine how well sputtered $\mathrm{Cu}$ with an adhesion layer of $10-20 \mathrm{~nm}$ of $\mathrm{Ti}$ adheres to a diamond turned disk of $\mathrm{Al} 1100$ after it has been masked with paint/Kapton

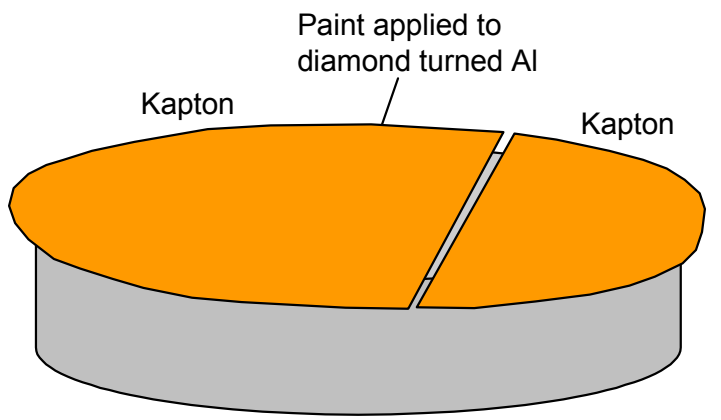

The sample has been diamond turned to $\mathrm{Rt}=30$ $40 \mathrm{~nm}, \mathrm{Rq}=3-7 \mathrm{~nm}$.

Kapton tape has been placed in two locations on the diamond turned surface.

(The sample contains some isolated scratches, and we know their size and locations.)

- Peel off the larger piece of Kapton, taking the paint off in the process. Leave the other piece of Kapton in place. Be careful not to scratch or otherwise damage the diamond turned surface.

- Examine the central portions of the two areas of interest with an SEM to determine how much residue was left by the paint and by the Kapton adhesive. Please save these SEM images for us.

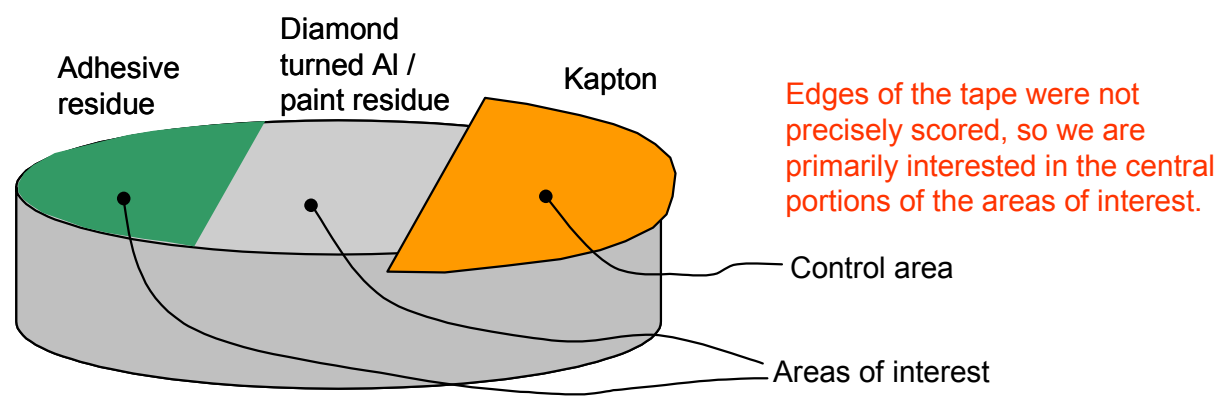

- Perform the normal cleaning procedure used for sputtering (it may include: aqueous detergent wash, DI and/or alcohol rinse, pre-sputter, ion milling, sputtering of an adhesion layer of $\mathrm{Ti}$, etc.) Use the procedure you would normally use to get good adhesion when sputtering $\mathrm{Cu}$ onto $\mathrm{Al}$ in the presence of Kapton tape.

- Repeat the SEM measurements on each of the areas of interest and save the images

- Sputter $5 \mu \mathrm{m}$ of $\mathrm{Cu}$ onto the disk

- Return the sputtered sample and SEM images to Matt Bono (2-5883).

- Please also provide details of the process used to clean / ion mill / pre-sputter the sample. 


\section{Appendix B - Data from cleaning tests}
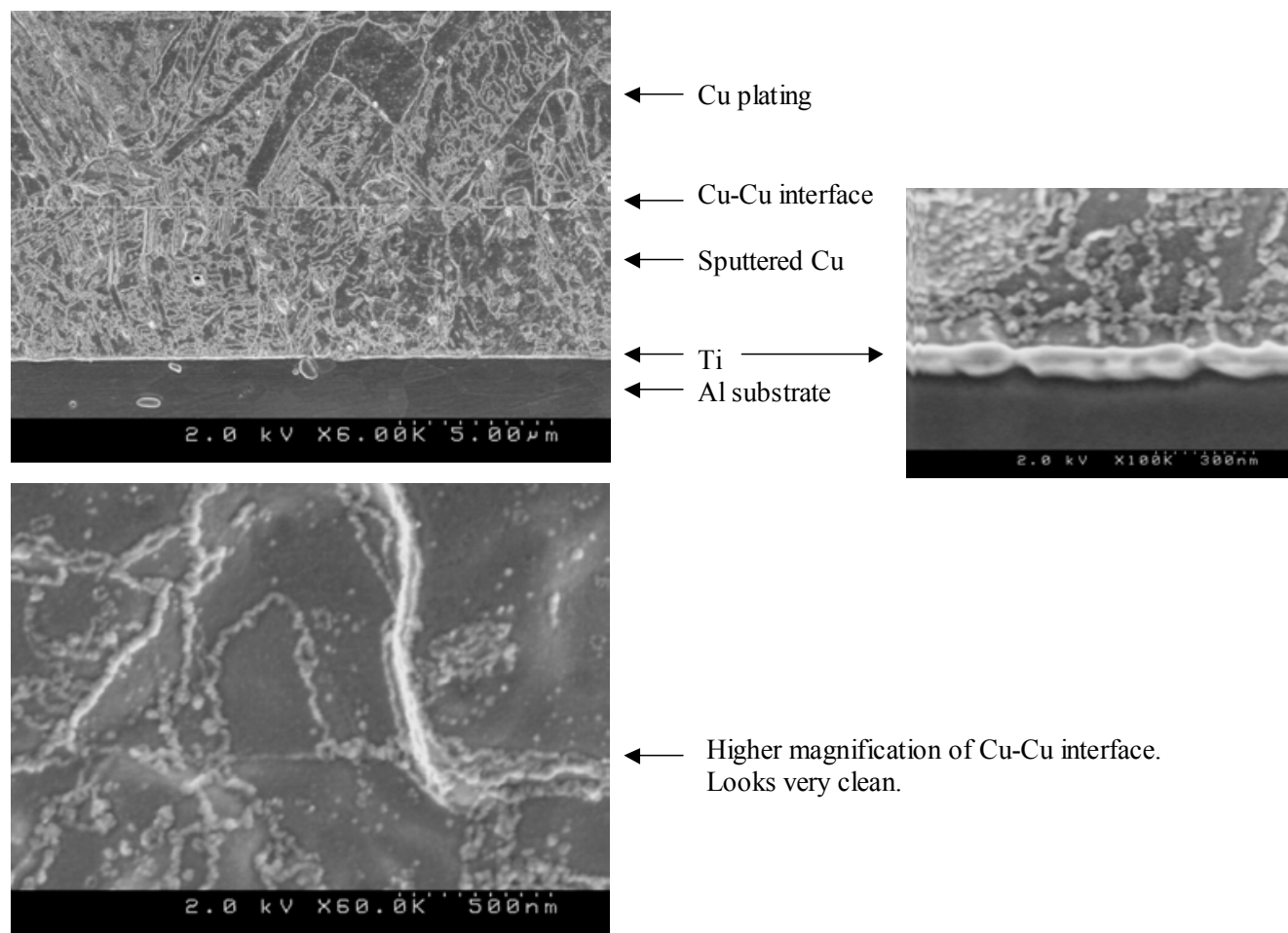

$\longleftarrow$ Higher magnification of $\mathrm{Cu}-\mathrm{Cu}$ interface. Looks very clean.

SEM images of polished Sample \#3
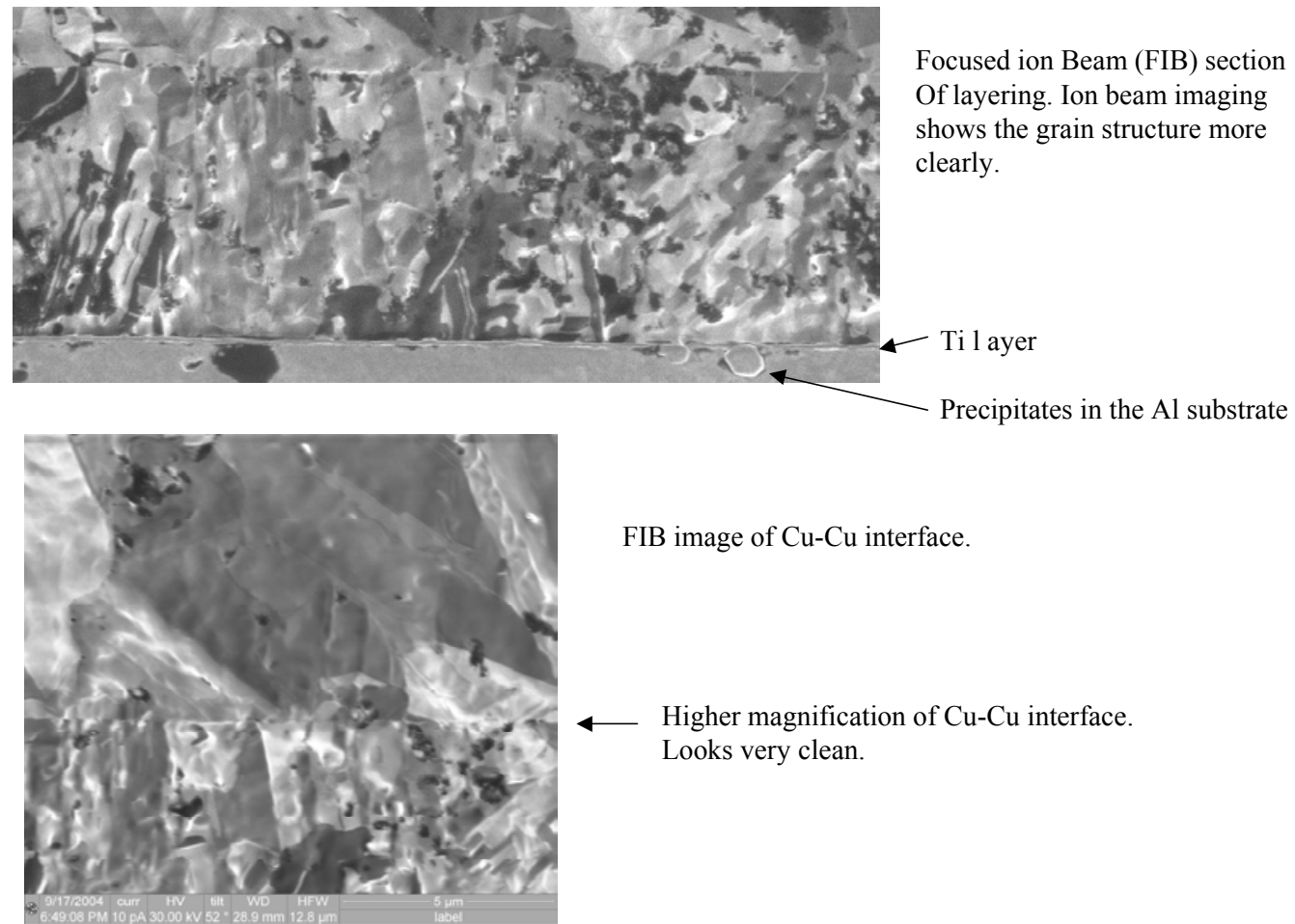

FIB image of $\mathrm{Cu}-\mathrm{Cu}$ interface.

SEM images of FIB machined Sample \#3

Higher magnification of $\mathrm{Cu}-\mathrm{Cu}$ interface.

Looks very clean. 
Appendix B - Data from cleaning tests

\section{Process Sheet for Diamond Turned 1" Al Disk - Sample \#4}

\begin{tabular}{|c|c|c|c|}
\hline Date & Task & $\begin{array}{l}\text { Performed } \\
\text { by }\end{array}$ & Notes \\
\hline $8 / 19 / 04$ & Diamond turn face using mineral spirits & Castro & \\
\hline $8 / 19 / 04$ & Measure surface finish with Wyko & Bono & $\mathrm{Rt}=30 \mathrm{~nm}$ at $20 \mathrm{x}, 50 \mathrm{~nm}$ at $10 \mathrm{x}$ \\
\hline $8 / 19 / 04$ & Clean with pentane, acetone, isopropyl (3 times) & Bono & \\
\hline $8 / 19 / 04$ & Measure surface finish with Wyko & Bono & Cleaning did not affect surface finish \\
\hline $8 / 20 / 04$ & $\begin{array}{l}\text { SIMS analysis of surface - focus on the inner portion, } \\
\text { because the edges may be contaminated from Latex } \\
\text { gloves }\end{array}$ & $\begin{array}{l}\text { Kuang Jen } \\
\text { Wu }\end{array}$ & $\begin{array}{l}\text { Identified traces of hydrocarbons on the surface, } \\
\text { which may result from outgassing of box used to } \\
\text { store part. Overall, the surface looked fairly clean. }\end{array}$ \\
\hline $8 / 20 / 04$ & Measure surface finish with Wyko & Bono & $\begin{array}{l}\text { Rt }=30 \mathrm{~nm} \text { at } 20 \mathrm{x}, \text { SIMS does not appear to have } \\
\text { affected surface finish }\end{array}$ \\
\hline $8 / 20 / 04$ & Apply masking paint and Kapton tape & Bono & $\begin{array}{l}\text { Applied a stripe of Bob Dively Liquid Masking Film } \\
\text { (paint) through the center of the part }\end{array}$ \\
\hline $8 / 23 / 04$ & Peel off Kapton and paint & Bono & $\begin{array}{l}\text { Held part using lens paper and nitrile clean room } \\
\text { gloves while peeling paint }\end{array}$ \\
\hline $8 / 24 / 04$ & Alcohol rinse & & \\
\hline $8 / 24 / 04$ & SIMS analysis of surface & $\mathrm{Wu}$ & $\begin{array}{l}\text { Did not see any peaks representing the signature of } \\
\text { either Mineral Spirits or Masking Paint. }\end{array}$ \\
\hline $\mathbf{x}$ & Reclean parts, if necessary & Bono & \\
\hline $9 / 2 / 04$ & Apply additional Kapton over part of the surface & Bono & $\begin{array}{l}\text { Put two pieces of Kapton on the surface, leaving a } \\
\text { stripe of exposed Al through the center of the part }\end{array}$ \\
\hline $\mathbf{x}$ & Measure surface finish with Wyko & Bono & \\
\hline 9/13/04 & $\begin{array}{l}\text { Minimal cleaning prior to sputtering. Use only } \\
\text { ethanol. (Do not use anything that will attack } \\
\text { Kapton or its adhesive- DO NOT use acetone, DO } \\
\text { NOT use methanol) }\end{array}$ & Lotscher & Part was blown with Ar gas \\
\hline $9 / 13 / 04$ & Ion mill surface prior to sputtering & Lotscher & $\begin{array}{l}\text { Part was ion milled for } 30 \text { seconds. Part was then } \\
\text { stored in a Fluoroware container and taken to Kuang } \\
\text { Jen Wu on } 9 / 14 / 04 \text {. }\end{array}$ \\
\hline 9/17/04? & SIMS analysis of surface & $\mathrm{Wu}$ & $\begin{array}{l}\text { There was no evidence of Kapton redeposited on the } \\
\text { surface. However, there were several new } \\
\text { substances that could have been residue from the } \\
\text { tape that was redeposited on the suface. }\end{array}$ \\
\hline $\mathbf{x}$ & Sputter 5 microns of Cu onto surface & Foreman & \\
\hline $\mathbf{x}$ & Electroplate additional $\mathrm{Cu}$ & Robles & \\
\hline $\mathbf{x}$ & Diamond turn $\mathrm{Cu}$ to $\sim 43$ micron thickness & Castro & \\
\hline
\end{tabular}

FINISHED

The samples we run did not show additional Kapton deposit on the A1" Al sample. The SIMS spectra are fairly comparable to those run previously in the low mass region $(\mathrm{m} / \mathrm{z}<100)$.

However, there are quite a number of additional peaks showed up at the mass range between $\sim 150-500$, the most pronounced peak is at $\mathrm{m} / \mathrm{z}=149$. Several significant peaks at high mass region suggest phthalate-related compounds. There might be other compounds present at the surface as well, albeit none of those peaks matched with any of the known compounds listed in our TOFSIMS database. Judging by the intensities of these high mass peaks, these compounds are in relatively low surface concentration.

It is possible that these phthalate-related compounds were released from the tapes, which used to covered the portion disk surface.

\section{We later discovered on $9 / \mathbf{1 4} / \mathbf{0 4}$ that ethanol created a white debris when applied to a} masked 4" disk with 1mm of exposed Al. 


\section{Appendix B - Data from cleaning tests}

\section{Process Sheet for Diamond Turned 1" Al Disk - Sample \#5}

\begin{tabular}{|c|c|c|c|}
\hline Date & Task & $\begin{array}{l}\text { Performed } \\
\text { by }\end{array}$ & Notes \\
\hline $8 / 19 / 04$ & Diamond turn face using mineral spirits & Castro & \\
\hline $8 / 19 / 04$ & Measure surface finish with Wyko & Bono & $\mathrm{Rt}=30 \mathrm{~nm}$ at $20 \mathrm{x}, 50 \mathrm{~nm}$ at $10 \mathrm{x}$ \\
\hline $8 / 19 / 04$ & Clean with acetone and isopropyl (3 times) & Bono & $\begin{array}{l}\text { The first of the } 3 \text { rinses included pentane. The last } \\
\text { two did not. }\end{array}$ \\
\hline $8 / 19 / 04$ & Measure surface finish with Wyko & Bono & Cleaning did not affect surface finish \\
\hline $8 / 20 / 04$ & $\begin{array}{l}\text { SIMS analysis of surface - focus on the inner portion, } \\
\text { because the edges may be contaminated from Latex } \\
\text { gloves }\end{array}$ & $\begin{array}{l}\text { Kuang Jen } \\
\text { Wu }\end{array}$ & $\begin{array}{l}\text { Identified traces of hydrocarbons on the surface, } \\
\text { which may result from outgassing of box used to } \\
\text { store part. Overall, the surface looked fairly clean. }\end{array}$ \\
\hline $8 / 20 / 04$ & Measure surface finish with Wyko & Bono & $\begin{array}{l}\mathrm{Rt}=30 \mathrm{~nm} \text { at } 20 \mathrm{x}, \text { SIMS does not appear to have } \\
\text { affected surface finish }\end{array}$ \\
\hline $8 / 20 / 04$ & Apply masking paint and Kapton tape & Bono & $\begin{array}{l}\text { Applied a stripe of Bob Dively Liquid Masking Film } \\
\text { (paint) through the center of the part }\end{array}$ \\
\hline $8 / 23 / 04$ & Peel off Kapton and paint & Bono & $\begin{array}{l}\text { Held part using lens paper and nitrile clean room } \\
\text { gloves while peeling paint }\end{array}$ \\
\hline & Alcohol rinse & Wu & \\
\hline $9 / 3 / 04$ & SIMS analysis of surface & $\mathrm{Wu}$ & $\begin{array}{l}\text { Did not see any peaks representing the signature } \\
\text { of either Mineral Spirits or Masking Paint. }\end{array}$ \\
\hline Finished & Apply additional Kapton over part of the surface & Bono & $\begin{array}{l}\text { The remaining steps have already been performed } \\
\text { on Sample } 3\end{array}$ \\
\hline $\mathbf{X}$ & Measure surface finish with Wyko & Bono & \\
\hline $\mathbf{X}$ & $\begin{array}{l}\text { Minimal cleaning prior to sputtering. Use only } \\
\text { ethanol. (Do not use anything that will attack } \\
\text { Kapton or its adhesive- DO NOT use acetone, DO } \\
\text { NOT use methanol) }\end{array}$ & Foreman & \\
\hline $\mathbf{X}$ & $\begin{array}{l}\text { Ion mill surface prior to sputtering. } \\
\text { This sample should NOT be ion milled }\end{array}$ & & \\
\hline $\mathbf{X}$ & Sputter 5 microns of $\mathrm{Cu}$ onto surface & Foreman & \\
\hline $\mathbf{X}$ & Electroplate additional $\mathrm{Cu}$ & Robles & \\
\hline $\mathbf{X}$ & Diamond turn $\mathrm{Cu}$ to $\sim 43$ micron thickness & Castro & \\
\hline
\end{tabular}

We later discovered on 9/14/04 that ethanol created a white debris when applied to a masked 4" disk with $1 \mathrm{~mm}$ of exposed Al. 
Appendix B - Data from cleaning tests

\section{Process Sheet for Diamond Turned 1" Al Disk - Sample \#1c}

\begin{tabular}{|c|c|c|c|}
\hline Date & Task & $\begin{array}{l}\text { Performed } \\
\text { by }\end{array}$ & Notes \\
\hline $8 / 27 / 04$ & Diamond turn face using mineral spirits & Castro & $\begin{array}{l}\text { Removed at least } 50 \text { microns of material. Part was } \\
\text { drag-wiped after machining. }\end{array}$ \\
\hline $8 / 31 / 04$ & Measure surface finish with Wyko & Bono & $\mathrm{Rt}=30 \mathrm{~nm}$ at $20 \times \mathrm{PSI}$ \\
\hline $8 / 31 / 04$ & $\begin{array}{l}\text { Clean with pentane, acetone, ethanol ( } 3 \text { times) } \\
\text { Store Pentane in glass container. }\end{array}$ & Bono & $\begin{array}{l}\text { Pentane was squirted onto part using a glass eye- } \\
\text { dropper pipette }\end{array}$ \\
\hline $8 / 31 / 04$ & Clean with oakite and rinse with DI water and ethanol & Bono & $\begin{array}{l}\text { Oakite swirl for } 30 \text { seconds in a glass dish. Rinsed } 6 \\
\text { times with DI water. Rinsed with ethanol. }\end{array}$ \\
\hline $8 / 31 / 04$ & Measure surface finish with Wyko & Bono & $\begin{array}{l}\text { Rt }=40 \mathrm{~nm} \text { at } 20 x \text { PSI. Cleaning with Oakite appears } \\
\text { to have affected Rt by at most } 10 \mathrm{~nm} \text {. }\end{array}$ \\
\hline $8 / 31 / 04$ & Apply masking paint and Kapton tape & Bono & $\begin{array}{l}\text { Applied a stripe of Bob Dively Liquid Masking Film } \\
\text { (paint) through the center of the part }\end{array}$ \\
\hline $9 / 1 / 04$ & Peel off Kapton and paint & Bono & $\begin{array}{l}\text { Held part using lens paper and nitrile clean room } \\
\text { gloves while peeling paint }\end{array}$ \\
\hline $9 / 1 / 04$ & Apply additional Kapton over part of the surface & Bono & $\begin{array}{l}\text { Put two pieces of Kapton on the surface, leaving a } \\
\text { stripe of exposed Al through the center of the part }\end{array}$ \\
\hline $9 / 15 / 04$ & $\begin{array}{l}\text { Minimal cleaning prior to E-Beam PVD. This may } \\
\text { include an aqueous detergent and/or ETHANOL. (Do } \\
\text { not use anything that will attack Kapton or its } \\
\text { adhesive - DO NOT use acetone or Methanol) }\end{array}$ & Jankowski & Alan did not provide the deposition parameters. \\
\hline $9 / 15 / 04$ & Deposit 60-100 microns of Cu by E-Beam PVD & Jankowski & $\begin{array}{l}\text { Deposited } \sim 100 \text { microns of } \mathrm{Cu} \text {. NEED DEPOSITION } \\
\text { PARAMETERS }\end{array}$ \\
\hline $9 / 16 / 04$ & Diamond turn $\mathrm{Cu}$ to $\sim 43$ micron thickness & Castro & $\begin{array}{l}\text { The Cu near the warped Kapton could be flaked } \\
\text { from the surface. Elsewhere on the disk, the } \mathrm{Cu} \\
\text { could not be pried up with a scalpel. }\end{array}$ \\
\hline
\end{tabular}

Finished

We discovered on 9/14/04 that ethanol created a white debris when applied to a masked 4 " disk with $1 \mathrm{~mm}$ of exposed Al. 


\section{Appendix B - Data from cleaning tests}

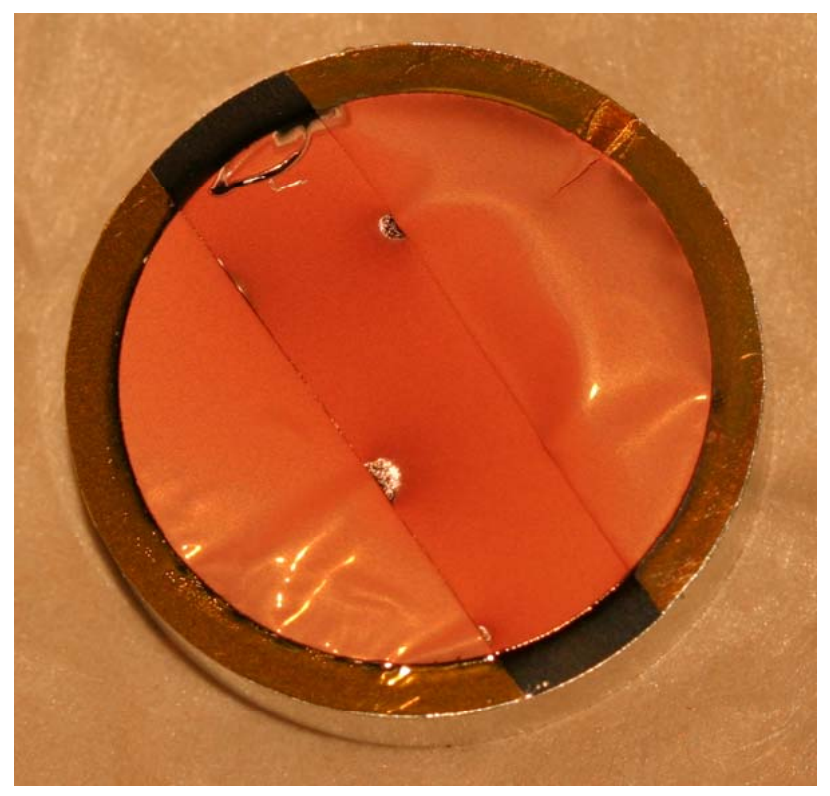

Disk as received on 9/16/04 after E-Beam PVD

There are two spots where the Kapton has warped.

Adjacent to these areas, the Cu does not adequately cover the Al, and there are patches of uncoated Al.

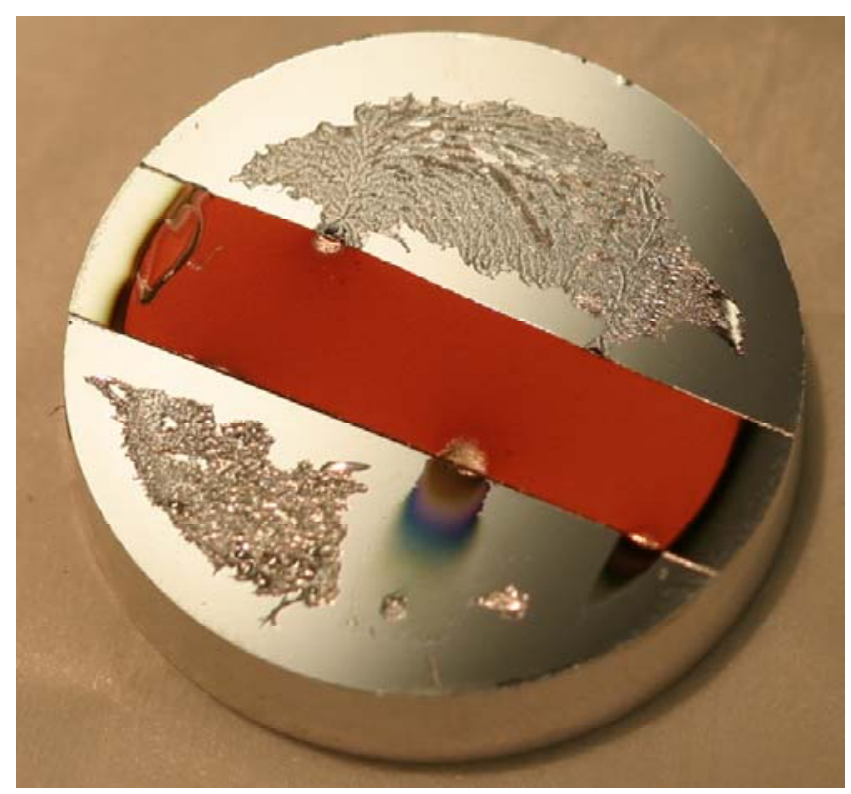

After scoring the Kapton with a razor blade and peeling it from the surface, much of the Kapton residue remained on the disk. In addition, there are burn marks beneath the Kapton in the area where the Kapton had warped, and there is a bit of $\mathrm{Cu}$ that made its way under the warped Kapton.

The adhesive residue was later washed off with acetone.

Images of Sample 1c 


\section{1" Diamond Turned Al Samples - Summary}

\begin{tabular}{|c|}
\hline Sample 4 \\
\hline $\begin{array}{l}\text { Diamond turn face using } \\
\text { mineral spirits }\end{array}$ \\
\hline $\begin{array}{l}\text { Measure surface finish } \\
\text { with Wyko }\end{array}$ \\
\hline $\begin{array}{l}\text { Clean with pentane, } \\
\text { acetone, isopropyl ( } 3 \\
\text { times) }\end{array}$ \\
\hline $\begin{array}{l}\text { Measure surface finish } \\
\text { with Wyko }\end{array}$ \\
\hline SIMS analysis of surface \\
\hline $\begin{array}{l}\text { Measure surface finish } \\
\text { with Wyko }\end{array}$ \\
\hline $\begin{array}{l}\text { Apply masking paint and } \\
\text { Kapton tape }\end{array}$ \\
\hline $\begin{array}{l}\text { Peel off Kapton and } \\
\text { paint }\end{array}$ \\
\hline Alcohol rinse \\
\hline SIMS analysis of surface \\
\hline $\begin{array}{l}\text { Reclean parts, if } \\
\text { necessary }\end{array}$ \\
\hline $\begin{array}{l}\text { Apply additional Kapton } \\
\text { over part of the surface }\end{array}$ \\
\hline $\begin{array}{l}\text { Measure surface finish } \\
\text { with Wyko }\end{array}$ \\
\hline $\begin{array}{l}\text { Minimal cleaning prior to } \\
\text { sputtering. This may } \\
\text { include ethanol }\end{array}$ \\
\hline $\begin{array}{l}\text { lon mill surface prior to } \\
\text { sputtering }\end{array}$ \\
\hline SIMS analysis of surface \\
\hline $\begin{array}{l}\text { Sputter } 5 \text { microns of } \mathrm{Cu} \\
\text { onto surface }\end{array}$ \\
\hline $\begin{array}{l}\text { Electroplate additional } \\
\mathrm{Cu}\end{array}$ \\
\hline $\begin{array}{l}\text { Diamond turn } \mathrm{Cu} \text { to } \sim 43 \\
\text { micron thickness }\end{array}$ \\
\hline $\begin{array}{l}\text { Finished - No Kapton, } \\
\text { but possibly adheisve } \\
\text { residue on surface }\end{array}$ \\
\hline
\end{tabular}

\begin{tabular}{|c|}
\hline Sample 5 \\
\hline $\begin{array}{l}\text { Diamond turn face using } \\
\text { mineral spirits }\end{array}$ \\
\hline $\begin{array}{l}\text { Measure surface finish } \\
\text { with Wyko }\end{array}$ \\
\hline $\begin{array}{l}\text { Clean with acetone, } \\
\text { isopropyl } \\
\text { (NO PENTANE) }\end{array}$ \\
\hline $\begin{array}{l}\text { Measure surface finish } \\
\text { with Wyko }\end{array}$ \\
\hline SIMS analysis of surface \\
\hline $\begin{array}{l}\text { Measure surface finish } \\
\text { with Wyko }\end{array}$ \\
\hline $\begin{array}{l}\text { Apply masking paint and } \\
\text { Kapton tape }\end{array}$ \\
\hline $\begin{array}{l}\text { Peel off Kapton and } \\
\text { paint }\end{array}$ \\
\hline Alcohol rinse \\
\hline SIMS analysis of surface \\
\hline $\begin{array}{l}\text { Reclean parts, if } \\
\text { necessary }\end{array}$ \\
\hline $\begin{array}{l}\text { Apply additional Kapton } \\
\text { over part of the surface }\end{array}$ \\
\hline $\begin{array}{l}\text { Measure surface finish } \\
\text { with Wyko }\end{array}$ \\
\hline $\begin{array}{l}\text { Minimal cleaning prior to } \\
\text { sputtering. This may } \\
\text { include ethanol }\end{array}$ \\
\hline $\begin{array}{l}\text { DO NOT DO ANY ION } \\
\text { MILLING }\end{array}$ \\
\hline SIMS analysis of surface \\
\hline $\begin{array}{l}\text { Sputter } 5 \text { microns of } \mathrm{Cu} \\
\text { onto surface }\end{array}$ \\
\hline $\begin{array}{l}\text { Electroplate additional } \\
\mathrm{Cu}\end{array}$ \\
\hline $\begin{array}{l}\text { Diamond turn } \mathrm{Cu} \text { to } \sim 43 \\
\text { micron thickness }\end{array}$ \\
\hline
\end{tabular}

Finished

\section{Sample 3}

Diamond turn face using mineral spirits

Measure surface finish with Wyko

Clean with pentane, acetone, isopropyl (5 times)

Measure surface finish with Wyko

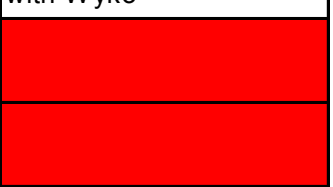

Apply masking paint and Kapton tape

Peel off Kapton and paint

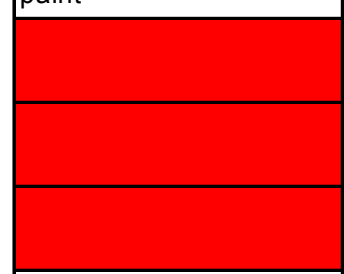

Apply additional Kapton over part of the surface

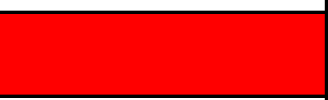

Minimal cleaning prior to sputtering. This may include ethanol

Ion mill surface prior to sputtering

Sputter 5 microns of $\mathrm{Cu}$ onto surface

Electroplate additional $\mathrm{Cu}$

Diamond turn $\mathrm{Cu}$ to $\sim 43$ micron thickness

Finished - no issues

\section{Sample 1c}

Diamond turn face using mineral spirits

Measure surface finish with Wyko

Clean with pentane, acetone, isopropyl (3 times), Oakite

Measure surface finish with Wyko

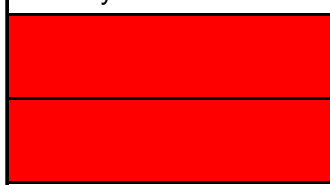

Apply masking paint and Kapton tape

Peel off Kapton and paint

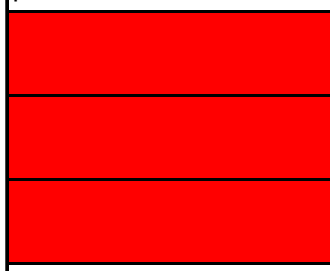

Apply additional Kapton over part of the surface

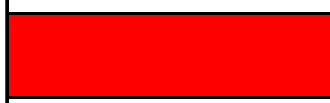

Minimal cleaning prior to sputtering. This may include oakite, DI water, and/or ethanol

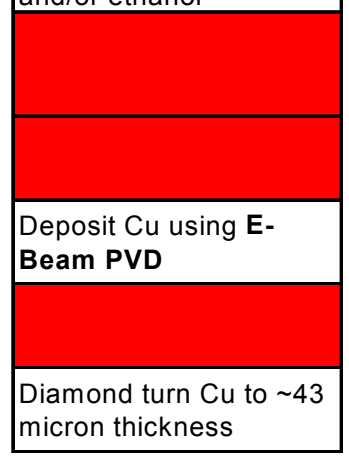

Finished - Cu adhered, but the Kapton warped 
- Bond an ICH pad to a polystyrene assembly cone using LocTite 3103 UV curing adhesive. Apply the smallest possible amount to hold the $\mathrm{ICH}$ pad to the cone. This process is performed using a benchtop assembly station. The bead of adhesive must be very flexible, so the pad can tip-tilt on the cone to lie flat against the Al during assembly. It may be necessary to stretch out the bead of adhesive prior to curing it.

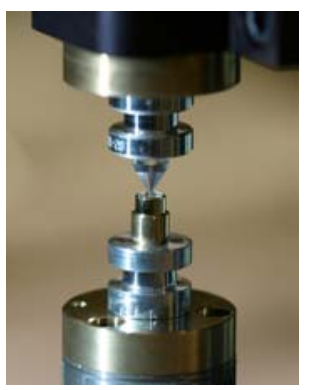

- Place the holder with the assembly cone and the ICH pad into the assembly station mounted on the tool holder of the DTM. Apply a small droplet of Hardman Green epoxy to the ICH pad using a hair. The epoxy must first be mixed with a plastic rod (do not use wood) and centrifuged to remove the bubbles generated from mixing the epoxy.

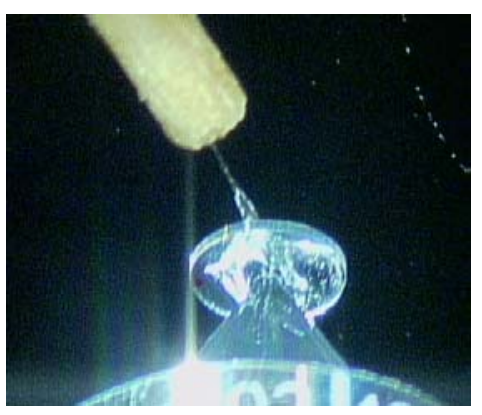

- Slowly bring the ICH pad into contact with the Al substrate. Press the pad into the Al until the force reaches 5 grams-force. Move the pad with respect to the $\mathrm{Al}$ in an X pattern, where the length of each of the four legs of the $\mathrm{X}$ is $0.75 \mathrm{~mm}$. Press the pad harder into the Al until the force reaches 10 grams-force. Move the pad with respect to the $\mathrm{Al}$ in an $\mathrm{X}$ pattern, where the length of each of the four legs of the $\mathrm{X}$ is $0.75 \mathrm{~mm}$.

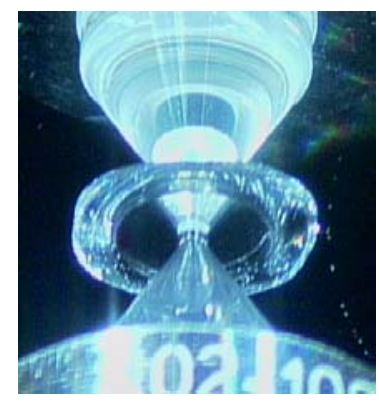

- After at least one hour, pull the assembly cone off of the ICH pad.

- Using an LVDT, measure the thickness of the resulting bondline.

- Allow the Hardman Green epoxy to cure for at least 24 hours.

- Machine the ICH pad to the final thickness. A finishing depth of cut of $5 \mu \mathrm{m}$ works well for this machining step. If the depth of cut is too small, then the debris generated by the cutting process will stick to the surface of the ICH. Use a dry cotton swab to remove any debris from the surface of the $\mathrm{ICH}$.

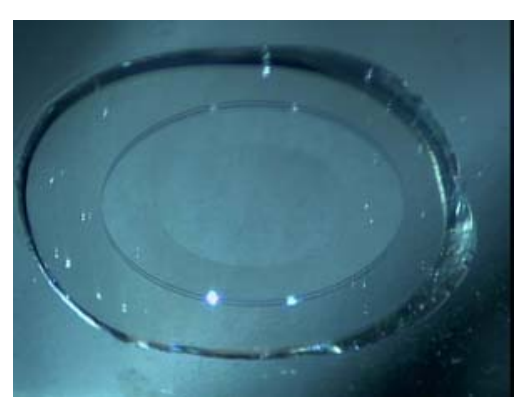

- Using an LVDT, measure the thickness of the resulting "adhesive-ICH pad" subassembly. 


\section{Appendix C - Process for bonding ICH and CH pads for EOS targets}

- Bond a CH pad to a polystyrene assembly cone using LocTite 3103 UV curing adhesive. Apply the smallest possible amount to hold the ICH pad to the cone. This process is performed using a benchtop assembly station.

- Place the holder with the assembly cone and the $\mathrm{CH}$ pad into the assembly station mounted on the tool holder of the DTM. Apply a small droplet of Stycast epoxy to the $\mathrm{CH}$ pad using a brush. A very small amount of epoxy should be applied; be careful not to apply too much. The epoxy must first be mixed with a plastic rod (do not use wood) and centrifuged to remove the bubbles generated from mixing.

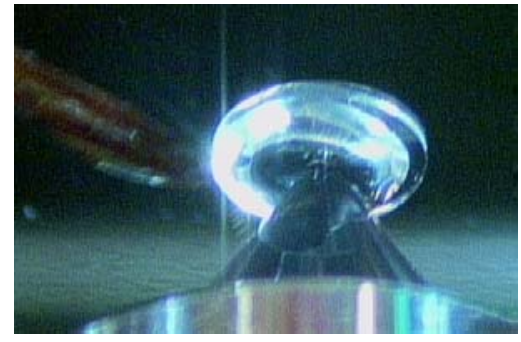

- Slowly bring the $\mathrm{CH}$ pad into contact with the ICH. Press the pad into the ICH until the force reaches 5 grams-force. Move the pad with respect to the ICH in an X pattern, where the length of each of the four legs of the $\mathrm{X}$ is $0.5 \mathrm{~mm}$. Press the pad harder into the ICH until the force reaches 10 grams-force. Move the pad with respect to the ICH in an X pattern, where the length of each of the four legs of the $\mathrm{X}$ is $0.5 \mathrm{~mm}$.

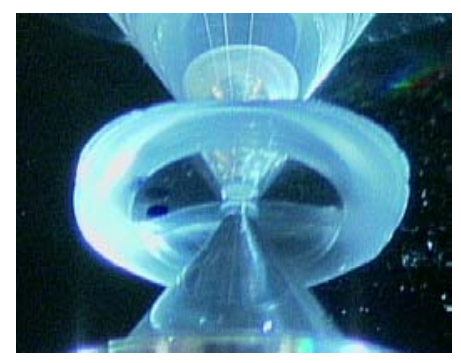

- After at least one hour, pull the assembly cone off of the $\mathrm{CH}$ pad.

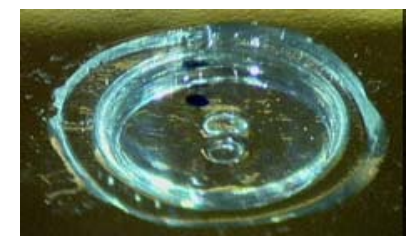

- Using an LVDT, measure the thickness of the resulting bondline.

- Allow the Stycast epoxy to cure for at least 2 days.

- Machine the $\mathrm{CH}$ pad to the final thickness. A finishing depth of cut of $5 \mu \mathrm{m}$ works well for this machining step. If the depth of cut is too small, then the debris generated by the cutting process will stick to the surface of the $\mathrm{CH}$. Use a dry cotton swab to remove any debris from the surface of the $\mathrm{CH}$.

- Using an LVDT, measure the thickness of the resulting "adhesive-CH pad" subassembly. 